Rodrigo Barroca Dias Ferraz

\title{
Proposta de Ferramenta para Desenvolvimento de Simuladores Interativos para Treinamento
}

\author{
Dissertação apresentada à Escola \\ Politécnica da Universidade de São \\ Paulo para obtenção do Título de \\ Mestre em Engenharia Elétrica.
}


Rodrigo Barroca Dias Ferraz

\title{
Proposta de Ferramenta para Desenvolvimento de Simuladores Interativos para Treinamento
}

\author{
Dissertação apresentada à Escola \\ Politécnica da Universidade de São \\ Paulo para obtenção do Título de \\ Mestre em Engenharia Elétrica. \\ Área de concentração: \\ Sistemas Eletrônicos \\ Orientadora: \\ $\operatorname{Prof}^{a}$. Dra. Roseli de Deus Lopes
}


Este exemplar foi revisado e alterado em relação à versão original, sob responsabilidade única do autor e com a anuência de seu orientador.

São Paulo, 18 de agosto de 2010.

Assinatura do autor

Assinatura do orientador

FICHA CATALOGRÁFICA

Ferraz, Rodrigo Barroca Dias

Proposta de ferramenta para desenvolvimento de simuladores interativos para treinamento / R.B.D. Ferraz. -- ed.rev. --São Paulo, 2010.

$124 \mathrm{p}$.

Dissertação (Mestrado) - Escola Politécnica da Universidade de São Paulo. Departamento de Engenharia de Sistemas Eletrônicos.

1. Simulação 2. Arquitetura de software 3. Realidade virtual I. Universidade de São Paulo. Escola Politécnica. Departamento de Engenharia de Sistemas Eletrônicos II. t. 
Dedico este trabalho aos meus pais Carlos Alberto e Rita de Cássia, à minha esposa Daniela e aos meus irmãos Andrea e Carlos Eduardo. 


\section{Agradecimentos}

À Profa. Dra. Roseli de Deus Lopes, minha orientadora, pela dedicação, apoio e por acreditar neste trabalho.

Ao meu pai, Carlos Alberto Medon Dias Ferraz, por me apoiar e ajudar durante todo este trabalho, principalmente nos momentos finais, transmitindo sua experiência profissional e acadêmica.

À minha família e à minha esposa Daniela por todo apoio ao longo deste trabalho, principalmente nos momentos mais difíceis.

Ao Prof. Dr. Marcelo Knörich Zuffo, coordenador dos Meios Eletrônicos Interativos, do Laboratório de Sistemas Integráveis da USP, pelo incentivo e disponibilização de recursos e tempo para a realização desta pesquisa.

Aos colegas do Núcleo de Realidade Virtual do Laboratório de Sistemas Integráveis da USP, em especial à Marcia Kondo, gerente do núcleo, Fabio Rodrigues, Fernando Teubl, Mário Nagamura e Olavo Belloc, pelas longas discussões sobre idéias para o projeto, pela contribuição com suas experiências e pelo incentivo. 


\section{Resumo}

Simulações man-in-the-loop, ou human-in-the-loop reproduzem virtualmente ambientes reais ou imaginários para o usuário, sendo aplicadas em diversas áreas como, entretenimento, treinamento, experimento e reabilitação.

$\mathrm{Na}$ área de treinamento, os simuladores são cada vez mais empregados visando principalmente a redução de custos e riscos, além do controle total das condições do treinamento. Simuladores de treinamento têm sido utilizados em diversas áreas, como medicina (simuladores de procedimentos cirúrgicos), aviação, trânsito, náutica, industrial, militar, entre outras.

Uma das dificuldades no desenvolvimento de simuladores para treinamento é projetar e implementar o modelo do ambiente virtual em software. Apesar de existirem diversas ferramentas (livres ou comerciais) que podem auxiliar no desenvolvimento dos simuladores, poucas se propõem à modelagem do sistema e sua execução, e estas são, em sua maioria, proprietárias.

O principal objetivo deste trabalho é conceber uma ferramenta genérica para auxiliar na modelagem, estruturação e implementação de simuladores de ambientes virtuais voltados para treinamento, partindo da proposta de uma arquitetura de software baseada na decomposição estrutural do sistema a ser simulado.

A utilização de uma ferramenta genérica tem a finalidade de reduzir o tempo e o custo de desenvolvimento de simuladores de treinamento, facilitando a integração simultânea de diversas equipes de trabalho e a reutilização de componentes de softwares para outras aplicações.

Foi concebida uma arquitetura de software baseada nos trabalhos da literatura e desenvolvido um protótipo da ferramenta genérica.

Para avaliar a ferramenta foi realizado um estudo de caso baseado no software de um simulador de aeronave de asas rotativas, modelo Bell Jet Ranger III e nos procedimentos operacionais reais.

O estudo foi realizado por meio da adaptação parcial do software do simulador original utilizando a ferramenta proposta. Os resultados obtidos mostraram a viabilidade da utilização da arquitetura e da ferramenta genérica para o desenvolvimento de simuladores de treinamento. 


\section{Abstract}

Man-in-the-loop or human-in-the-loop simulations reproduce virtually real or imaginary environments to the user, being used for several purposes, such as, entertainment, training, experiment and rehabilitation.

In training area, the simulators are more and more used aiming, specially for costs and risks reduction besides the total control of training conditions. Training simulators have been used in several areas such as medicine (surgical procedures simulators), evaluation, traffic, nautical, industrial, military, among others.

One of the difficulties in the simulator development for training is to project and implement the virtual environment model in software. Even though there are several free and commercial tools that might help in simulator development, few of them focus on system modeling and execution, and those are, in it's majority, proprietary.

The main purpose of this work is to design a generic tool to assist the modeling, structuring and implementation of virtual environment simulators for training, starting from the proposal of a software architecture based on the structural decomposition of the system to be simulated.

The use of a generic tool aims to reduce time and cost of developing training simulators, facilitating simultaneous integration of various workgroups and reuse of software components for other applications.

Initially, a software architecture for training simulators was designed based on academic researches and a prototype of a generic tool was developed.

To evaluate this tool, a case study was conducted based on the Bell Jet Ranger III rotorcraft simulator software and real operational procedures.

The study was performed by partially adapting the original simulator software using the proposed tool. The results showed the feasibility of using the purposed architecture and generic tool for training simulators development. 


\section{Lista de Figuras}

2.1 Visão geral de simuladores man-in-the-loop. . . . . . . . . . . 23

2.2 Visão geral de simuladores hardware-in-the-loop. . . . . . . . . . . 23

2.3 Comparação entre eventos discretos e passo fixo. . . . . . . . . . 26

3.1 Visão geral do AVSM. . . . . . . . . . . . . . . . . . . . . 30

3.2 Componentes. . . . . . . . . . . . . . . . . . . . 31

3.3 Controlador de subsistema. . . . . . . . . . . . . . . . . . . 32

3.4 Sequenciador periódico. . . . . . . . . . . . . . . . . . 34

3.5 Manipulador de eventos. . . . . . . . . . . . . . . . . 35

3.6 Sincronizador de tempo. . . . . . . . . . . . . . . . . 35

3.7 Ciclo de execução do AVSM . . . . . . . . . . . . . . . . . 36

3.8 Arquitetura ModSim . . . . . . . . . . . . . . . . . . . . . 37

3.9 Visão geral da DARTS. . . . . . . . . . . . . . . . . . . . . . . 38

4.1 Modelo estrutural. . . . . . . . . . . . . . . . . . . . . 45

4.2 Visão geral da arquitetura proposta. . . . . . . . . . . . . . . . 46

4.3 Visão geral da composição das entidades da arquitetura. . . . . . . 47

4.4 Perspectiva da execução. . . . . . . . . . . . . . . . . . . . . . . 52

5.1 Visão geral da implementação do protótipo. . . . . . . . . . . . 56

5.2 Diagrama de classes do gerenciador de objetos. . . . . . . . . 57

5.3 Diagrama de classes do executor. . . . . . . . . . . . . . 59

5.4 Ciclo de execução do SimFlow. . . . . . . . . . . . . . . . 60

5.5 Implementação das conexões entre portas. . . . . . . . . . . . . . 62

5.6 Diagrama de classes do sistema de distribuição de dados. . . . . . . 63

5.7 Diagrama de classes do sistema de propriedades. . . . . . . . . 65 
5.8 Diagrama de classes do componente aplicação. . . . . . . . . . . . 66

5.9 Exemplo de fluxo de dados. . . . . . . . . . . . . . . . . . 70

6.1 Fluxo de dados entre subsistemas do Bell Jet Ranger III. . . . . . 75

6.2 Fluxo de dados entre os subsistemas ELEC, FUEL e ENGS. . . . 77

6.3 Fluxo de dados do subsistema de motores (ENGINES). . . . . . . 80

6.4 Árvore de objetos do estudo de caso. . . . . . . . . . . . . . . . . 81

6.5 Divisão dos componentes em grupos de execução. . . . . . . . . . 82

7.1 Entradas e saídas em função do tempo de simulação para o procedimento padrão de partida e desligamento. . . . . . . . . . . 87

7.2 Curvas de torque em função de N1 (Pressão = 14.7 PSI) . . . . . . 90

7.3 Evolução de N1 (30 ciclos por segundo). . . . . . . . . . . . . . . 91

7.4 Tempo de cópia de regiões de memória. . . . . . . . . . . . . . . . 94 


\section{Lista de Tabelas}

2.1 Comparação entre simulações analíticas e ambientes virtuais [1] 24

3.1 Comparação das arquiteturas . . . . . . . . . . . . . . . . . . . 42

4.1 Comparação entre o SDD e a VNET . . . . . . . . . . . . . . . 50

4.2 Comparação das arquiteturas . . . . . . . . . . . . . . . 54

6.1 Subsistemas do simulador Bell Jet Ranger III. . . . . . . . . . . . 75

7.1 Divisão dos componentes nos grupos de execução. . . . . . . . . 83

7.2 Lista de checagem de acionamento. . . . . . . . . . . . . . . 84

7.3 Lista de checagem de desligamento. . . . . . . . . . . . . . . . 84

7.4 Valores das componentes do torque resultante. . . . . . . . . . . . 89

7.5 Tempos médios e máximos por grupo de execução. . . . . . . . . . 93

7.6 Tempos médios. . . . . . . . . . . . . . . . . . . . . . . 94

A.1 ENGINE PRE-START CHECK . . . . . . . . . . . . . . 124

A.2 ENGINE STARTING . . . . . . . . . . . . . . . . 124

A.3 ENGINE RUN-UP CHECK . . . . . . . . . . . . . . . . . . 125

A.4 ENGINE SHUTDOWN . . . . . . . . . . . . . . . 125 


\section{Lista de Abreviaturas}

AVSM Air Vehicle Structural Model

CIAAN Centro de Instrução e Adestramento Aero-Naval

COTS Commercial Off-The-Shelf

DARTS Domain Architecture for Reuse in Training Systems

DIS Distributed Interactive Simulation

HITL Hardware-in-the-Loop

HLA High-Level Architecture

ILS Instrument Landing System

IPC Inter-Process Communication

MITL Man-in-the-Loop

MMU Memory Management Unit

NDB Non-Directional Beacon

RTOM Run-Time Object Manager

SDD Sistema de Distribuição de Dados

SEI Software Engineering Institute

TCP Transport Control Protocol

VNET Virtual Network

VOR Very High Frequency Omni-directional Range 


\section{Sumário}

1 Introdução 16

1.1 Importância das Simulações de Ambientes Virtuais . . . . . . . 17

1.2 Motivação . . . . . . . . . . . . . . . . . . . 18

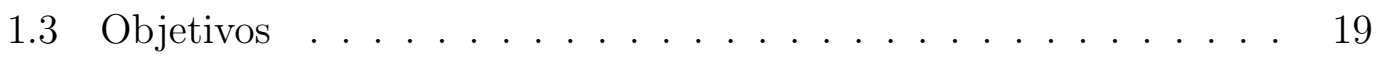

1.4 Contribuições . . . . . . . . . . . . . . . . . . 20

1.5 Estrutura do Trabalho . . . . . . . . . . . . . . . . . . 20

2 Conceitos Básicos $\quad 21$

2.1 Conceitos de Tempo nas Simulações . . . . . . . . . . . . . . . . 21

2.2 Classificação dos Simuladores . . . . . . . . . . . . . . . 22

2.2.1 Quanto à Aplicação . . . . . . . . . . . . . . . . . 22

2.2.2 Quanto ao Passo de Execução . . . . . . . . . . . . . . 24

2.2.3 Quanto à Mudança de Estados . . . . . . . . . . . 25

2.3 Modelagem Estrutural de Simuladores de Ambientes Virtuais . . . 26

2.4 Síntese . . . . . . . . . . . . . . . . . . . . . . . . 28

3 Estado da Arte $\quad 29$

3.1 AVSM . . . . . . . . . . . . . . . . . . . 29

3.2 ModSim . . . . . . . . . . . . . . . . . . 36

3.3 DARTS . . . . . . . . . . . . . . . . . . 37

3.4 Comparação entre Arquiteturas . . . . . . . . . . . . . . . . . . . 41

3.5 Síntese . . . . . . . . . . . . . . . . . . . . 41

4 Proposta de Arquitetura para Desenvolvimento de Simuladores de Treinamento 44 
4.1 Visão Geral . . . . . . . . . . . . . . . . . . . . . . . . . . . . 45

4.2 Entidades da Arquitetura . . . . . . . . . . . . . . . . . 47

4.2.1 Componentes . . . . . . . . . . . . . . . 47

4.2 .2 Composição . . . . . . . . . . . . . . . . . . . . . . . . . 48

4.2.3 Grupo de Execução . . . . . . . . . . . . . . . . . . . . . . 48

4.2.4 Gerenciador de Execução . . . . . . . . . . . . . . . . . . . 48

4.2.5 Sistema de Distribuição de Dados . . . . . . . . . . . . . . 49

4.2 .6 Serviços . . . . . . . . . . . . . . . . . 50

4.3 Funcionalidades . . . . . . . . . . . . . . . . . . 50

4.3.1 Estrutura da Aplicação . . . . . . . . . . . . . . . . . 50

4.3 .2 Execução . . . . . . . . . . . . . . . . . . . . . 51

4.3.3 Fluxo de Dados . . . . . . . . . . . . . . . . . . 51

4.4 Síntese . . . . . . . . . . . . . . . . . . . 53

5 Implementação de Referência SimFlow $\quad 55$

5.1 Visão Geral da Ferramenta . . . . . . . . . . . . . . . . . . . . 55

$5.2 \quad$ Núcleo . . . . . . . . . . . . . . . . . . . . . 55

5.2.1 Gerenciador de Objetos em Tempo de Execução . . . . . . 56

5.2 .2 Executor . . . . . . . . . . . . . . . . 59

5.2 .3 Sistema de Distribuição de Dados . . . . . . . . . . . . . . 61

5.2.4 Propriedades ..................... 64

5.2 .5 Motor de Simulação . . . . . . . . . . . . . . . . . 65

5.3 Aplicação . . . . . . . . . . . . . . . . . . . . 65

5.4 Serviços . . . . . . . . . . . . . . . . . . 67

5.5 Utilitários . . . . . . . . . . . . . . . . . . . . . 67

5.6 Utilização . . . . . . . . . . . . . . . . . . . . . . . . . . 68

5.6.1 Implementação de Componentes de Simulação . . . . . . 68

5.6.2 Implementação da Rede de Fluxo de Dados . . . . . . . 70 
5.7 Controle da Simulação . . . . . . . . . . . . . . . . . . . . 72

5.8 Síntese . . . . . . . . . . . . . . . . . . . . . 72

$6 \quad$ Estudo de Caso $\quad 74$

6.1 Arquitetura de Software Original . . . . . . . . . . . . . . . 74

6.1 .1 Aplicação . . . . . . . . . . . . . . . . . 74

6.1 .2 Sistema Executivo . . . . . . . . . . . . 76

6.2 Descrição dos Subsistemas Utilizados . . . . . . . . . . . . . 76

6.3 Adaptação do Simulador . . . . . . . . . . . . . . . . . . . . . 81

6.4 Síntese . . . . . . . . . . . . . . . . . 82

7 Testes e Resultados Obtidos $\quad 83$

7.1 Execução Paralela . . . . . . . . . . . . . . . . . . . . 83

7.2 Testes de Procedimentos Normais de Operação . . . . . . . . . . . . 84

7.2.1 Detalhamento do Procedimento de Acionamento e Desligamento ....................... 85

7.2.2 Resultados da Simulação dos Procedimentos . . . . . . . . 86

7.3 Comparação com as Rotinas Originais . . . . . . . . . . . . . 88

7.4 Desempenho da Ferramenta SimFlow . . . . . . . . . . . . . . . . 92

7.5 Síntese . . . . . . . . . . . . . . . . . . 95

$\begin{array}{llr}8 & \text { Conclusões } & 96\end{array}$

8.1 Principais Contribuições . . . . . . . . . . . . . . . . . . . . . . 97

8.2 Trabalhos Futuros . . . . . . . . . . . . . . . . . . . . . . 97

$\begin{array}{lr}\text { Referências Bibliográficas } & 99\end{array}$

Apêndice A - Descrição dos Subsistemas e Rotinas do Simulador da Aeronave Bell Jet Ranger III 102

A.1 Subsistema de Aerodinâmica (FLYT) . . . . . . . . . . . . . . 102

A.2 Subsistema Auxílio por Rádio (RAID) . . . . . . . . . . 105 
A.3 Sistema de Controle de Voo Automático (AFCS) . . . . . . . . 108

A.4 Subsistema Combustível (FUEL) . . . . . . . . . . . . . . 109

A.5 Subsistema Motores (ENGS) . . . . . . . . . . . . 110

A.6 Subsistema Elétrico (ELEC) . . . . . . . . . . . . . . . . . 111

A.7 Subsistema Hidráulico (HYDS) ～. . . . . . . . . . . . . . . 111

A.8 Subsistema Som (SOND) . . . . . . . . . . . . . . . . 111

Apêndice B - Implementação do estudo de caso

Anexo A - Procedimentos normais de operação da aeronave Bell Jet Ranger III 


\section{Introdução}

Uma simulação computacional é uma computação que modela o comportamento de algum sistema real ou imaginário ao longo do tempo [1]. Simulações são amplamente utilizadas para análise de sistemas e processos dinâmicos, como controle de tráfego aéreo, redes de comunicação, processos físicos e biológicos, projeto de equipamentos, entre outros. É também utilizada para criar ambientes virtuais interativos, aplicados principalmente nas áreas de treinamento, reabilitação, educação e entretenimento.

Fujimoto (2000) destaca duas grandes classes de simulações, as simulações analíticas e as simulações de ambientes virtuais As simulações analíticas são utilizadas para analisar de forma quantitativa e detalhada modelos matemáticos de sistemas dinâmicos, como processos físicos, químicos, econômicos, logísticos, entre outros. Neste tipo de simulação, a prioridade é a precisão do resultado, independente do tempo de execução.

Diferentemente das simulações analíticas, noas simulações de ambientes virtuais usuários ou dispositivas físicos interagem fortemente com a simulação. Nesta categoria destacam-se os simuladores tipo Hardware-in-the-Loop (HITL) e Manin-the-Loop (MITL), que apresentam como prioridade manter o tempo de simulação compatível com o tempo do mundo real, em detrimento da precisão dos modelos e resultados.

Nas simulações HITL, o componente central é um dispositivo físico real interagindo com um ambiente virtual através de suas interfaces. São empregadas principalmente para análises e testes de protótipos de equipamentos reais cujo emprego imediato no mundo real é proibitivo devido principalmente a riscos, custos elevados ou ambiente pouco controlado.

A principal característica das simulações man-in-the-loop, conhecida também como human-in-the-loop, é a participação do usuário na simulação através de dispositivos de entrada e saída. Simuladores desta categoria são amplamente empregados para treinamento de pessoas em situações cuja utilização de equipa- 
mentos reais no mundo real é proibitiva. Exemplo deste tipo de aplicação são os simuladores de voo, de tanques de guerra, embarcações, carros, guindastes, sala de operação de usinas nucleares, entre outros. Pode-se destacar as seguintes vantagens na utilização de simuladores:

- redução de custos no treinamento;

- redução de riscos no treinamento;

- controle total das condições de simulação (condições climáticas, condições de emergências, falhas etc);

- possibilidade de treinamento em situações de emergência;

- pouco ou nenhum impacto ambiental;

- facilidade de avaliação através de recursos como análises estatísticas e reprodução da simulação.

\subsection{Importância das Simulações de Ambientes Virtuais}

Em 1910, após o voo dos irmãos Wright (1903) e de Alberto Santos-Dumont (1906), surgiu o primeiro simulador de voo, cuja finalidade era treinar os pilotos para operarem os primeiros protótipos de aviões. Este simulador utilizava como dispositivo de interação o próprio avião, fixado a uma estrutura em solo, para o treinamento [2]. Desde então, os simuladores vem ganhando cada vez mais importância para o preparo de operadores, não só de aeronaves, mas de uma infinidade de veículos e equipamentos; e seu desenvolvimento começou a ser sistematizado.

Existem simuladores de treinamento para diversos tipos de equipamentos como aeronaves (asas fixas ou rotativas), carros, caminhões, guindastes, navios e salas de operação de fábricas. Porém, apesar de existirem algumas arquiteturas conhecidas, a maioria utiliza ferramentas e bibliotecas proprietárias.

Além do uso civil, as forças armadas de vários países fazem uso intensivo de simuladores, tanto para treinamento individual (simuladores de voo, tanques, armamento) quanto para treinamento coletivo (guerras simuladas, treinadores de missões, treinamento estratégico). O foco das pesquisas militares está voltado para padrões abertos para a integração de simuladores e simulação em conjunto. 
No Brasil, existe uma demanda crescente por simuladores de treinamento, porém a maior parte se baseia em tecnologias importadas, devido ao incipiente desenvolvimento neste setor. As forças armadas brasileiras têm buscado cada vez mais a nacionalização e a independência externa no setor, incentivando e articulando parcerias com universidades e empresas nacionais.

O Laboratório de Sistemas Integráveis da Escola Politécnica da Universidade de São Paulo (LSI-EPUSP) desenvolve pesquisas na área de simulação de ambientes virtuais para treinamento, entretenimento e educação. Entre eles, o projeto GPBrasil [3], realizado em parceria com empresas do setor privado e concluído em 2005, cujo o resultado foi um simulador de corridas de automóveis voltado para o entretenimento. Atualmente, o laboratório participa de projetos em parceria com a Marinha do Brasil para o desenvolvimento de simuladores de manobra de navios e de aeronaves de asas rotativas.

\subsection{Motivação}

No início da década de 90 surgiram esforços para desenvolver arquiteturas de software para simuladores de voo, as quais foram elaboradas considerando as arquiteturas de computadores e linguagens de programação específicas para esta finalidade.

Atualmente, com o avanço do poder de processamento dos computadores pessoais, a tendência é utilizar as tecnologias convencionais (Commercial OffThe-Shelf - COTS) para tarefas específicas. Assim, estas arquiteturas apresentam algumas limitações que poderiam ser superadas hoje.

No âmbito internacional, existem empresas como Presagis ${ }^{1}$ e Mäk ${ }^{2}$ que produzem ferramentas de produtividade para auxiliar o desenvolvimento de simuladores para treinamento. Porém, seus produtos são voltados principalmente para:

- visualização;

- produção de cenários sintéticos;

- integração de simuladores através dos de protocolos High-Level Architecture (HLA) e Distributed Interactive Simulation (DIS);

\footnotetext{
${ }^{1}$ Presagis website: http://www.presagis.com/. Acesso: Fevereiro/2010

${ }^{2}$ Mäk website: http://www.mak.com/. Acesso: Fevereiro/2010
} 
- simulações de missões integradas.

São poucas as ferramentas destinadas a auxiliar o desenvolvimento do software de um simulador específico. Algumas ferramentas como Presagis FlightSim, Presagis HeliSim e X-Plane $\mathrm{SDK}^{3}$ são específicas para desenvolvimento de simuladores de voo.

Uma ferramenta genérica para desenvolvimento de simuladores pode reduzir significativamente o tempo e o custo de desenvolvimento, aumentando a reutilização de código e a paralelização do projeto e implementação.

Desta forma, a principal motivação deste trabalho é contribuir para o desenvolvimento de uma ferramenta computacional que venha auxiliar na modelagem, estruturação e implementação de simuladores de ambientes virtuais voltados para treinamento.

\subsection{Objetivos}

Dada a importância do assunto e a escassez de trabalhos publicados na área, o objetivo é propor uma arquitetura de software e uma ferramenta para auxiliar o desenvolvimento de simuladores de treinamento baseado na decomposição dos sistemas a serem simulados em hierarquias de blocos funcionais inter-conectados por meio de suas entradas e saídas.

Os objetivos específicos são:

- Pesquisar técnicas e metodologias de desenvolvimento de simuladores de treinamento;

- conceber uma arquitetura de software para desenvolvimento de simuladores para treinamento;

- projetar, implementar e avaliar um protótipo de ferramenta de software baseada na arquitetura proposta, a fim de analisar seu desempenho e a viabilidade de sua utilização;

- aplicar a ferramenta desenvolvida na adaptação parcial de um simulador de aeronave de asas rotativas.

\footnotetext{
${ }^{3}$ X-Plane website: http://www.x-plane.com/. Acesso: Fevereiro/2010
} 


\subsection{Contribuições}

A aplicação deste trabalho está direcionada para a área de desenvolvimento de simuladores para treinamento. A contribuição é proporcionar uma orientação inicial para a implementação do software através dos seguintes aspectos:

- Uma arquitetura de software alternativa para desenvolvimento de simuladores.

- Protótipo de uma ferramenta para desenvolvimento de simuladores de treinamento utilizando modelagem estrutural concorrente.

\subsection{Estrutura do Trabalho}

No capítulo 2 são apresentados os conceitos básicos e classificações de simuladores.

A revisão da literatura sobre arquiteturas de software para simuladores de treinamento é apresentada no capítulo 3.

O capítulo 4 apresenta a proposta de uma nova arquitetura de software baseado na hierarquia estrutural do modelo.

O protótipo de uma ferramenta baseado na arquitetura proposta é apresentado no capítulo 5.

A adaptação de um simulador de aeronave de asas rotativas para a arquitetura proposta, utilizando o protótipo, é apresentada no capítulo 6 .

Os resultados são apresentados e discutidos no capítulo 7 .

O capítulo 8 apresenta as considerações finais, contribuições e trabalhos futuros.

O apêndice A descreve os elementos de software originais do simulador utilizado como estudo de caso, e o apêndice B contém as listagens dos principais elementos da implementação do estudo de caso. 


\section{Conceitos Básicos}

Simulações computacionais são ferramentas poderosas utilizadas em diversas áreas. Para cada aplicação são utilizados tipos específicos de simuladores, classificados quanto à sua finalidade ou algoritmos de execução. Porém alguns conceitos são comuns para todas as categorias.

O objetivo deste capítulo é apresentar os conceitos básicos de uma simulação computacional, as principais formas de classificação e uma introdução à modelagem estrutural de simuladores de ambientes virtuais.

\subsection{Conceitos de Tempo nas Simulações}

Segundo Fujimoto (2000), em uma simulação computacional existem três conceitos distintos de tempo. São eles:

- Tempo Físico: É o tempo no sistema físico simulado.

- Tempo da Simulação: É a representação do tempo físico na simulação. A representação pode ser uma variável de ponto flutuante, por exemplo. Assim, se o tempo de simulação for de 1.5, então o tempo físico será 1 hora e 30 minutos.

- Tempo de Execução (wallclock time): É o tempo que a simulação leva para ser executada.

O tempo físico e o da simulação são relacionados por um fator multiplicativo. Já o tempo de execução pode ou não ser acoplado com os demais tempos. Nas simulações analíticas normalmente não existe tal relação, porém, nos ambientes virtuais, geralmente o tempo físico e o tempo de execução estão relacionados. 


\subsection{Classificação dos Simuladores}

Segundo Fujimoto (2000), as simulações de computadores podem ser classificadas de acordo com a aplicação, quanto ao passo de execução e quanto à mudança de estados. Estas classificações são detalhadas nas subseções seguintes.

\subsubsection{Quanto à Aplicação}

Quanto á aplicação, as simulações podem ser classificadas como analíticas ou de ambientes virtuais. As simulações analíticas são caracterizadas pela precisão nos resultados e desacoplamento entre o tempo de simulação e de execução (wallclock). São utilizadas quando se deseja analisar, de forma detalhada e quantitativa, um modelo ou sistema dinâmico. Exemplos de aplicações são simulação de circuitos eletrônicos, de processos físicos (modelos climáticos, astronômicos etc), de análises econômicas e projeto e avaliação de redes de comunicações.

Nas simulações analíticas usuários ou dispositivos físicos não fazem parte da simulação, assim não existe relação entre o tempo de simulação e o tempo de execução. Desta forma, tipicamente o passo de simulação escolhido é o "mais rápido possível", ou seja, executar o mais rápido possível os cálculos do modelo.

Outra preocupação das simulações analíticas é manter a causalidade do sistema. Ou seja, garantir que as mudanças de estados ocorram na ordem correta (por exemplo, em uma simulação de tráfego aéreo, um avião não deve partir de um determinado aeroporto, antes de ter chegado ao mesmo). Em execuções seriais (não paralelas), a causalidade é respeitada implicitamente. Porém, em simulações paralelas e distribuídas, uma das principais preocupações é manter o sistema causal.

Os ambientes virtuais são utilizados em aplicações onde o(s) usuário(s) (manin-the-loop ou human-in-the-loop) ou dispositivos físicos (hardware-in-the-loop) fazem parte da simulação. Como o objetivo é criar um "mundo virtual" para uma entidade externa (usuário ou dispositivo), é necessário que o tempo físico seja sincronizado com o tempo de execução, ou seja, um segundo na simulação deve ser executada em um segundo. Os simuladores hardware-in-the-loop (HITL) são utilizados principalmente para testar e avaliar equipamentos de forma isolada e em ambientes controlados (por exemplo, testar um sistema de piloto automático). Já as simulações man-in-the-loop (MITL) são empregadas para entretenimento (jogos eletrônicos), reabilitação, treinamento (como simuladores de voo, caminhões e procedimentos médicos), experimentos acadêmicos (análises psicológicas, com- 
portamento em grupo, entre outros). As figuras 2.1 e 2.2 ilustram os simuladores tipo man-in-the-loop e hardware-in-the-loop, respectivamente.

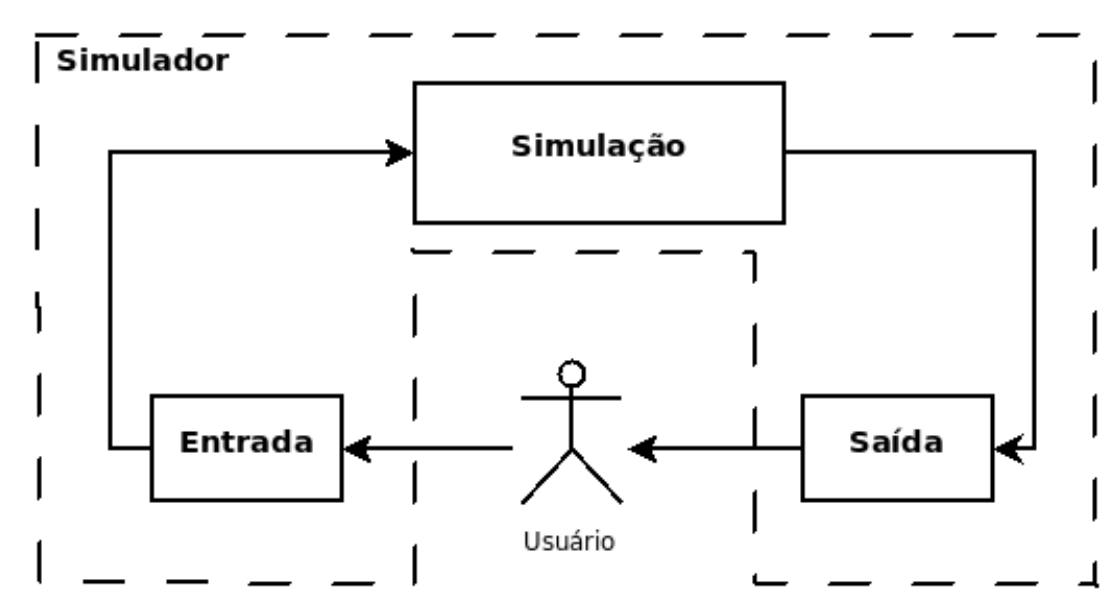

Figura 2.1: Visão geral de simuladores man-in-the-loop.

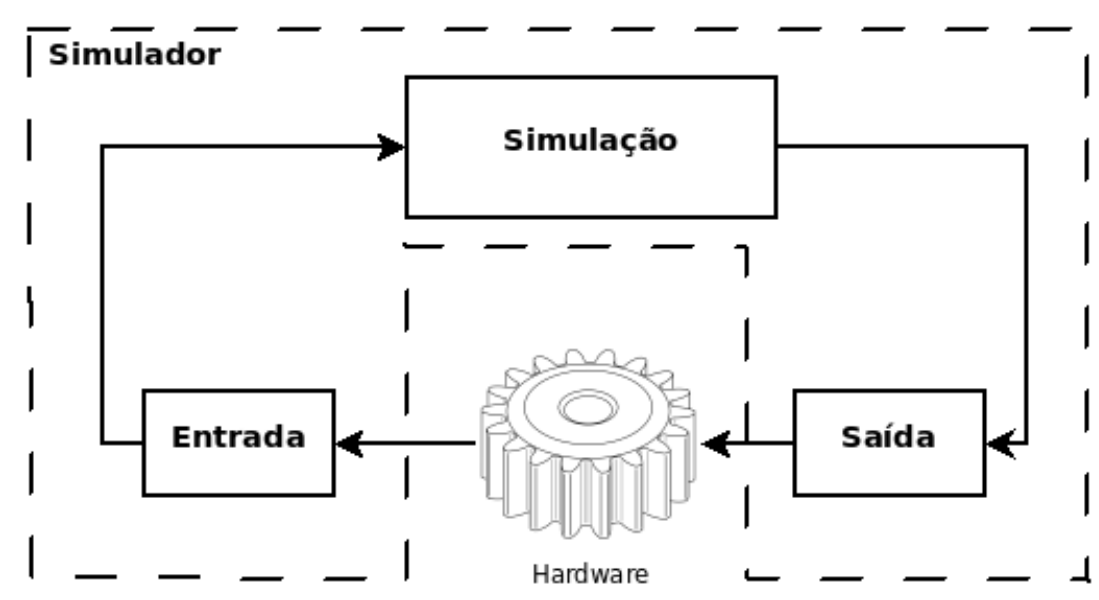

Figura 2.2: Visão geral de simuladores hardware-in-the-loop.

Como as entidades externas normalmente apresentam uma tolerância aos estímulos gerados pelo simulador e à percepção do tempo, muitas vezes os modelos simulados são simplificados de forma a garantir que todo o processamento de um passo da simulação seja executado dentro do limite de tempo. Por exemplo: em um simulador de carro, um erro de cinco milímetros no posicionamento do veículo é tolerável (e, em algumas situações, imperceptível), bem como um passo de simulação de 30 ms é suficiente para "enganar" o usuário.

A tabela 2.1 comparas simulações analíticas e de ambientes virtuais quanto ao passo de execução (detalhado na seção 2.2.2), à finalidade, o grau de interação com o usuário e a relação de causalidade. 
Tabela 2.1: Comparação entre simulações analíticas e ambientes virtuais [1]

\begin{tabular}{cll}
\hline Simulação & Analítica & de Ambientes Virtuais \\
\hline $\begin{array}{c}\text { Passo de } \\
\text { Execução }\end{array}$ & $\begin{array}{l}\text { Tipicamente "o mais } \\
\text { rápido possível" }\end{array}$ & Tempo Real \\
\hline Finalidade & $\begin{array}{l}\text { Análise quantitativa } \\
\text { de sistemas complexos }\end{array}$ & $\begin{array}{l}\text { Criar uma representação de } \\
\text { umbiente }\end{array}$ \\
\hline $\begin{array}{c}\text { Interação com } \\
\text { Usuário }\end{array}$ & $\begin{array}{l}\text { Oouca (normalmente interage para con- } \\
\text { nenhuma observador) ou }\end{array}$ & $\begin{array}{l}\text { trolar o comportamento de } \\
\text { tual (no caso de simulador } \\
\text { MITL) }\end{array}$ \\
\hline $\begin{array}{c}\text { Relação } \\
\text { Antes-e-Depois }\end{array}$ & $\begin{array}{l}\text { Deve reproduzir pre- } \\
\text { cisamente as relações } \\
\text { de antes-e-depois }\end{array}$ & $\begin{array}{l}\text { Deve repróes antes-e-depois que } \\
\text { podem ser percebidas pelo } \\
\text { usuário ou dispositivo }\end{array}$ \\
\hline
\end{tabular}

\subsubsection{Quanto ao Passo de Execução}

Em uma simulação em computador, o passo (ou iteração, ou quadro) representa o período da execução em que todas as variáveis de estados e o tempo físico são atualizadas seguindo as regras do modelo. A execução pode ser classificada da seguinte forma: Tempo-Real, Tempo-Real Escalado, "O mais rápido possível".

Em simuladores com passo de tempo-real o tempo físico equivale ao tempo de execução. Exemplificando, se uma iteração demora um segundo para ser executada, então o avanço do tempo físico deverá ser também de um segundo. Simuladores MITL usualmente utilizam o passo de tempo-real para que o usuário tenha a sensação que o tempo do mundo virtual avança de forma natural.

A execução em tempo-real escalado é semelhante ao tempo-real, porém o avanço do tempo físico é proporcional ao tempo de execução. Ou seja, o tempo físico equivale ao tempo de execução multiplicado por um fator de proporção (inteiro).

Já na execução "o mais rápido possível" não existe relação entre o tempo da simulação e o tempo de execução. A prioridade nesta classe é finalizar a simulação o mais rápido possível. Este é o modelo utilizado nas simulações analíticas, pois normalmente o objetivo é somente o resultado final, sem a interação com usuários ou dispositívos. 


\subsubsection{Quanto à Mudança de Estados}

Outra classificação corresponde à maneira de atualizar as variáveis de estado do modelo de acordo com o avanço do tempo da simulação. O fluxo da simulação pode ser classificado como contínuo ou discreto.

Nas simulações de fluxo contínuo, o estado do sistema é visto como sendo atualizado continuamente ao longo do tempo. Normalmente, as variáveis de estado são descritas através de equações diferenciais. Simuladores de fluxo contínuo eram, no passado, implementados através de computadores analógicos. Atualmente, este tipo de simulação é executado da mesma forma que as discretas de passo fixo, porém com o avanço do tempo de simulação suficientemente pequeno para processar todos os transitórios do sistema.

Já nas simulações de fluxo discreto, o estado do modelo é atualizado em pontos discretos da simulação. Ou seja, o sistema salta de um estado para outro. Esta classe de simuladores é dividida em duas subcategorias: Execução de Passo Fixo e Guiado por Eventos.

Na Execução de Passo Fixo, o sistema é atualizado em tempos constantes, ou seja, o tempo da simulação é dividido em interações iguais e com duração (no tempo da simulação) fixa. Em uma simulação em tempo-real (ou tempo-real escalado) cada passo de tempo deve ser igual ao tempo de execução da iteração. Para alcançar este sincronismo, toda computação da iteração é executada num tempo menor que o tempo do passo, e então o simulador aguarda o tempo restante.

Em casos onde todas as variáveis de estados são atualizadas constantemente, é utilizado o modelo de Execução de Passo Fixo. Em outros casos, o estado do sistema é atualizado somente quando um evento ocorre. Nas simulações Guiadas por Evento, as variáveis são atualizadas somente quando um evento é lançado. Desta forma, o tempo de simulação de cada passo não é fixo. Neste modelo, o evento é uma abstração utilizada para modelar uma ação instantânea no sistema físico [1]. Cada evento tem um tempo de simulação associado, indicando o momento em que ele ocorre. Durante a execução, cada passo consiste em atualizar algumas variáveis de estado e agendar novos eventos futuros. Então o simulador avança até o próximo evento e inicia um novo passo.

A figura 2.3 compara os modelos de execução de passo fixo (2.3a) e guiado por eventos (2.3b). Nos diagramas mostrados, o eixo horizontal representa o avanço do tempo, enquanto o eixo vertical representa as variáveis de estado. As linhas verticais de cada variável representam os instantes de tempo em que ocorrem 
atualizações.

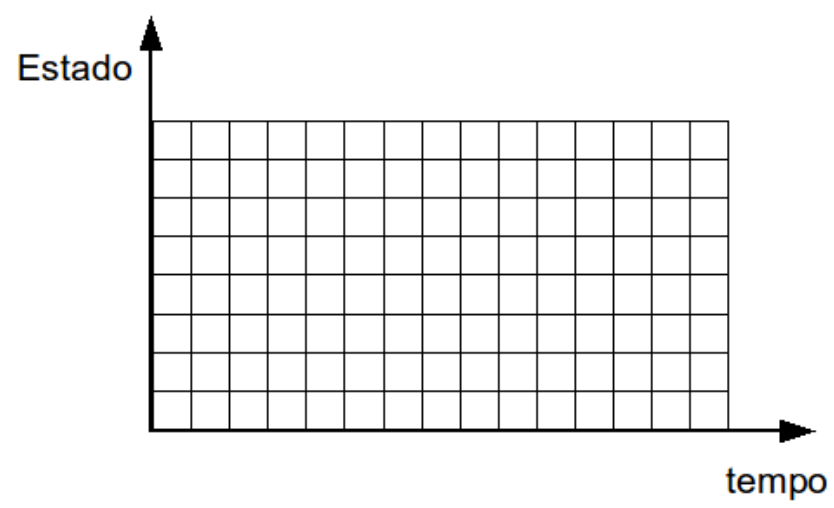

(a) Diagrama espaço-tempo para execução de passo fixo

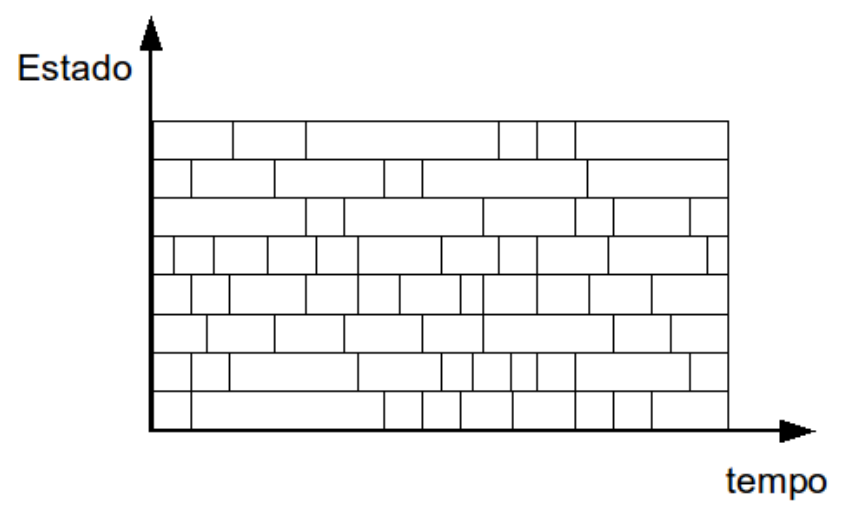

(b) Diagrama espaço-tempo para execução guiada por eventos.

Figura 2.3: Comparação entre eventos discretos e passo fixo.

Simuladores para treinamento que seguem a modelagem estrutural utilizam tipicamente a execução de passo fixo devido à presença de equações dinâmicas que resultam em atualizações constantes no sistema.

\subsection{Modelagem Estrutural de Simuladores de Ambientes Virtuais}

Softwares de simulação são geralmente compostos por dois módulos: Módulo Executor e Módulo de Aplicação. O módulo executor, como o nome diz, é responsável por executar a simulação, coordenando as iterações e atualizando o tempo da simulação. Um módulo executor bem projetado pode ser utilizado para diversas simulações sem a necessidade de alteração em seu código.

O módulo de aplicação implementa o modelo do sistema a ser simulado, impossibilitando, ao contrário do executor, a reutilização completa em outras simulações. 
Em uma simulação guiada por eventos, a aplicação agenda eventos no executor. Este por sua vez atualiza o tempo da simulação e entrega o próximo evento para os destinatários na aplicação. Já no caso de uma simulação de passo fixo, o executor faz o controle da iteração, acionando cada processo do modelo a cada passo (tempo fixo), e fornecendo mecanismos de troca de dados entre eles.

Para a simulação de sistemas complexos, o modelo é muitas vezes dividido em sub-modelos menos complexos. Estes, por sua vez, são divididos em outros submodelos e, assim por diante, até o nível de componentes de menor complexidade. Em simuladores para treinamento em equipamentos ou veículos, é comum particionar o modelo final de acordo com a própria organização e funcionamento do sistema. A interação entre estes blocos de simulação ocorre através de interfaces de entrada e saída.

Por exemplo, um simulador de voo pode ter seu modelo dividido nos seguintes sub-modelos (ou blocos), seguindo a própria organização estrutural da aeronave:

- modelo aerodinâmico,

- motor,

- sistema elétrico,

- sistema pneumático,

- sistema hidráulico,

- sistema de radio-navegação.

Estes blocos possuem entradas e saídas que são interligadas. Por exemplo, o sistema elétrico recebe como uma das entradas o número de revoluções por minuto (RPM) do bloco motor (saída). Este parâmetro é utilizado para calcular se os geradores elétricos estão abastecendo o sistema elétrico ou não. Saídas do motor também alimentam o modelo aerodinâmico para o cálculo da força de propulsão que o motor gera sobre a aeronave.

Cada um destes blocos pode ser subdividido em outros blocos. Por exemplo, o sistema de radio-navegação pode ser particionado em Very High Frequency Omnidirectional Range (VOR), Non-Directional Beacon (NDB), Instrument Landing System (ILS) etc.

Existem diversos métodos de modelagem que podem ser aplicados em cada bloco. Os principais são [2]: 
- Modelo de Componentes:

O bloco é modelado de acordo com os componentes básicos e as grandezas envolvidas. Por exemplo, o sistema elétrico é composto por barramentos elétricos, disjuntores, chaves, geradores, baterias etc; e as grandezas envolvidas são correntes e tensões. Os componentes e grandezas são então representados por equações.

- Modelo de Entrada/Saída:

Esta técnica, conhecida também como caixa-preta, consiste em representar um bloco inteiro através das relações de entradas e saídas, desconsiderando os detalhes de funcionamento interno. Normalmente, estas relações são implementadas na forma de curvas fornecidas pelo fabricante ou obtidas empiricamente de um equipamento real.

- Modelo Matemático:

Neste tipo de modelo, o bloco é representado através de equações matemáticas que relacionam as entradas e saídas. Geralmente são utilizadas equações diferenciais para sistemas contínuos (por exemplo, o modelo aerodinâmico) ou equações booleanas (sistema elétrico, por exemplo).

Estas técnicas são utilizadas em conjunto em um simulador complexo. Modelos matemáticos e de entrada/saída são aplicados nos blocos atômicos, enquanto o modelo de componentes é utilizado nos blocos situados nos níveis mais altos na hierarquia.

\subsection{Síntese}

Este capítulo apresentou os conceitos básicos e as diferentes classificações envolvidos no desenvolvimento de softwares de simulação. No capítulo 3 serão apresentadas os principais trabalhos existentes na área de desenvolvimento de ambientes virutais para treinamento. 


\section{Estado da Arte}

Este capítulo apresenta a revisão bibliográfica sobre arquiteturas software e tecnologias envolvidas no desenvolvimento de simuladores para treinamento. Para este estudo foram consideradas principalmente publicações acadêmicas. Serão apresentadas as principais arquiteturas abertas para o desenvolvimento de simulações para treinamento.

\subsection{AVSM}

O Modelo Estrutural de Veículos Aéreos (Air Vehicle Structural Model - AVSM) [4] é uma estratégia de engenharia de software desenvolvido em conjunto pela força aérea dos Estados Unidos e Instituto de Engenharia de Software (Software Engineering Institute - SEI) da Universidade Carnegie Mellon. O desenvolvimento de simuladores de voo baseado no fluxo de dados utilizado anteriormente apresentava muitos problemas de integração e manutenção devido a ausência de arquiteturas de software bem definidas e independentes da arquitetura computacional. Percebendo esta deficiência, em 1986 foi iniciado o desenvolvimento do AVSM. Desde então, esta arquitetura tem sido aplicada em projetos de simuladores com bastante êxito.

Um modelo estrutural é uma coleção de classes reutilizável de diferentes níveis de abstração, provendo a base da qual o software do simulador de voo é derivado [4]. Assim como diversos simuladores, o AVSM é dividido em nível de aplicação e nível executivo. O primeiro contém o modelo que simula uma determinada aeronave, e é organizado de forma semelhante à construção do veículo. Já o nível executivo é responsável pela execução do modelo, interface com instrutor e operador, e integridade dos dados caso a plataforma seja multiprocessada. Ao contrário do nível de aplicação, que é específico para cada tipo de aeronave, o executivo pode ser reutilizado em diferentes simuladores.

O AVSM é composto por cinco elementos principais, ilustrados na figura 3.1: 
- componentes,

- controladores de subsistema,

- sequenciador periódico,

- manipulador de eventos,

- sincronizador de tempo.

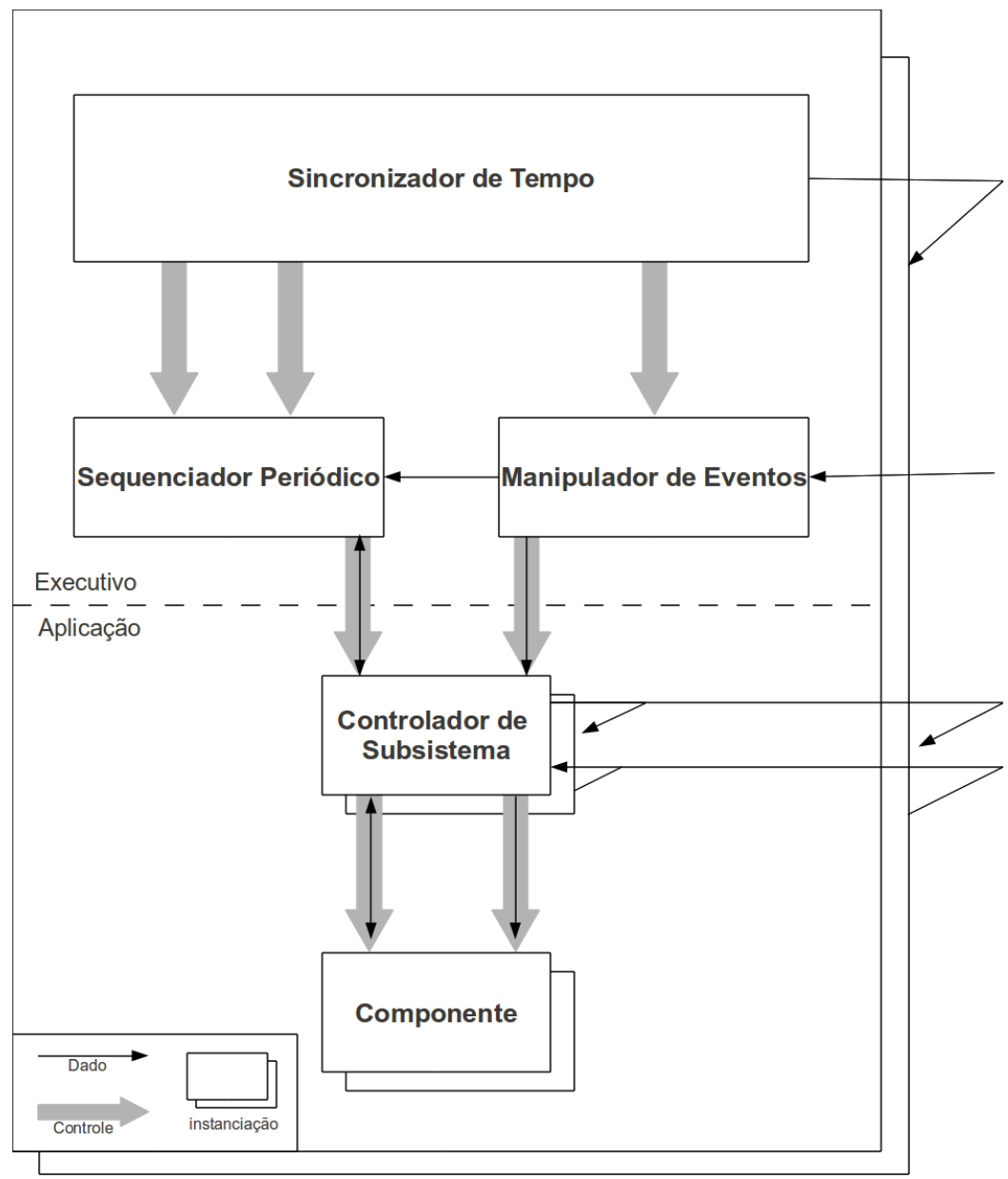

Modificado a partir de [4]

Figura 3.1: Visão geral do AVSM.

Conforme a figura 3.1, os elementos sincronizador de tempo, manipulador de eventos e sequenciador periódico fazem parte da camada executiva. Normalmente, apenas uma instância de cada um destes elementos existe na simulação. A camada de aplicação é constituída por componentes e controladores de subsistema. Estes dois tipos de elementos aparecem em várias instâncias, cada uma com uma implementação específica.

Cada um destes elementos é explicado a seguir com mais detalhes: 


\section{Componentes}

Os componentes representam os elementos de mais baixo nível em uma aeronave (válvulas, bombas hidráulicas, geradores elétricos, reguladores etc). De fato, todo o modelo da aeronave é implementado nesta camada (em vários componentes), sendo os demais apenas elementos de suporte e controle da execução.

A interação entre os componentes e os demais elementos da arquitetura ocorre através de dois tipos de operações (figura 3.2): periódicas e aperiódicas. A única operação periódica é a Update, utilizada para sinalizar que o componente deve atualizar o seu estado interno dado o intervalo de tempo que a simulação avançou. Os dados de entrada utilizados para atualização são fornecidos para o componente através de parâmetros da operação. Os valores resultantes (saídas) são retornados como respostas da requisição.

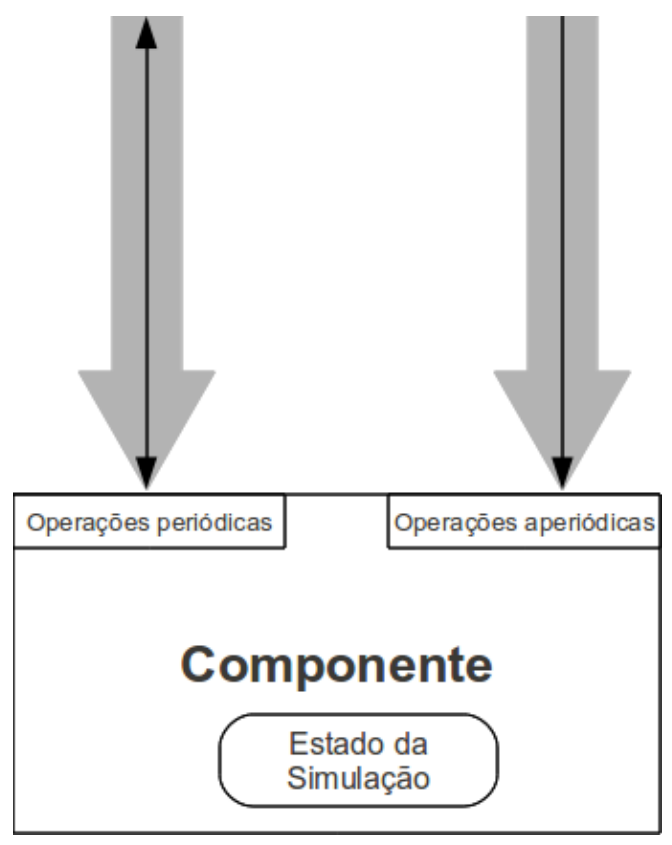

Modificado a partir de [4]

Figura 3.2: Componentes.

As operações aperiódicas (ou eventos) são utilizadas esporadicamente, de forma assíncrona em relação ao ciclo de execução. São elas:

- initialize: Traz o componente ao estado inicial.

- set_parameter: Modifica parâmetros internos do componente.

- process_malfunction: Solicita ao componente para simular um determinado defeito. 


\section{Controladores de Subsistema}

Este tipo de elemento é utilizado para controlar um conjunto de componentes de funcionalidades compatíveis, constituindo um subsistema. Estes agrupamentos representam um subsistema real da aeronave simulada, por exemplo: combustível, hidráulica, motores, modelo aerodinâmico, elétrico etc. Os subsistemas também servem como unidades básicas de software para alocação de recursos computacionais. A figura 3.3 ilustra as interfaces de um controlador de subsistema.

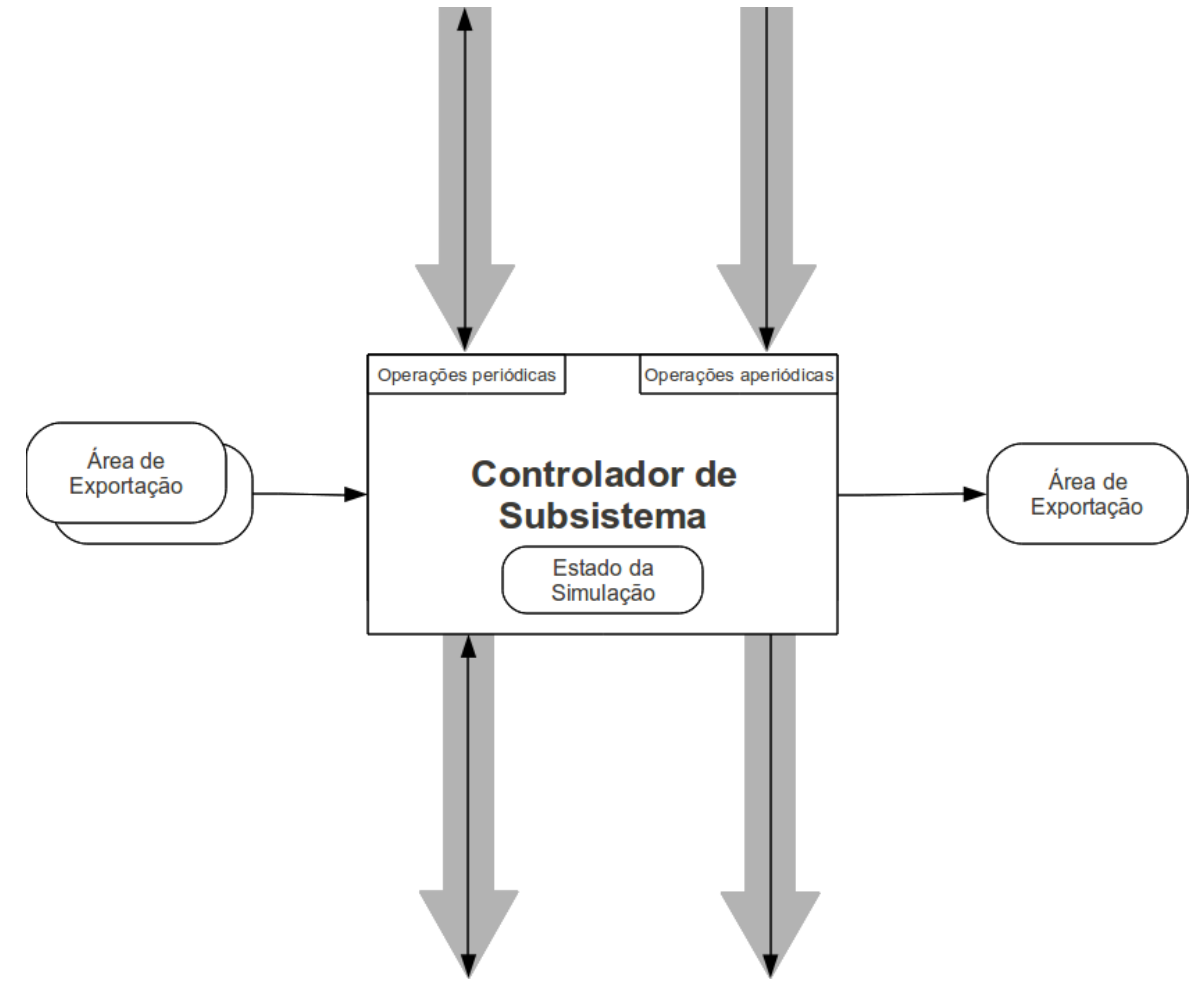

Modificado a partir de [4]

Figura 3.3: Controlador de subsistema.

O controlador de subsistema, além de coordenar o funcionamento dos componentes internos, faz a interface com o restante do sistema. Assim como os componentes, o controlador de subsistema permite operações periódicas e aperiódicas. A comunicação com os demais subsistemas ocorre através de áreas de memória compartilhada (áreas de exportação). Cada uma destas regiões só pode ser escrita por um único subsistema, mas podem ser lidas por vários simultaneamente. Desta forma, cada controlador de subsistema é responsável por garantir a integridade dos dados.

As operações periódicas são:

- update: Esta operação sinaliza o controlador para atualizar seu estado interno e seus componentes. Conforme descrito, as entradas e saídas desta 
operação são através de áreas de exportação. O controlador passa estes dados para os componentes através dos parâmetros de entrada de suas operações de uptade. Os resultados (retornado pelos componentes) são escritos na área compartilhada do subsistema. O controlador é responsável em ordenar a atualização dos componentes de forma coerente, garantindo a estabilidade e integridade da simulação. O retorno desta operação indica que o subsistema está atualizado e estabilizado (os dados de saídas já podem ser utilizados por outros subsistemas).

- import: Sinaliza ao controlador que as áreas de exportação de outros subsistemas podem ser acessadas (é garantida a estabilidade dos dados).

- stabilize: Esta operação retorna se os dados na área de exportação do subsistema estão estáveis.

Além das operações aperiódicas dos componentes (initialize, set_parameter e process_malfunction), o controlador de subsistema contém:

- hold_parameter: Esta operação "congela" a atualização de uma determinada variável. É utilizada para simulações parciais (por exemplo, sem consumo de combustível) e análises.

- configure: Configura o subsistema para um determinado estado (através da operação set_parameter dos componentes).

As operações aperiódicas initialize, set_parameter e process_malfunction, funcionam direcionando a requisição para um componente específico.

\section{Sequenciador Periódico}

Este elemento gerencia todos os processos periódicos do simulador, acionando as operações nos controladores de subsistema. A figura 3.4 ilustra este elemento.

O sequenciador periódico utiliza uma tabela de escalonamento pré-definida contendo a ordem e a taxa de atualização de cada subsistema (através do controlador). Este elemento também gerencia o estado geral do simulador, selecionando quais subsistemas devem ou não ser invocados.

As operações são:

- data_moves: Invoca a operação import nos subsistemas.

- periodic_processing: Atualiza os subsistemas (operação de update). 


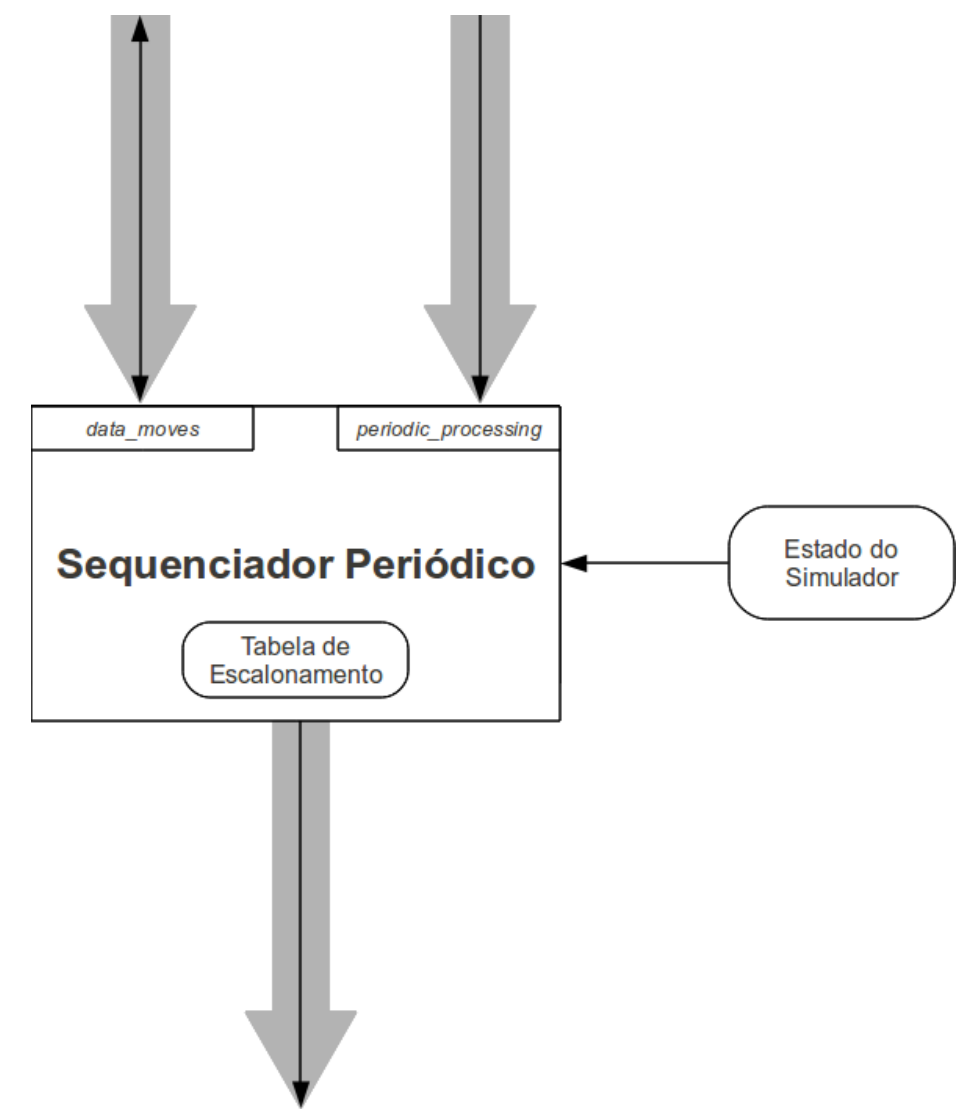

Modificado a partir de [4]

Figura 3.4: Sequenciador periódico.

\section{Manipulador de Eventos}

O manipulador de eventos é responsável pelo gerenciamento de todos os processos aperiódicos do sistema, estando no mesmo nível que o sequenciador periódico na arquitetura AVSM. O principal propósito é despachar os comandos da interface do instrutor/operador do sistema (eventos), como mudanças no estado geral (executando, congelado, reinicialização etc) e ativação de simulação de falhas. Os detalhes deste elemento são ilustrados na figura 3.5.

Quando um evento é gerado (geralmente pelo terminal do instrutor/operador), ele é adicionado em uma fila (Event Queue) para ser entregue no momento adequado da simulação. Quando a operação event_processing é invocada, o manipulador de eventos distribuí estes eventos para os subsistemas (através das operações aperiódicas). As informações de roteamento de eventos (quais os subsistemas interessados em um determinado tipo de evento) são armazenadas na tabela de despacho.

Os eventos de mudanças de estado geral da simulação não são encaminhados para controladores de subsistema, mas sim para o sequenciador periódico. 


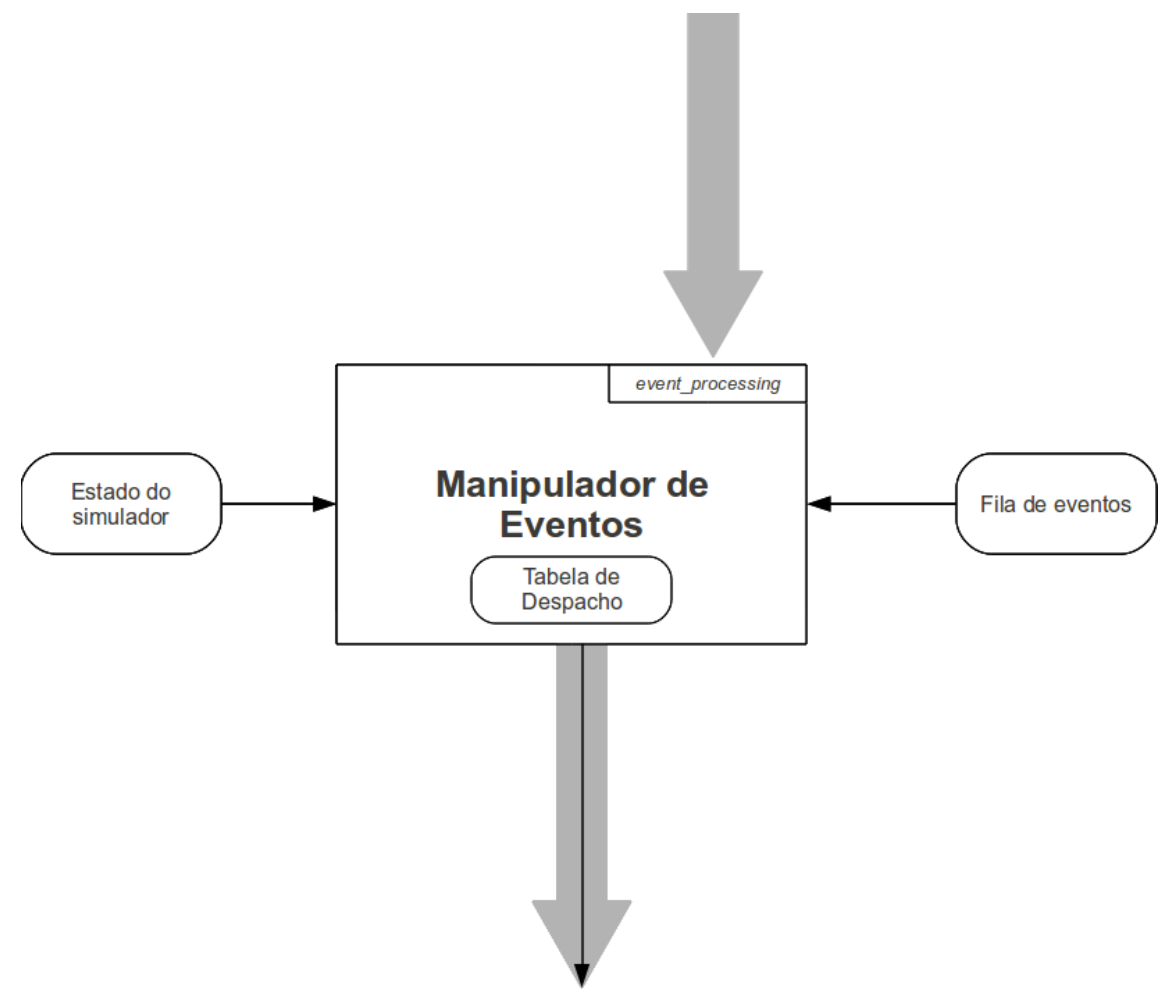

Modificado a partir de [4]

Figura 3.5: Manipulador de eventos.

\section{Sincronizador de Tempo}

O sincronizador de tempo (figura 3.6) é um executor cíclico responsável por sincronizar cada ciclo de simulação e coordenar a execução geral do sistema.

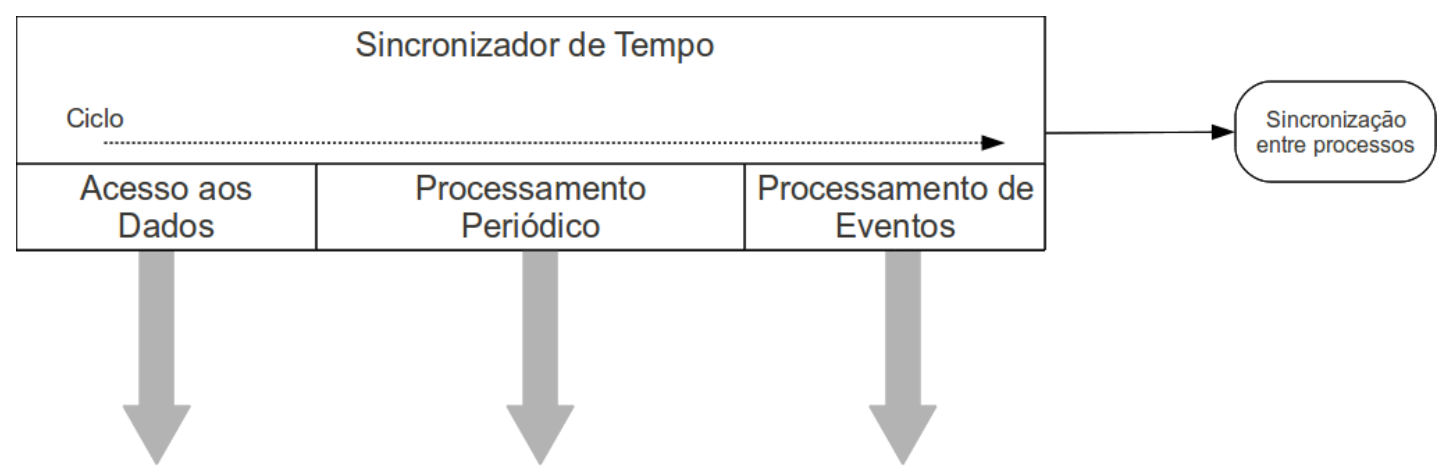

Modificado a partir de [4]

Figura 3.6: Sincronizador de tempo.

O tempo em cada processador é dividido em ciclos. O ciclo na arquitetura AVSM é ilustrado na figura 3.7. O primeiro ponto de sincronismo (no inicio do ciclo) garante que os ciclos de todos os processos iniciem simultaneamente. Neste momento todas as áreas de exportação (subsistemas) já estão estabilizadas 
e os subsistemas já podem importar os dados (data_moves) e o manipulador de eventos pode despachar a fila. O segundo ponto de sincronismo garante que todos os processamentos periódicos serão executados simultaneamente. Após atualizar todos os subsistemas, o processador fica em espera (idle) até o término do ciclo.

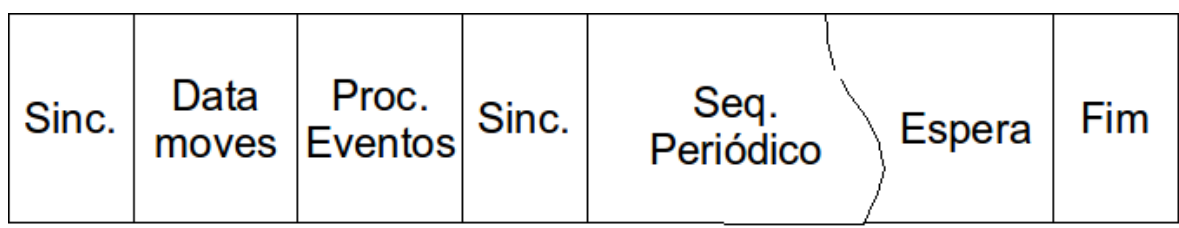

Modificado a partir de [4]

Figura 3.7: Ciclo de execução do AVSM

Em ambientes multiprocessados, existe um sincronizador de tempo mestre, sendo os demais escravos. O mestre é responsável por gerar os sinais de sincronização através de técnicas de comunicação entre processos (Inter-Process Communication (IPC)).

\subsection{ModSim}

O desenvolvimento da arquitetura ModSim (Modular Simulator) [5] teve inicio no final de 1982 pela Boeing. O propósito deste programa foi desenvolver um projeto modular e genérico de simuladores de voo, utilizando módulos e interfaces de comunicação padronizadas. Após ser aprovada pela força aérea dos Estados Unidos, diversas companhias entraram para o programa, entre elas: Scientific Applications Internation Company (SAIC), Rediffusion Simulation Limited (RSL). O desenvolvimento da arquitetura ModSim ocorreu em paralelo e de forma independente da arquitetura AVSM.

Os objetivos do ModSim foram reduzir os custos e o tempo de desenvolvimento de simuladores de voo através de uma arquitetura modular com interfaces bem definidas, que permitiu uma maior reutilização de software, paralelização e subcontratação no desenvolvimento.

A arquitetura ModSim é composta por doze segmentos de software interligados através de uma rede virtual de dados (Virtual Network (VNET)), conforme ilustrado na figura 3.8. As funções ou objetos do simulador devem ser divididos entre estes segmentos funcionais.

Cada segmento da arquitetura ModSim possui interfaces externas (para comunicação com outros segmentos) bem definidas, permitindo a paralelização do 


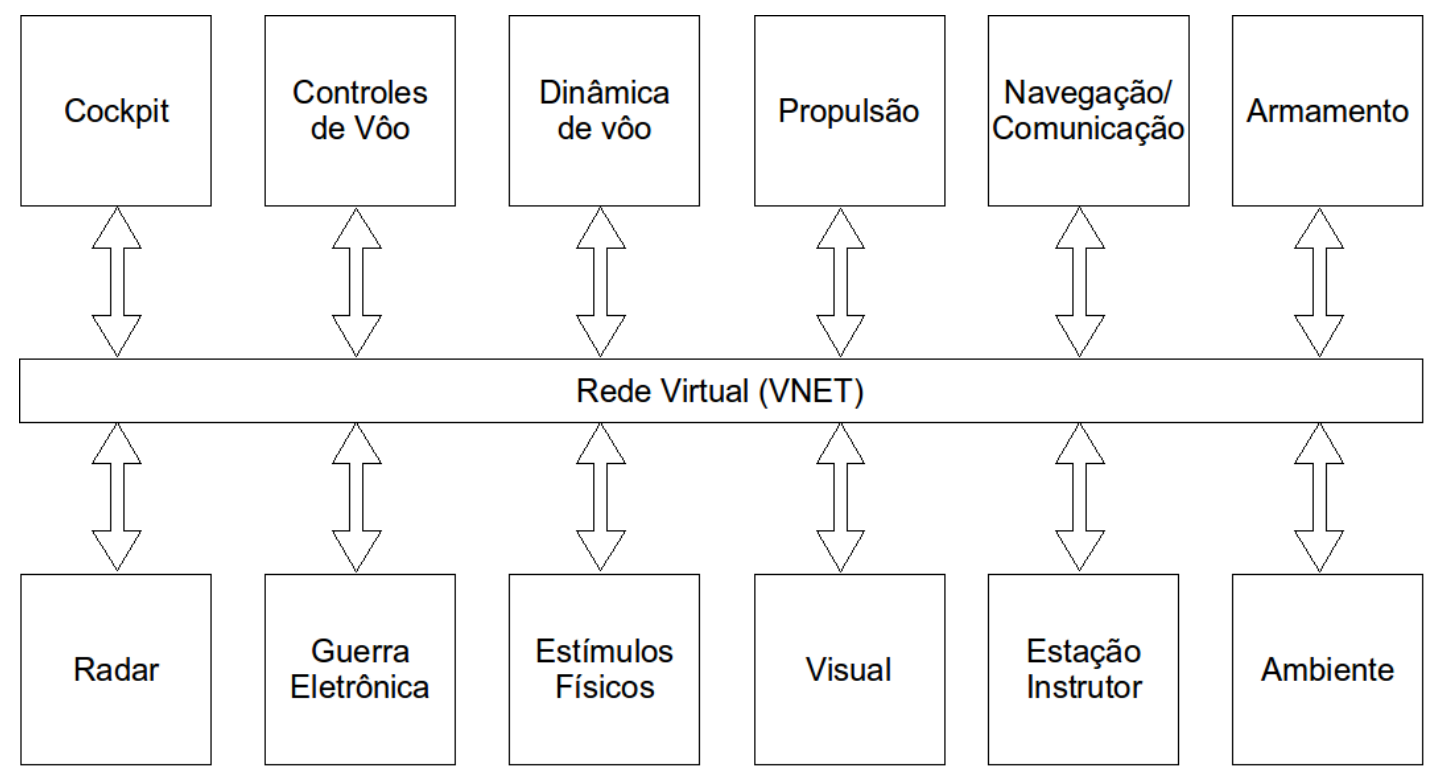

Modificado a partir de [5]

Figura 3.8: Arquitetura ModSim

desenvolvimento e facilitando a integração final. Estas interfaces são definidas por um conjunto fixo de tipos de mensagens que trafegam pela rede virtual.

Nas versões preliminares do ModSim, é convencionado que cada segmento seja executado em um computador (módulo computacional) diferente, conectados através de canais de fibra óptica. Já nas versões posteriores, devido ao aumento do poder de processamento dos computadores, um conjunto de segmentos pode ser agrupados em um único módulo computacional.

A comunicação entre segmentos ocorre através de mensagens enviadas pela rede virtual (VNET). A função da VNET é abstrair qualquer meio ou protocolo de comunicação, dos segmentos, encapsulando todos os detalhes de implementação em uma interface pré-estabelecida. Assim cada módulo desconhece a localização dos demais e dos detalhes da comunicação. A VNET pode ter diversas implementações, como memória compartilhada, comunicação através de um back plane ou uma rede de dados. Porém, a interface com os segmentos deve ser constante.

\subsection{DARTS}

Com a experiência obtida no programa ModSim e sob influência da arquitetura AVSM, a Boeing Defense \& Space Group desenvolveu internamente a Arquitetura de Domínio para Reutilização em Sistemas de Treinamento (Domain Architecture for Reuse in Training Systems - DARTS). Desta forma, o DARTS tenta explorar 
a forma reutilizável alcançada através do modelo estrutural (em particular o AVSM), e o conteúdo reutilizável do ModSim [6].

A visão geral desta arquitetura é mostrada na figura 3.9. Na DARTS, o sistema é dividido em segmentos; os segmentos são divididos em subsistemas; e os subsistemas são divididos em componentes. Os segmentos são então agrupados em módulos [7].

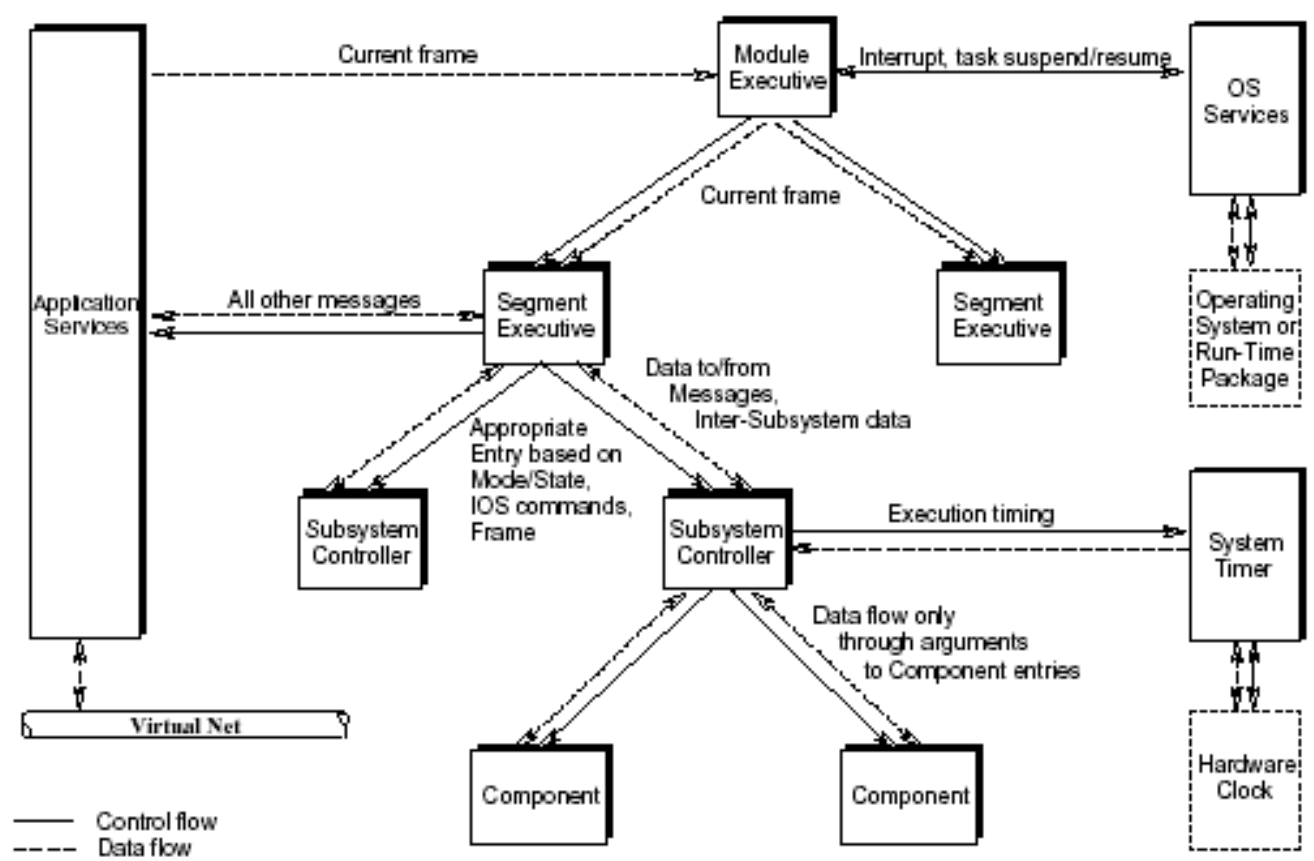

Extraído de [7]

Figura 3.9: Visão geral da DARTS.

Assim como o ModSim, o sistema é inicialmente dividido em segmentos funcionais. Porém, como a DARTS pode operar em qualquer tipo de arquitetura computacional, não é necessário manter um segmento por unidade de processamento (como as versões preliminares do ModSim). Desta forma, o DARTS faz distinção entre segmentos funcionais (conjunto de objetos coesos) e módulos (sistemas computacionais). A comunicação entre segmentos ocorre também através de mensagens em uma VNET, garantindo a integridade dos dados.

Diferente do ModSim, na DARTS o número de segmentos e a função de cada um não é fixa. Assim, nesta arquitetura segmentos são definidos como grupos de funções ou objetos que se relacionam internamente e com acoplamento fraco com funções de outros segmentos. Dois fatores são considerados para medir a coerência entre objetos: A quantidade de dados compartilhados entre eles, e a dependência de ordem de execução (um objeto deve ser executado sempre antes 
que outro, por exemplo). A interface de comunicação entre segmentos é bem definida, permitindo a paralelização do desenvolvimento e facilitando a integração final. O número de segmentos utilizados e sua organização interna são específicos para cada simulador, desde que as interfaces externas sejam mantidas.

A DARTS é composta por cinco elementos estruturais:

\section{- VNET}

- executor de módulo (module executive);

- executor de segmento (segment executive);

- controlador de subsistema (subsystem controller);

- componente (component).

\section{VNET}

Este elemento é o meio através do qual os segmentos do sistema se comunicam. Assim como no ModSim, a VNET é uma abstração do meio físico e protocolo, ocultando ao restante da aplicação todos os detalhes de transmissão de dados. Desta forma, a interface da rede virtual com os demais elementos do sistema são operações como Enviar e Receber (Send e Receive).

A transmissão dos dados na VNET é na forma de mensagens, definida como tipos da linguagem de programação Ada. Cada sistema de simulação define um conjunto específico de mensagens, contendo todo o fluxo de dados entre os segmentos. A VNET utiliza uma tabela interna de roteamento de mensagens que relaciona os emissores e receptores de cada tipo.

Segundo [6] e [7], esta abordagem apresenta diversas vantagens, como:

- Ter maior segurança do dado, lidando com acesso concorrente à informação.

- Ser independente de tecnologias, podendo, inclusive, utilizar diversos métodos de comunicação em um mesmo sistema (por exemplo, memória compartilhada entre segmentos no mesmo módulo, e rede Ethernet entre segmentos em módulos diferentes).

- Apresentar centralização da comunicação, facilitando modificações nos detalhes de transmissão, sem alterar o restante do sistema. 


\section{$\underline{\text { Executor de Módulo }}$}

Um Módulo é uma unidade computacional do sistema de computação, e seus recursos associados. Na prática cada computador do simulador é um Módulo (independente do número de processadores). O Executor de Módulo é o elemento que faz a interface entre o sistema operacional e os recursos computacionais e restantes do sistema de simulação. Sua função principal é executar seus segmentos, seja através de chamadas de operações nos segmentos ou agendando tarefas para cada um deles no sistema.

Em uma simulação distribuída, cada computador executa um executor de módulo.

\section{Executor de Segmento}

O Executor de Segmento é o elemento responsável pela execução e interface com a VNET de um segmento da simulação. Todas as trocas de mensagens entre a VNET e os subsistemas e componentes passam por este elemento.

A execução dos subsistemas ocorre de forma semelhante à arquitetura AVSM, através de uma tabela de escalonamento para as operações periódicas. As operações aperiódicas chegam ao segmento através de mensagens. O executor então as processam (caso seja operações de mudança de modo) ou repassa para o subsistema correto.

\section{Controlador de Subsistema}

Assim como na AVSM, a função do Controlador de Subsistema é executar seus componentes, sendo a interface para o restante do sistema. Porém, na AVSM a troca de dados entre subsistemas ocorre através de memória compartilhada. $\mathrm{Na}$ DARTS, o Controlador de Segmento fornece ao controlador de subsistema os dados das mensagens recebidas e constrói as mensagens para serem enviadas, caso a comunicação seja entre subsistemas em diferentes segmentos. O fluxo de dados interno ocorre através de regiões de memórias mantidas pelo executor do segmento.

\section{Componente}

Um Componente, assim como na arquitetura AVSM, é o elemento estrutural mais específico e representa as entidades físicas de uma aeronave (bombas hidráulicas, válvulas de combustível, geradores elétricos etc). Os componentes são auto-contidos, gerenciando sua execução e estados internos.

Assim como na AVSM, o fluxo de dados entre um componente e o restante 
do sistema ocorre através de parâmetros de entrada e retornos de funções. Isto diminui a dependência entre objetos, facilitando a reutilização de código.

\subsection{Comparação entre Arquiteturas}

Nesta seção serão comparadas as três arquiteturas descritas. Quatro aspectos foram considerados nesta comparação: organização da aplicação, modelo de execução, fluxo de dados e multiprocessamento.

A tabela 3.1 resume a comparação das três arquiteturas estudadas.

Todas as arquiteturas analisadas dividem a aplicação em uma hierarquia de componentes. Porém o número de níveis desta hierarquia é particular para cada uma delas.

O modelo de execução é como a arquitetura controla a atualização em tempo real da aplicação.

O fluxo de dados representa o caminho que a informação gerada e consumida por cada componente percorre dentro da aplicação. Cada arquitetura utiliza diferentes mecanismos para implementação do fluxo de dados, como memória compartilhada, barramento de mensagens, passagens de parâmetros, entre outros.

O último aspecto analisado é como uma aplicação pode ser paralelizada em um computador multiprocessado, ou distribuída em um aglomerado computacional.

\subsection{Síntese}

Neste capítulo foram apresentadas algumas arquiteturas de software para o desenvolvimento de simuladores para treinamento.

O Modelo Estrutural de Veículos Aéreos (AVSM) define o conceito de modelagem estrutural aplicado ao desenvolvimento de simuladores de voo. Esta arquitetura separa a aplicação em subsistemas de forma análoga à aeronave a ser simulada. Os subsistemas, por sua vez, são compostos por entidades autônomas e de funcionalidades específicas, denominadas componentes.

Simuladores desenvolvidos segundo a arquitetura ModSim (Modular Simulator) são compostos por até doze segmentos de funcionalidades específicas. Para a comunicação entre segmentos, esta arquitetura introduziu o conceito de rede 
Tabela 3.1: Comparação das arquiteturas

\begin{tabular}{|c|c|c|c|}
\hline & AVSM & ModSim & DARTS \\
\hline $\begin{array}{l}\text { Hierarquia do } \\
\text { Modelo }\end{array}$ & $\begin{array}{c}2 \text { níveis } \\
\text { (Subsistemas e } \\
\text { Componentes) }\end{array}$ & $\begin{array}{c}1 \text { nível } \\
\text { (Segmentos) }\end{array}$ & $\begin{array}{c}3 \text { níveis } \\
\text { (Segmentos, } \\
\text { Subsistemas e } \\
\text { Componentes) }\end{array}$ \\
\hline Execução & $\begin{array}{c}\text { Hierárquico } \\
\text { (executivo } \rightarrow \\
\text { Subsistema } \rightarrow \\
\text { Componentes) }\end{array}$ & $\begin{array}{c}\text { Execução dos } \\
\text { Segmentos depende } \\
\text { da implementação }\end{array}$ & $\begin{array}{c}\text { Hierárquico } \\
(\text { Segmento } \rightarrow \\
\text { Subsistema } \rightarrow \\
\text { Componente) }\end{array}$ \\
\hline Fluxo de Dados & $\begin{array}{c}\text { Parâmetros de } \\
\text { operação no nível } \\
\text { de Componentes, } \\
\text { memória } \\
\text { compartilhada no } \\
\text { nível de } \\
\text { Subsistema }\end{array}$ & VNET & $\begin{array}{l}\text { VNET no nível de } \\
\text { Segmentos, } \\
\text { memória } \\
\text { compartilhada no } \\
\text { nível de } \\
\text { Subsistemas, } \\
\text { parâmetros no } \\
\text { nível de } \\
\text { Componentes }\end{array}$ \\
\hline Paralelismo & $\begin{array}{l}\text { Todos os elementos } \\
\text { devem estar em } \\
\text { cada linha de } \\
\text { execução }\end{array}$ & $\begin{array}{l}\text { Dependente da } \\
\text { Implementação, no } \\
\text { nível de Segmento }\end{array}$ & $\begin{array}{l}\text { Nível de Segmento. } \\
\text { O Executor de } \\
\text { Módulo é único } \\
\text { por computador }\end{array}$ \\
\hline $\begin{array}{l}\text { Comunicação } \\
\text { entre processos }\end{array}$ & $\begin{array}{c}\text { Memória } \\
\text { Compartilhada }\end{array}$ & VNET & VNET \\
\hline Distribuição & $\begin{array}{c}\text { idem ao } \\
\text { Paralelismo }\end{array}$ & $\begin{array}{l}\text { Segmentos são } \\
\text { agrupados em } \\
\text { módulos } \\
\text { computacionais }\end{array}$ & $\begin{array}{l}\text { Nível de Executor } \\
\text { de Módulo }\end{array}$ \\
\hline $\begin{array}{l}\text { Comunicação } \\
\text { entre nós }\end{array}$ & $\begin{array}{c}\text { Memória } \\
\text { Compartilhada }\end{array}$ & VNET & VNET \\
\hline
\end{tabular}

virtual (VNET). Esta entidade tem o objetivo de abstrair todos os detalhes de comunicação e localização dos segmentos, mantendo a uniformidade na comunicação.

Baseado na AVSM e na ModSim, no início dos anos 90 foi apresentada a Arquitetura de Domínio para Reutilização em Sistemas de Treinamento (DARTS). Assim como a ModSim, esta arquitetura divide a aplicação em segmentos que se comunicam através de uma rede virtual. Cada segmento, por sua vez, organiza seus elementos de acordo com o AVSM, ou seja, em subsistemas e componentes.

Estas arquiteturas, apesar de flexíveis e permitirem a reutilização de código, foram elaboradas seguindo as restrições tecnológicas da época. Como consequência, 
apresentam desvantagens que atualmente poderiam ser contornadas. O próximo capítulo irá apresentar uma proposta de arquitetura, visando à implementação de uma ferramenta para auxiliar o desenvolvimento de simuladores para treinamento, seguindo a abordagem estrutural. 


\section{Proposta de Arquitetura para Desenvolvimento de Simuladores de Treinamento}

O capítulo 3 mostrou diversas arquiteturas de software para simuladores de treinamento (especialmente os de voo). Todas elas são centradas na modelagem estrutural do objeto a ser simulado. Estes modelos foram propostos nas décadas de 80 e 90, sendo influenciados pelas tecnologias e limitações computacionais da época. Desta forma, estas arquiteturas apresentam algumas desvantagens, como o número fixo de níveis da hierarquia e controle de fluxo de dados não uniforme, sendo diferente para cada tipo de elemento. Porém, com o avanço do poder de processamento e de memória dos computadores, hoje é possível contornar estas desvantagens.

Os modelos estruturais envolvem três áreas de desenvolvimento: sistema executor, elementos estruturais (componentes, subsistemas e segmentos) e integração. O grau de reutilização do sistema executor pode ser alto, dependendo da implementação, ficando limitado ao ambiente computacional. Já a reutilização dos elementos estruturais varia de acordo com sua finalidade (por exemplo, um componente que representa uma válvula hidráulica pode ser utilizado em diversos simuladores, porém o subsistema elétrico de uma determinada aeronave apresenta baixa reutilização). O processo de integração é específico de cada simulador, sendo necessário em todos os projetos.

Devido à escassez de aplicativos e bibliotecas de software que auxiliem a modelagem estrutural de simuladores de treinamento, a implementação de novos projetos exige uma equipe de desenvolvimento altamente capacitada, com membros especialistas tanto na área da computação, quanto na área de modelagem de simuladores.

O objetivo deste capítulo é apresentar uma arquitetura para a implementação de simuladores de treinamento seguindo uma modelagem estrutural. 


\subsection{Visão Geral}

$\mathrm{Na}$ visão estrutural, o simulador é dividido em elementos que processam entradas, gerando saídas; interligados em uma rede de fluxo de dados. Estes elementos podem ser componentes, implementados através de modelos matemáticos ou de caixa-preta; ou uma composição de outros elementos. Assim, o número máximo de níveis na hierarquia é virtualmente infinito. As interfaces de dados dos elementos são as portas de entradas e saídas, que são conectadas com portas de outros elementos, formando a rede de fluxo de dados. A figura 4.1 ilustra este modelo.

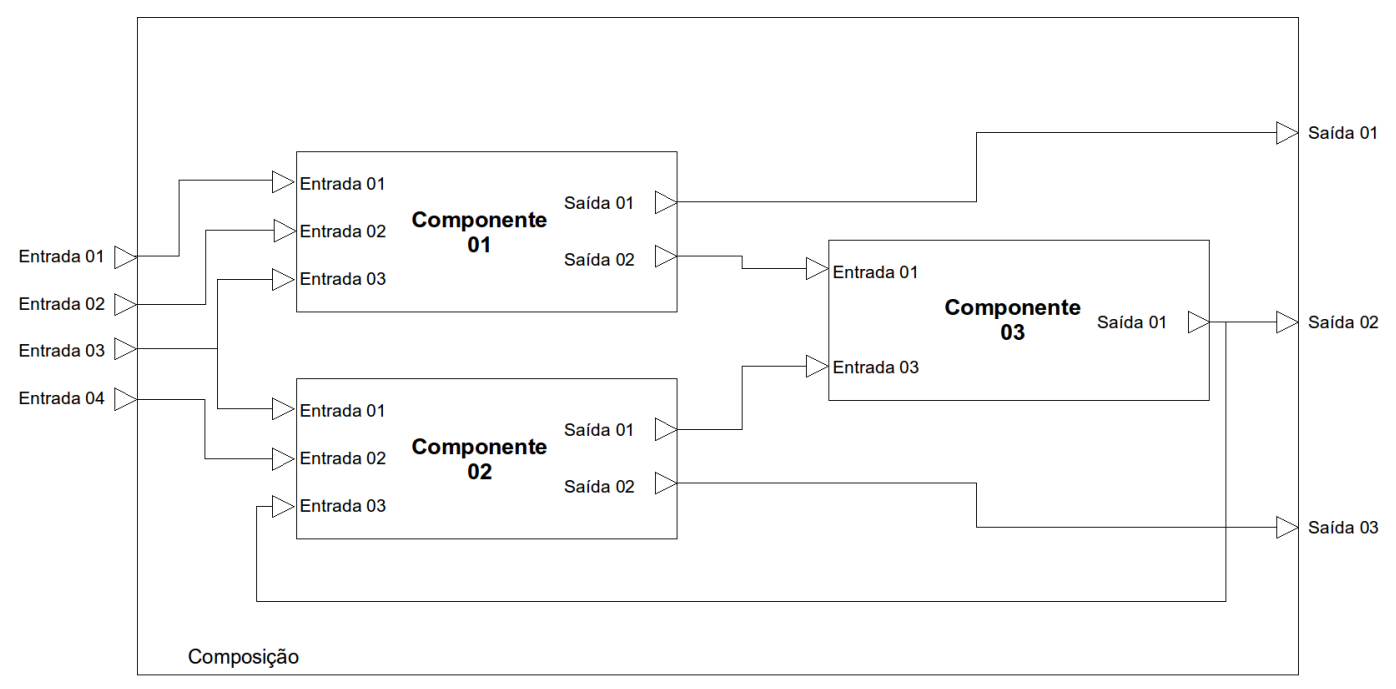

Figura 4.1: Modelo estrutural.

Os componentes e as composições são instâncias de uma determinada classe. Por exemplo, o componente que representa o disjuntor que conecta o sistema de comunicação UHF no barramento elétrico do sistema A, é uma instância da classe disjuntor. Além das portas de entrada e saída e da descrição comportamental (modelo), as classes determinam um conjunto de propriedades que podem ser alteradas em tempo de execução . Cada instância pode ter valores diferentes para cada propriedade, resultando em comportamento diferenciado. No exemplo da classe disjuntor, uma propriedade possível é a corrente de desarme; assim cada instância irá desarmar com um valor de corrente diferente. Esta abordagem eleva o grau de reutilização de código em um projeto.

Portanto, a integração, neste ambiente, consiste em instanciar os elementos, ajustar as propriedades, fazer composições e conexões. A equipe para esta etapa poderá ser reduzida, e os integrantes não precisam ter conhecimentos avançados na área da computação. É necessário apenas conhecer a organização estrutural do objeto a ser simulado. 
A biblioteca proposta organiza o software de simulação em uma arquitetura baseada nos modelos AVSM e DARTS, porém com algumas modificações visando aumentar a flexibilidade e melhor adequar com as novas tecnologias computacionais. A figura 4.2 contém a visão geral da arquitetura.

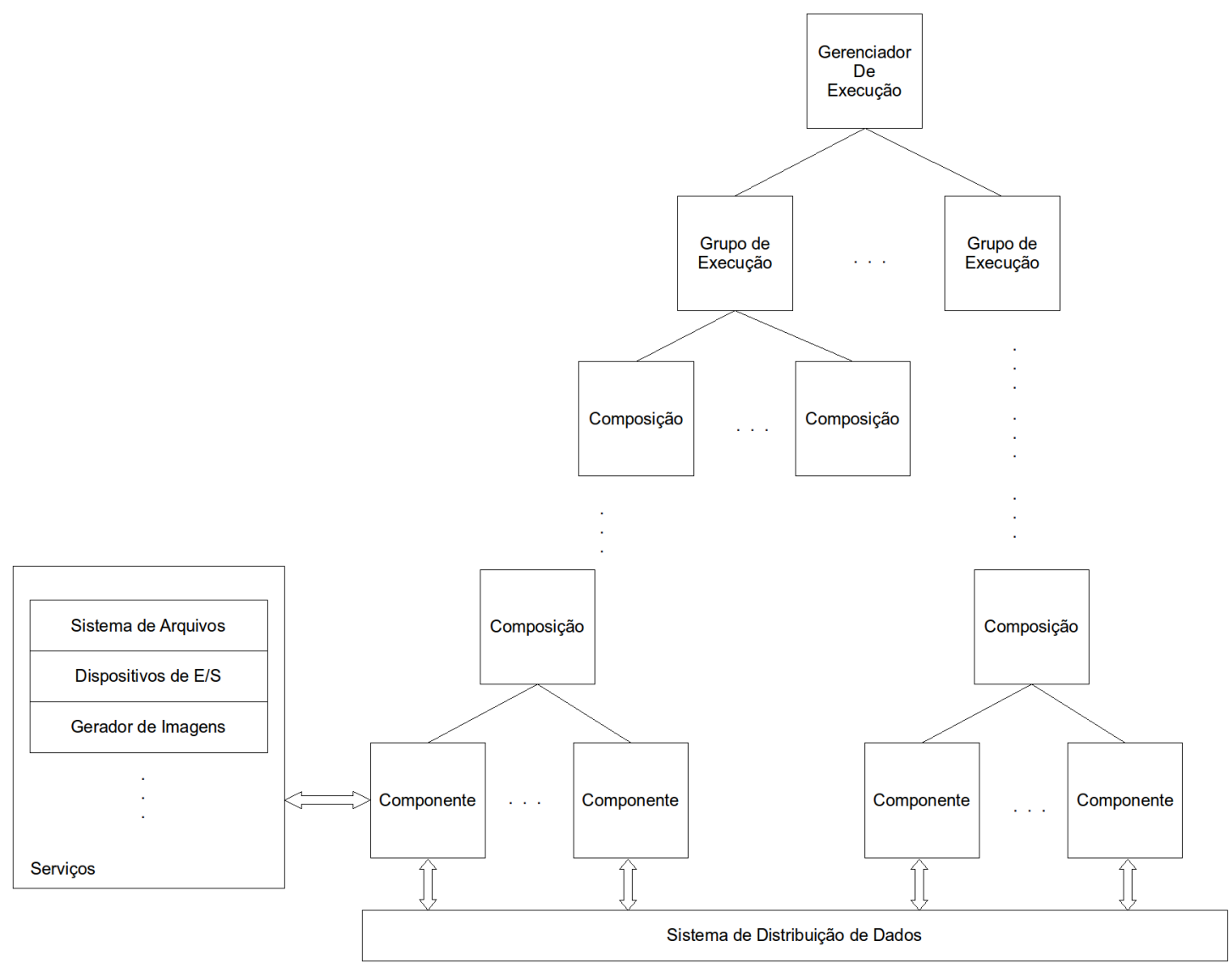

Figura 4.2: Visão geral da arquitetura proposta.

Nesta arquitetura, a simulação é dividida em blocos de processamento que são executados em paralelos. Estes blocos, denominado Grupos de Execução, contêm diversos elementos, que podem ser um componente ou uma composição. As composições, por sua vez, são compostas por outras composições e componentes, e assim por diante. A troca de dados entre componentes ocorre através do Sistema de Distribuição de Dados, abstraindo protocolos e a localização de cada elemento. Os componentes podem também utilizar serviços para auxiliar em tarefas que não fazem parte do modelo, tais como a geração de imagens, reprodução de áudio e o acesso ao sistema de arquivos. A figura 4.3 ilustra de forma geral a composição das entidades da arquitetura. 


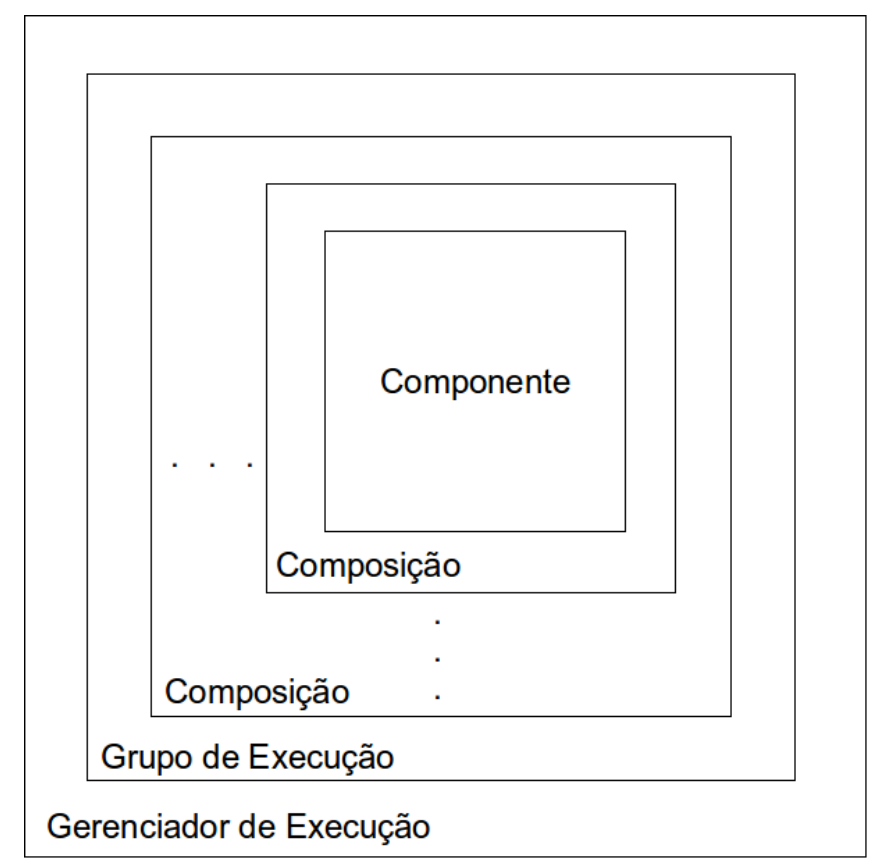

Figura 4.3: Visão geral da composição das entidades da arquitetura.

\subsection{Entidades da Arquitetura}

A arquitetura proposta é dividida em Executor e Aplicação. O Executor é composto por Gerenciadores de Execução, Grupos de Execução, Sistema de Distribuição de Dados (SDD) e Serviços. Já a Aplicação é constituída por Composições e Componentes. Estas entidades são detalhadas nas subseções seguintes.

\subsubsection{Componentes}

O Componente é o elemento estrutural atômico de uma simulação. Assim como nas arquiteturas estudadas (AVSM e DARTS), esta entidade implementa uma funcionalidade específica do objeto a ser simulado, como uma chave elétrica, uma válvula hidráulica, cálculo do arrasto hidrodinâmico (no caso de um simulador de embarcação), entre outros.

Um Componente é composto por operação de Atualização, propriedades e portas de entradas e saídas. Estas portas são interfaces na qual o Componente lê/escreve dados que são gerados/utilizados por outros Componentes, de acordo com o fluxo de dados (representado pelas conexões entre portas) estabelecido no processo de integração.

A operação de Atualização solicita que o Componente execute mais um passo da simulação, atualizando seu estado interno. Esta operação é chamada pelo sistema executor (em específico, o Grupo de Execução) nos momentos adequados 
durante a simulação (de acordo com a frequência de atualização do Componente e a ordenação dentro de um Grupo de Execução). No momento da atualização, o executor garante que os dados disponíveis nas portas de entrada estejam em um estado consistente.

Cada Componente é uma instância de uma classe específica. Em tempo de execução os Componentes são instanciados (conceito análogo ao de classes e instâncias das linguagens orientadas a objetos). O comportamento das classes pode ser parametrizado através de Propriedades, contendo valores que podem ser modificados em tempo de execução, especializando o comportamento de um Componente em relação ao seu tipo básico.

\subsubsection{Composição}

A Composição é um elemento da aplicação cujo funcionamento é descrito através do agrupamento de outras Composições e Componentes, representando um submodelo da simulação.

As Composições possuem portas de entrada e saída, e propriedades que são mapeados para os elementos internos. As portas de entradas são roteadas para entradas de um ou mais elementos. Cada porta de saída é conectada a uma saída de um único elemento.

\subsubsection{Grupo de Execução}

O Grupo de Execução é um agrupamento de hierarquias de elementos que são atualizados serialmente. A execução destes grupos ocorre em paralelo (em sistemas multiprocessados) e/ou distribuído em um aglomerado computacional. Esta entidade é responsável por manter a frequência e a ordem de atualização dos Componentes internos.

\subsubsection{Gerenciador de Execução}

O Gerenciador de Execução coordena os Grupos de Execução em um computador, sendo responsável pelo inicio da execução (através de threads ou processos) e sincronização de cada passo da simulação.

Em um ambiente distribuído, cada computador executa um Gerenciador de Execução. Um deles será o Mestre da simulação, e os demais, os Escravos. A diferença entre eles é que o Mestre gera um sinal para sincronizar os passos da 
simulação em todos os nós.

\subsubsection{Sistema de Distribuição de Dados}

O Sistema de Distribuição de Dados (SDD) é responsável pelo fluxo de dados entre Componentes, através das portas e conexões. Esta entidade é responsável pelo roteamento dos dados entre as portas, de forma transparente quanto ao protocolo e o meio de comunicação; e por garantir a consistência das informações. Desta forma, as conexões são independentes da localização física dos Componentes (que podem estar no mesmo Grupo de Execução, em grupos diferentes mas no mesmo computador, ou em outro nó do aglomerado de processamento).

O Sistema de Distribuição de Dados é equivalente à Rede Virtual (VNET) das arquiteturas MODSIM e DARTS, estudadas no capítulo 3. Ambas as abordagens têm o objetivo de fornecer uma interface transparente de troca de dados. Porém, a VNET atua no nível mais alto da hierarquia (os Segmentos). No DARTS, a responsabilidade pelo roteamento das informações dentro de um segmento segue a hierarquia, ou seja, a VNET faz a comunicação entre Segmentos, que faz entre os Subsistemas, que faz entre os Componentes.

Nesta arquitetura, a comunicação em todos os níveis (Composições ou Componentes) é uniforme (através das portas). O SDD gerencia a criação de portas e conexões entre elas, alocando os recursos necessários (memória) e estabelecendo uma tabela de roteamento no nível dos Componentes. Internamente os dados são compartilhados apenas entre os Componentes, uma vez que as Composições são apenas agrupamentos, e seu comportamento é definido apenas por seus elementos internos e conexões.

Na VNET os dados são transmitidos através de mensagens de tipos prédefinidos, utilizando operações de envio ( $p u t$ ) e recebimento (get). O SDD utiliza o modelo de memória compartilhada e distribuída, abstraído pelo conceito das portas. Ou seja, quando um Componente lê ou escreve em uma porta, internamente este dado é colocado ou obtido de uma determinada região de memória. Utilizando o recurso de orientação a objetos e sobrecarga de operadores que algumas linguagens oferecem (como o $\mathrm{C}++$ ), é possível implementar a interface de portas de forma a ter o comportamento semelhante a uma variável ou atributo comum da linguagem.

A tabela 4.1 mostra um resumo da comparação entre a VNET e o SDD. 
Tabela 4.1: Comparação entre o SDD e a VNET

\begin{tabular}{ccc}
\hline & VNET & SDD \\
\hline $\begin{array}{c}\text { Nível de } \\
\text { Atuação na } \\
\text { Hierarquia }\end{array}$ & Segmento & Composição e Componente \\
\hline $\begin{array}{c}\text { Transferência de } \\
\text { Dados }\end{array}$ & Mensagens pré-determinadas & Memória Compartilhada \\
\hline $\begin{array}{c}\text { Acesso aos } \\
\text { Dados }\end{array}$ & Operações na VNET (put e get) & Portas \\
\hline
\end{tabular}

\subsubsection{Serviços}

Serviços são módulos independentes que permanecem na memória do computador durante toda a execução, auxiliando a simulação, mas sem fazer parte do modelo. Exemplo de Serviços são o gerador de imagens, síntese de áudio, sistema de arquivos, interface com o hardware de entrada e saída, acesso a banco de dados, entre outros.

Em uma simulação distribuída, um determinado Serviço não necessita estar presente em todos os nós. Por exemplo, o Serviço de geração de imagens só irá executar no computador que está conectado à infra-estrutura de exibição gráfica.

\subsection{Funcionalidades}

A arquitetura proposta cobre três aspectos de uma simulação:

- Estrutura da Aplicação - como os componentes são organizados dentro da arquitetura.

- Execução - como os componentes são executados.

- Fluxo de Dados - como os componentes compartilham os dados.

\subsubsection{Estrutura da Aplicação}

Conforme explicado em 4.1, o modelo a ser simulado é estruturado hierarquicamente. Assim, o objeto a ser simulado é dividido em blocos. Estes por sua vez são compostos por outros elementos mais específicos, e assim por diante até alcançar o nível atômico, ou seja, os Componentes. 
Esta abordagem foi escolhida pois muitos objetos de simulação são organizados da mesma forma no mundo real (como veículos, plantas industriais e equipamentos), tornando o processo de desenvolvimento do modelo mais fácil e intuitivo. Por exemplo, um navio é composto por uma estrutura de flutuação, motores, sistemas hidráulicos, sistemas elétricos, sistemas de navegação, entre outros elementos. Cada um destes elementos é composto por elementos mais específicos, assim sucessivamente.

As arquiteturas estudadas no capítulo 3 também são baseadas em hierarquia, porém o número de níveis é fixo e o papel de cada um no modelo é constante. No DARTS, por exemplo, os níveis sempre são: Segmentos, Subsistemas e Componentes.

\subsubsection{Execução}

Nas arquiteturas estudadas, a execução do modelo segue a hierarquia dos elementos estruturais. No caso do DARTS, por exemplo, o Executor de Módulo executa os Segmentos. Estes, por sua vez, são responsáveis em atualizar os Subsistemas na ordem correta. Por fim, cada Subsistema solicita a atualização de cada Componente.

O modelo de execução proposto consiste em agrupar os elementos (Composições e Componentes) em grupos que executarão em paralelo. Estes grupos, denominado de Grupos de Execução, podem ser executados no mesmo computador (através de threads ou processos), ou distribuídos em um aglomerado computacional. Cada Grupo de Execução atualiza diretamente seus componentes, sem delegar a responsabilidade para as Composições.

A figura 4.4 ilustra a arquitetura do ponto de vista da execução. Como descrito, a execução dos componentes é solicitada diretamente pelo grupo de execução, sem intermédio das Composições. Esta abordagem generalizada e uniforme de escalonamento dos elementos, em todos os níveis da hierarquia, simplifica o desenvolvimento das composições, uma vez que é necessário informar apenas a taxa de atualização e a ordem (caso a implementação não utilize de um algoritmo de ordenação automática) de execução de cada sub-componente.

\subsubsection{Fluxo de Dados}

Conforme descrito no início do capítulo, os elementos da aplicação (Componentes ou Composições) possuem portas de entradas e saídas. O fluxo de dados acontece 


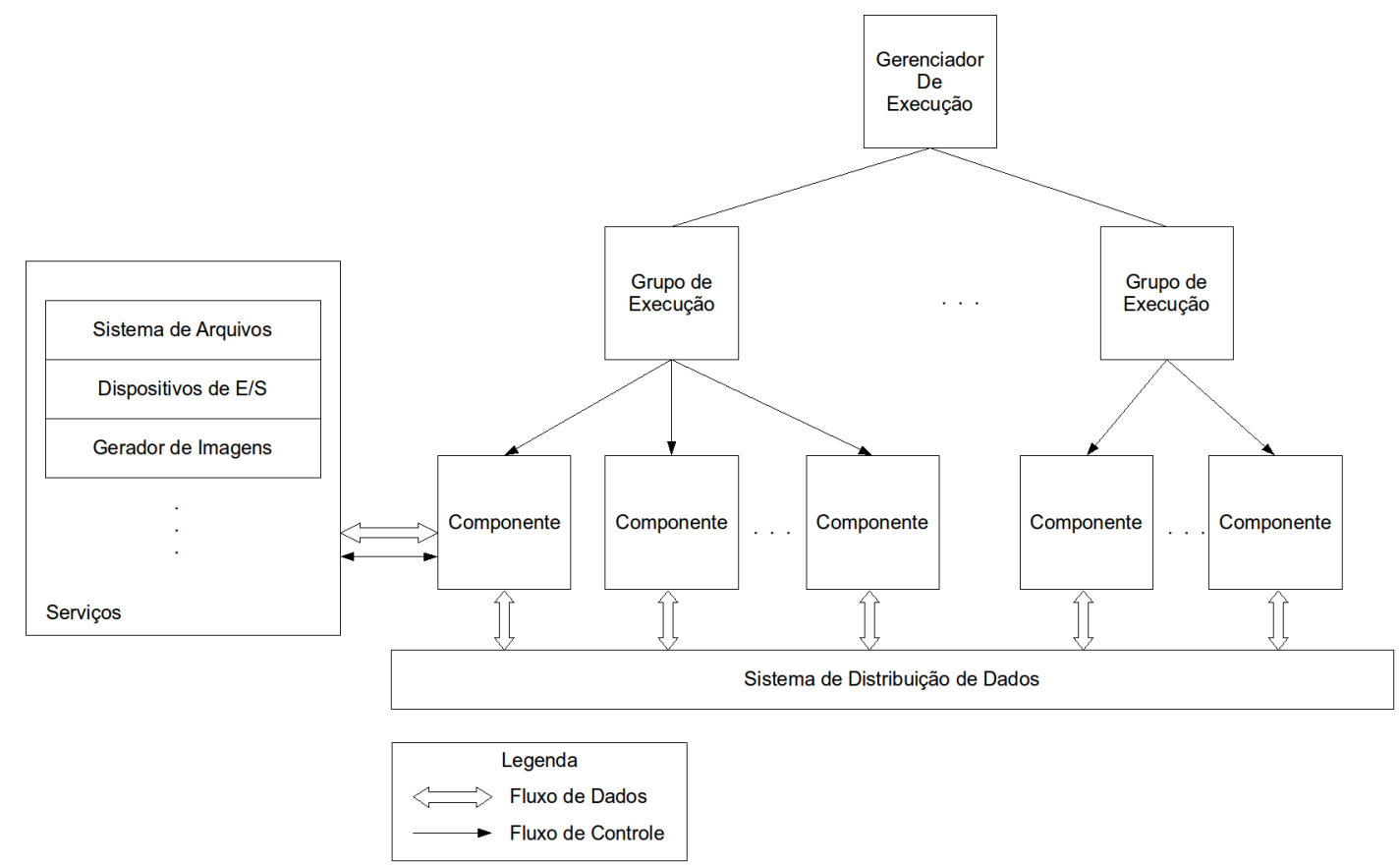

Figura 4.4: Perspectiva da execução.

através de conexões entre estas portas.

As portas podem ser conectadas de duas formas:

- saída-entrada: para as conexões entre elementos.

- entrada-entrada/saída-saída (ou de interface): para conexões entre a interface de uma composição com os elementos internos.

Nas conexões entrada-saída, uma saída pode ser conectada às diversas entradas, porém uma entrada pode estar conectada à apenas uma saída. Já nas conexões de interface, a entrada da interface pode estar conectada às diversas entradas internas, porem a saída de interface é conectada à apenas uma saída interna.

Nas arquiteturas apresentadas no capítulo 3, cada elemento estrutural é responsável pelo roteamento dos dados entre as entidades no nível abaixo. No DARTS, por exemplo, o Subsistema passa as entradas para cada Componente através de parâmetros de função, e obtém as saídas através dos retornos. A troca de dados entre Subsistemas ocorre através de memória compartilhada, gerenciada pelo Segmento. Finalmente, a comunicação entre Segmentos acontece através da VNET.

$\mathrm{Na}$ abordagem de portas e conexões, o fluxo de dados ocorre de forma transparente e uniforme, independente do nível na hierarquia. Durante a execução, o 
SDD é responsável por rotear e garantir a consistência dos dados nas portas dos Componentes.

Apesar das Composições também possuírem portas, durante a inicialização todas as conexões são convertidas em roteamentos no nível de Componentes.

\subsection{Síntese}

Este capítulo propôs uma arquitetura de software alternativa para superar alguma destas limitações e uniformizar os mecanismos de execução e fluxo de dados.

Na arquitetura proposta, a simulação é organizada estruturalmente em uma hierarquia de elementos, na qual os componentes são agrupados sucessivamente de acordo com suas características e funcionalidades. Esta abordagem facilita a reutilização de elementos e a paralelização no desenvolvimento.

A troca de dados entre estes elementos é realizada através das interfaces de entradas e saídas (Portas) dos elementos de simulação de forma transparente quanto à detalhes de implementação e de localidade (local ou remoto) dos elementos.

A tabela 4.2 compara a arquitetura proposta com as apresentadas no capítulo 3. 
Tabela 4.2: Comparação das arquiteturas

\begin{tabular}{|c|c|c|c|c|}
\hline & AVSM & ModSim & DARTS & Proposta \\
\hline $\begin{array}{l}\text { Hierarquia } \\
\text { do Modelo }\end{array}$ & 2 níveis & 1 nível & 3 níveis & Ilimitado \\
\hline Execução & Hierárquico & $\begin{array}{c}\text { Execução dos } \\
\text { Segmentos } \\
\text { depende da } \\
\text { imple- } \\
\text { mentação }\end{array}$ & Hierárquico & Componente \\
\hline $\begin{array}{c}\text { Fluxo de } \\
\text { Dados }\end{array}$ & $\begin{array}{l}\text { Parâmetros } \\
\text { de funções e } \\
\text { memória } \\
\text { compartil- } \\
\text { hada }\end{array}$ & VNET & $\begin{array}{l}\text { Parâmetros } \\
\text { de funções, } \\
\text { memória } \\
\text { compartil- } \\
\text { hada e } \\
\text { VNET }\end{array}$ & $\begin{array}{l}\text { Portas de } \\
\text { Entrada e } \\
\text { Saída }\end{array}$ \\
\hline $\begin{array}{c}\text { Par- } \\
\text { alelismo }\end{array}$ & $\begin{array}{c}\text { Todos os } \\
\text { elementos } \\
\text { devem estar } \\
\text { em cada linha } \\
\text { de execução }\end{array}$ & $\begin{array}{l}\text { Nível de } \\
\text { Segmento }\end{array}$ & $\begin{array}{l}\text { Nível de } \\
\text { Segmento }\end{array}$ & $\begin{array}{l}\text { Nível de } \\
\text { Grupo de } \\
\text { Execução }\end{array}$ \\
\hline $\begin{array}{l}\text { Dis- } \\
\text { tribuição }\end{array}$ & $\begin{array}{c}\text { idem ao } \\
\text { Paralelismo }\end{array}$ & $\begin{array}{c}\text { Nível de } \\
\text { módulos com- } \\
\text { putacionais }\end{array}$ & $\begin{array}{c}\text { Nível de } \\
\text { Executor de } \\
\text { Módulo }\end{array}$ & $\begin{array}{c}\text { Nível de } \\
\text { Gerenciador } \\
\text { de Execução }\end{array}$ \\
\hline
\end{tabular}




\section{Implementação de Referência SimFlow}

Baseado na arquitetura proposta no capítulo 4, o presente capítulo apresenta de forma detalhada a implementação de um protótipo de ferramenta para auxiliar o desenvolvimento de simuladores para treinamento, denominada SimFlow. Apesar da arquitetura proposta no capítulo anterior ser possibilitar a execução paralela e distribuída da simulação, o protótipo apresentada neste trabalho suporta somente execução paralela (multi-thread).

\subsection{Visão Geral da Ferramenta}

O SimFlow é constituído por uma biblioteca de software contendo todo o sistema executor, desenvolvido em linguagem $\mathrm{C}++$. Esta biblioteca foi projetada para ser flexível, permitindo, futuramente, a adição de novas funcionalidades e o desenvolvimento de ferramentas gráficas para construção de simuladores.

O Simflow é composto pelos componentes Núcleo, Aplicação, Serviços e Utilitários relacionados conforme a figura 5.1.

\subsection{Núcleo}

Este componente implementa as funcionalidades básicas do sistema, sendo responsável pelo gerenciamento de memória e execução da aplicação. O núcleo é composto por quatro subcomponentes, a saber:

- Gerenciador de Objetos em Tempo de Execução (RTOM),

- Executor,

- Sistema de Distribuição de Dados,

- Sistema de Propriedades. 


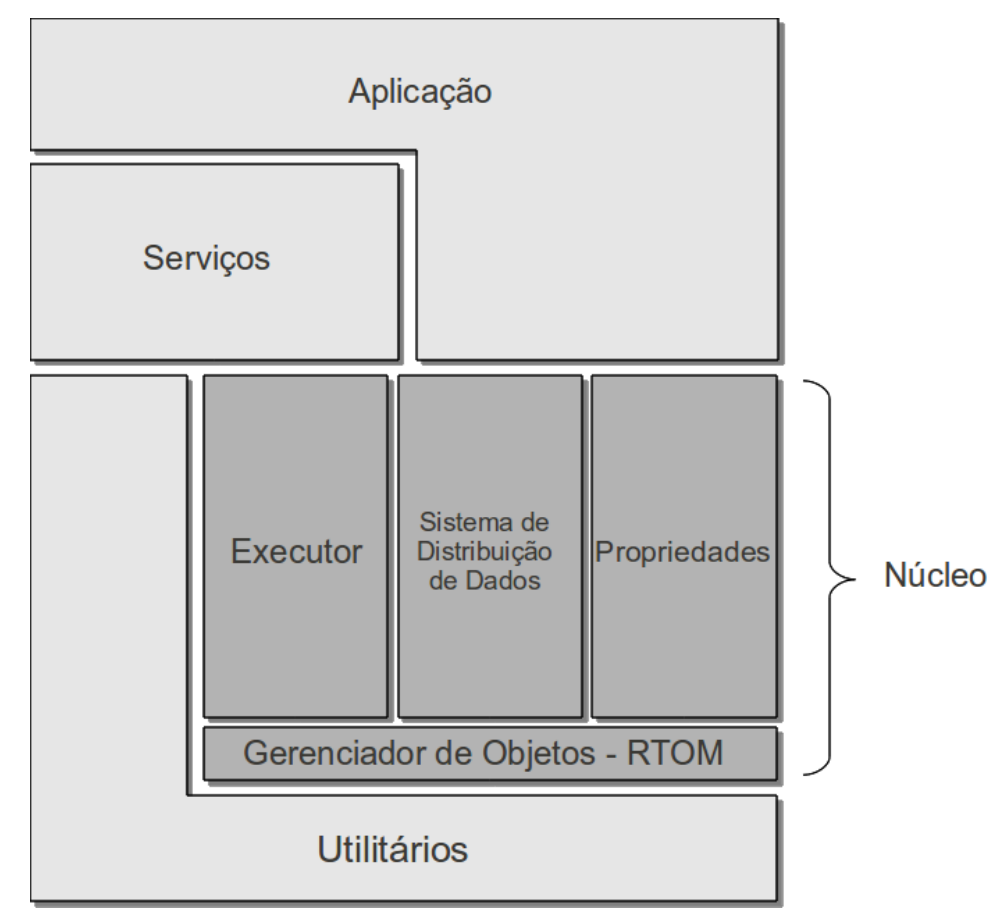

Figura 5.1: Visão geral da implementação do protótipo.

\subsubsection{Gerenciador de Objetos em Tempo de Execução}

O Gerenciador de Objetos em Tempo de Execução (Run-Time Object Manager (RTOM)) é responsável pelo gerenciamento de memória, organização de objetos e fornecimento de informações sobre hierarquia de classes em tempo de execução. Internamente é utilizada a técnica de ponteiros inteligentes (smart pointers) combinada com o padrão de projeto factory method ${ }^{1}$. O diagrama de classes deste componente é apresentado na figura 5.2.

O ponteiros inteligentes são objetos em $\mathrm{C}++$ que se comportam como ponteiros nativos [9]. A classe de ponteiro inteligente sobrecarrega os operadores de acesso $(*$ e $->$ ) permitindo a utilização conforme a sintaxe nativa para operação de ponteiros do $\mathrm{C}++[10]$. Esta técnica é utilizada principalmente para evitar vazamento de memória, desalocando objetos automaticamente quando não estiverem mais em uso. O método utilizado no SimFlow consiste em manter um contador de referências para cada objeto que se deseja gerenciar. Este contador tem seu valor incrementado para cada nova referência ao objeto, e decrementado para as de-referencias. Quando o valor chega a zero, então o objeto é desalocado da memória.

Na biblioteca, a classe base Referenced mantém o contador de referências

\footnotetext{
${ }^{1} \mathrm{O}$ padrão de projeto Factory Method define uma interface única para instanciar um objeto, passando a responsabilidade da criação para outras classes [8]
} 


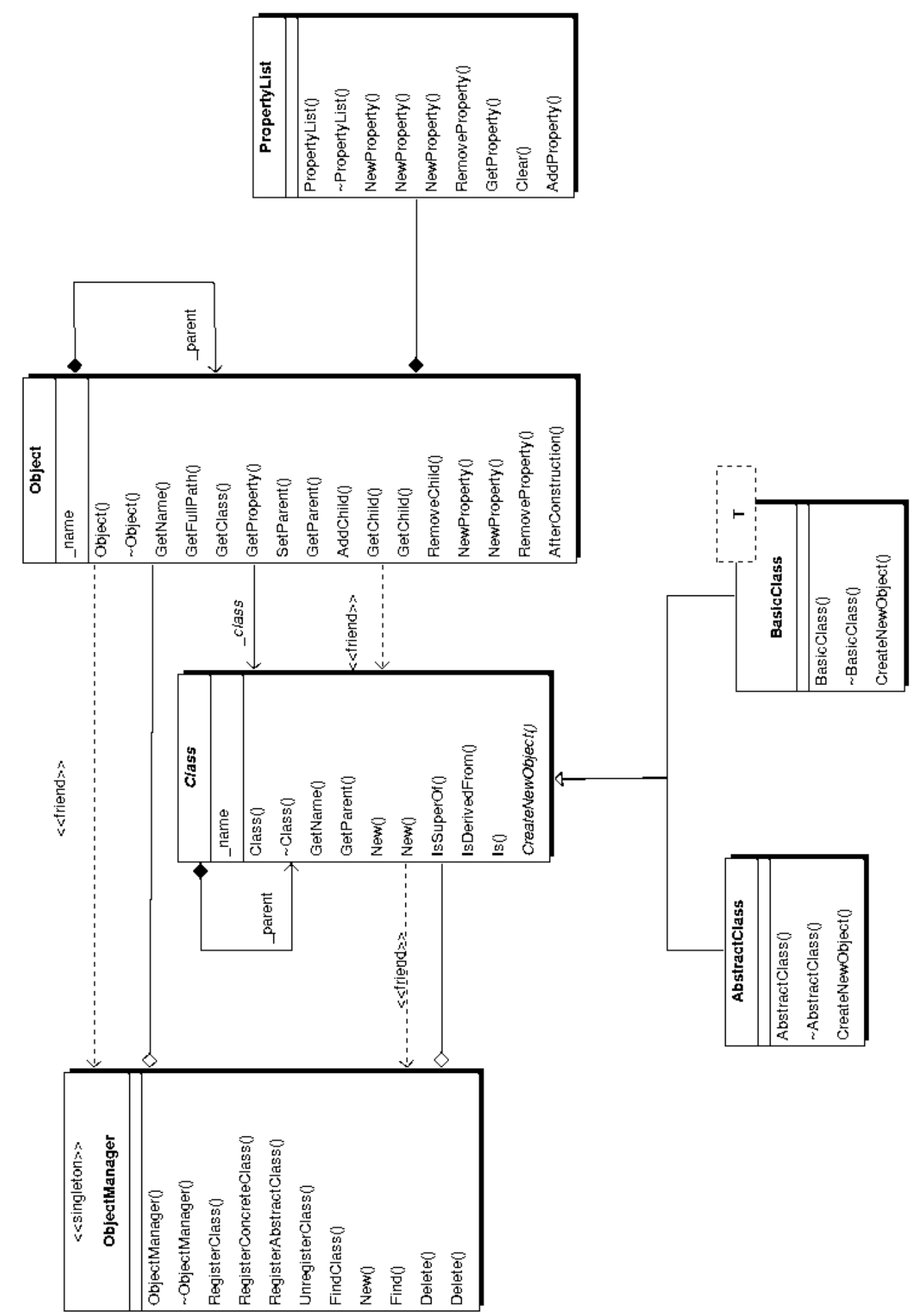

Figura 5.2: Diagrama de classes do gerenciador de objetos. 
para os objetos que as herdam. Para tornar a utilização transparente para o desenvolvedor, a classe genérica (template) Ptr faz a sobrecarga dos principais operadores $\left(=,->\mathrm{e}^{*}\right)$, de forma a incrementar e decrementar o contador da instância automaticamente.

O RTOM organiza os objetos em uma estrutura de árvore. Cada instância possuí um objeto pai, e vários objetos filhos. Este modelo de organização foi adotado, pois representa de forma explícita a composição dos objetos do Módulo Executor e do Módulo de Aplicação. Os objetos são nomeados e endereçados de forma semelhante aos sistemas de arquivos convencionais. Por exemplo, se um objeto tem o caminho /simulation/composition/component, então o nome dele é component, seu pai é composition, e o pai do pai é simulation.

Além de organizar os objetos, o RTOM implementa uma infra-estrutura simplificada para acessar informações de hierarquia de classes em tempo de execução. Objetos do tipo Class representam as principais classes do sistema, contendo o nome da classe (tipo) e informações sobre heranças. Esta classe também é responsável pela criação de objetos do tipo que representa, conforme o padrão de desenvolvimento factory.

A classe ObjectManager é um singleton ${ }^{2}$ de interface do RTOM. Esta classe armazena os tipos conhecidos (através de objetos do tipo Class) e os objetos instanciados, e contém métodos para criação e obtenção de objetos.

O RTOM permite registrar novos tipos de objetos e gerenciar os objetos instanciados em tempo de execução, fornecendo vantagens como:

- Facilidade na depuração da aplicação;

- permitir adição futura de novas funcionalidades no Módulo Executor;

- encapsulamento e distribuição de novos elementos de simulação através de plug-ins;

- base para implementação de interfaces de alto nível para desenvolvimento e controle da simulação (console de comandos, por exemplo);

- base para implementação de ferramentas gráficas para desenvolvimento de simuladores.

\footnotetext{
${ }^{2}$ Singleton é um padrão de projeto que garante que a classe tenha uma única instância, e provê um ponto de acesso global [8]
} 
A principal desvantagem é o tempo adicional overheadutilizado na criação de novos objetos. Desta forma, para garantir a otimização do simulador, os objetos deverão ser criados na inicialização e não durante a execução da simulação.

\subsubsection{Executor}

O Executor, cujo diagrama de classes é apresentado na figura 5.3, coordena a execução da simulação através do Gerenciador de Execução e do Grupo de Execução, já descritos no capítulo 4.

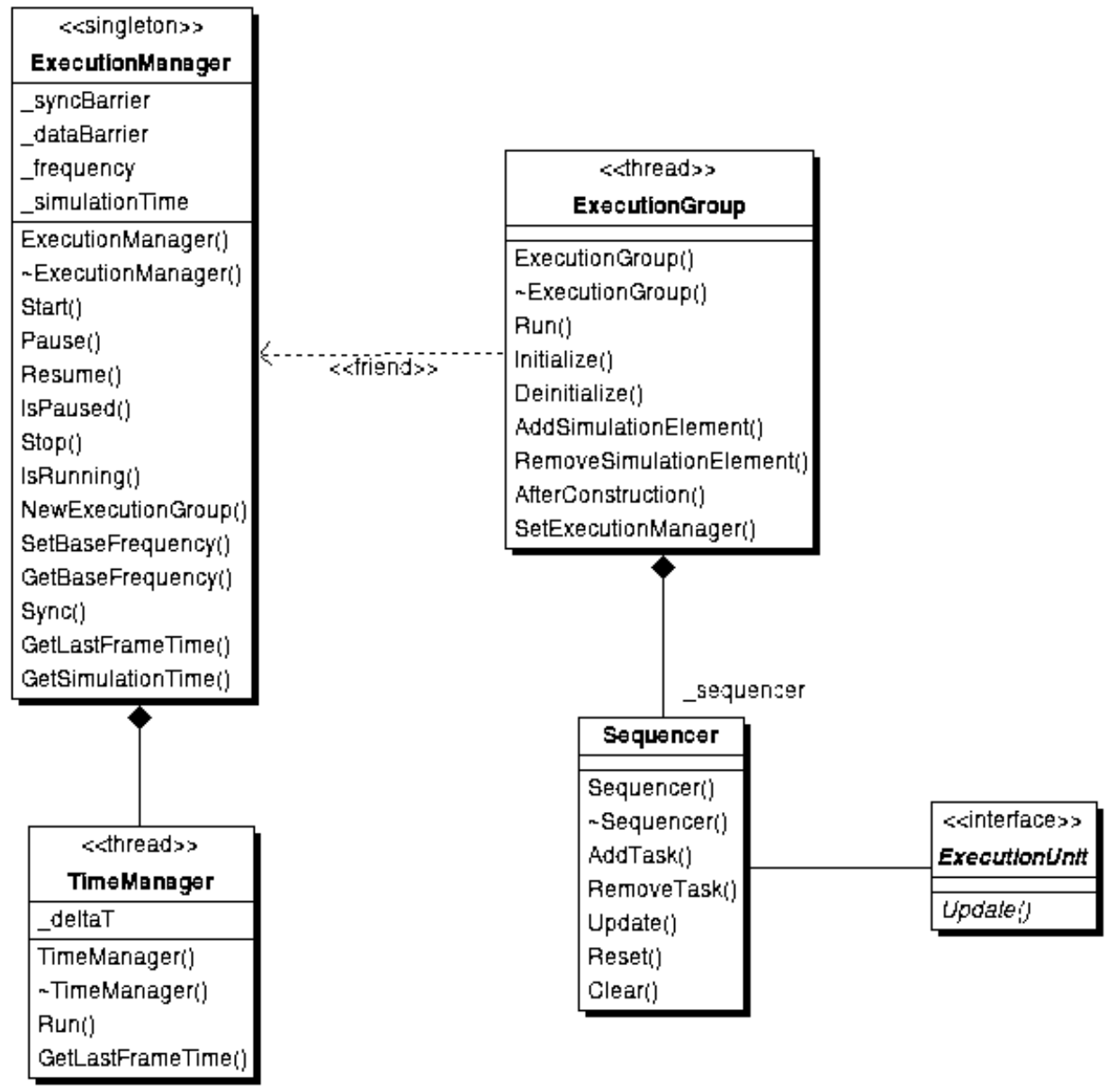

Figura 5.3: Diagrama de classes do executor.

Conforme a arquitetura proposta, o Grupo de Execução (classe ExecutionGroup) atualiza um conjunto de componentes de simulação na frequência e ordem correta. Os Grupos de Execução são executados independentemente e em paralelo. Nesta implementação, o modelo adotado de paralelismo foi o multi-thread (em oposição ao multi-process) através da biblioteca pthread, devido a facilidade de sincronismo e compartilhamento de dados. 
Para auxiliar a execução sequencial dos componentes de simulação o Grupo de Execução é composto por um objeto Sequenciador (classe Sequencer). Este objeto mantém uma tabela interna com os componentes de simulação, o período de repetição e defasagem. Como Sequenciador não coordena o ciclo e nem mantém a frequência base do simulador, as informações de período de repetição e defasagem são representadas por um número natural normalizados pela frequência base. Exemplificando, um componente que deve ser atualizado nos ciclos impares terá o período de repetição 2 (a cada dois ciclos), e defasagem 1.

Apesar do Grupo de Execução sequenciar apenas os componentes de simulação, é possível adicionar ou remover composições. Neste caso, a operação de adição ou remoção de um elemento percorre a árvore de objetos abaixo da composição até chegar ao nível dos componentes (folhas).

A classe ExecutionManager é um Singleton que representa o Gerenciador de Execução da arquitetura proposta. A principal função deste objeto é coordenar os ciclos de simulação, mantendo uma taxa de atualização constante (frequência base) e o sincronismo entre os Grupos de Execução. Como função secundária o Gerenciador de Execução inicia e finaliza os threads de execução.

O ciclo é composto pelas etapas Sincronização de Dados e Execução dos Componentes, conforme ilustrado na figura 5.4.

\begin{tabular}{|l|c|c|c|c|}
\hline Sinc. & $\begin{array}{c}\text { Sincronização } \\
\text { de Dados }\end{array}$ & Sinc. & $\begin{array}{c}\text { Execução dos } \\
\text { Componentes }\end{array}$ & Fim \\
\hline
\end{tabular}

Figura 5.4: Ciclo de execução do SimFlow.

Durante a Sincronização de Dados, cada Grupo de Execução disponibiliza para os demais os dados de saída atualizados de seus componentes. Mais detalhes sobre esta etapa são apresentados na seção 5.2.3. Na etapa de Execução dos Componentes, o Sequenciador de cada Grupo atualiza os componentes de simulação.

Estas etapas são sincronizadas através de duas barreiras: uma no início do ciclo, outra no início da Etapa de Processamento. Desta forma os Grupos de Execução executam cada uma das etapas na mesma ordem e no mesmo momento.

Para manter constante o período de cada ciclo, a classe TimerManager, interna à classe ExecutionManager, executa um thread que monitora o tempo do ciclo corrente, liberando a barreira de inicio de ciclo no momento adequado. Este 
modelo assume que o tempo de sincronismo de dados e processamento de cada Grupo de Execução seja inferior ao período base. Caso contrário, o ciclo da simulação terá um período maior que o especificado, exigindo a redistribuição dos componentes entre os grupos de execução.

\subsubsection{Sistema de Distribuição de Dados}

Este componente de software mantém a rede de fluxo de dados do simulador, sendo responsável pelo gerenciamento de memória para esta finalidade, e distribuição consistente dos dados entre os Grupos de Execução.

Conforme descrito no capítulo 4, a troca de dados entre os componentes de simulação ocorre através de conexões entre portas de entradas e saídas. No SimFlow, as portas de entrada e saída são representadas por classes genéricas em relação ao tipo de dado (através do recurso template da linguagem $\mathrm{C}++$ ). Estas classes sobrecarregam alguns operadores básicos, permitindo a manipulação dos dados de forma transparente (da mesma forma que uma variável nativa) e protegida (somente a porta de saída pode ter o valor alterado pelo componente).

Internamente, as portas mantêm um ponteiro para regiões de memória onde o dado será escrito ou lido. Ou seja, um conjunto de portas conectadas entre si operam na mesma região de memória, respeitando a semântica da conexão (apenas uma porta pode gerar dados). Desta forma, escritas e leituras nas portas são traduzidas para operações em memória, minimizando o overhead.

Para manter a consistência dos dados na execução paralela, regiões de memória só podem ser compartilhadas entre portas de componentes de um mesmo Grupo de Execução (mesmo thread). A ordem de execução dos componentes em um ciclo, mantida pelo Sequenciador, garante que os dados sejam propagados através das portas de forma correta (satisfazendo as dependências de cada dado). Porém, a ordem de execução entre componentes em Grupos de Execução distintos não é assegurada.

Para manter a consistência dos dados entre Grupos de Execução foi utilizada a técnica de Duplo Buffer (Double Buffering) . Esta abordagem consiste em utilizar duas regiões de memória para um mesmo dado; uma região de escrita e outra de leitura. O thread produtor escreve a informação na região de escrita, enquanto os threads consumidores acessam a região de leitura. No momento adequado, as regiões são trocadas ou a área de escrita é copiada para a outra.

No SimFlow, cada porta se saída que produz dados (portas de saída associadas 
à componentes de simulação) está relacionada com duas regiões de memória; interna e externa. As portas conectadas de componentes do mesmo Grupo de Execução compartilham o endereço de memória interna (pois a consistência é garantida pela sequencia de atualização). Já as portas de componentes de outros Grupos de Execução apontam para a região externa. Na etapa de Sincronização de Dados de um ciclo, os dados das regiões internas são copiados para as regiões externas.

A principal desvantagem desta abordagem é que alterações nos dados de saídas são disponibilizadas para outros Grupos de Execução com atraso de um ciclo. Desta forma, deve-se evitar, na fase de projeto de um simulador, caminhos de dados (data paths) longos entre componentes de diferentes Grupos de Execução, pois o tempo de atraso pode ser longo (devido ao atraso acumulativo de um ciclo), invalidando a simulação.

Com a finalidade de otimizar a Sincronização dos Dados, as regiões de memória das portas de um Grupo de Execução são alocados sequencialmente, formando um bloco único de memória. Como a cópia de uma região grande de memória através da chamada memcpy é significativamente mais rápido que copiar diversos pedaços de memória, para cada Grupo de Execução existe um par de blocos de memória, um interno e outro externo, conforme ilustrado na figura 5.5.

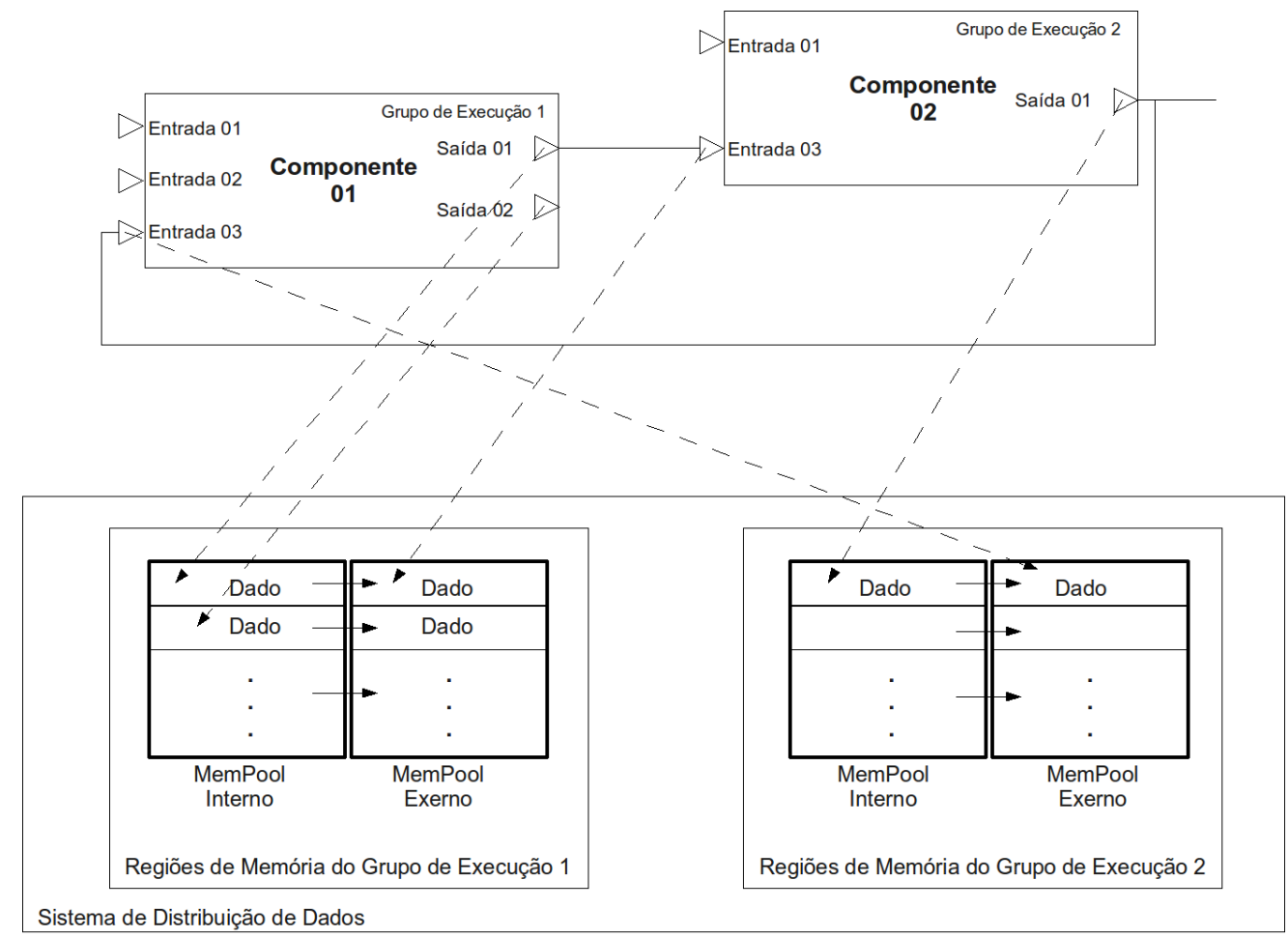

Figura 5.5: Implementação das conexões entre portas.

O diagrama de classes do Sistema de Distribuição de Dados é apresentado na 
figura 5.6.

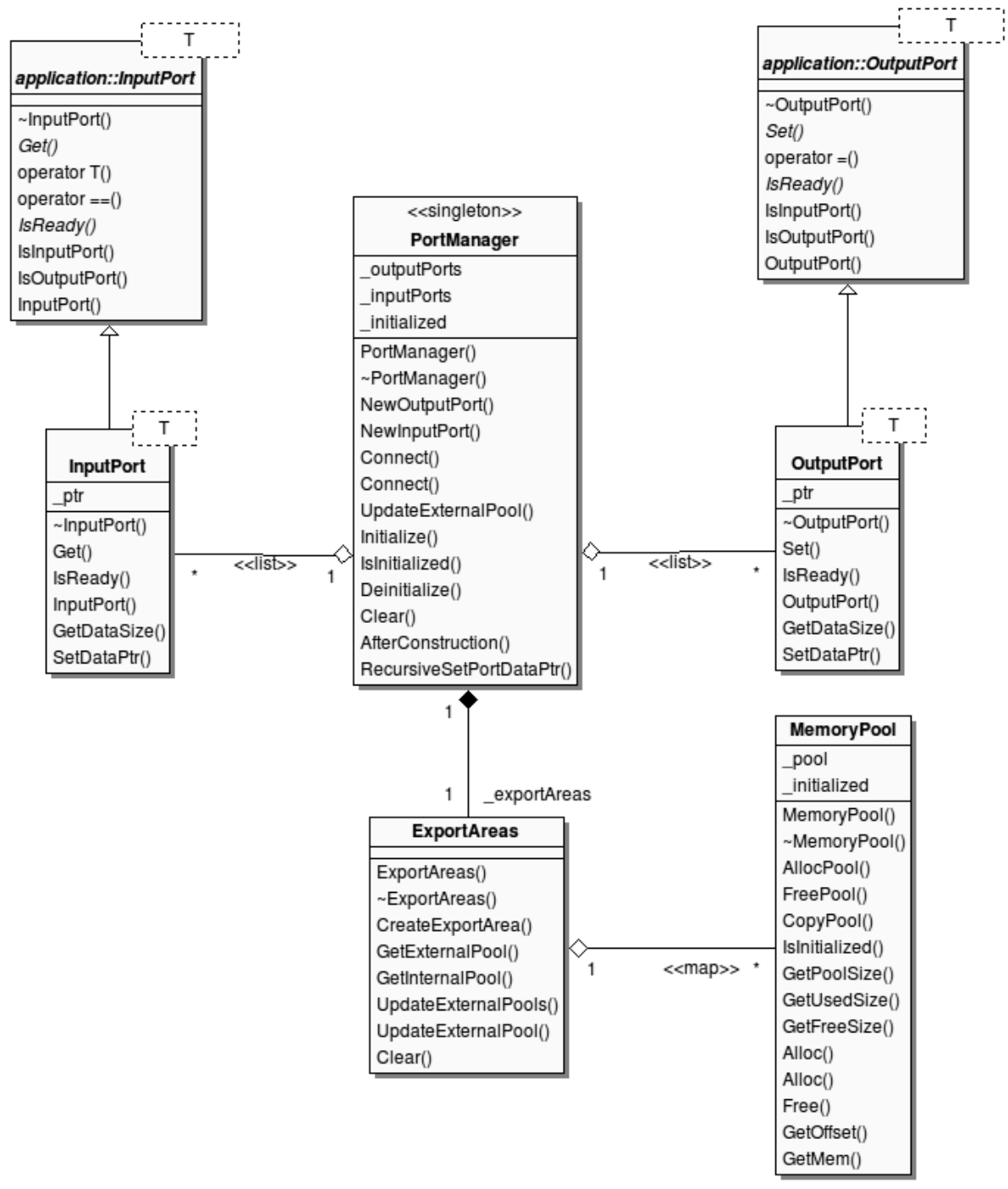

Figura 5.6: Diagrama de classes do sistema de distribuição de dados.

Objetos do tipo MemoryPool alocam um bloco único de memória e particionam em diversas regiões menores para as portas. Na etapa de Sincronização de Dados, estes blocos são copiados em uma única chamada. Para cada Grupo de Execução, são criados dois MemoryPools, interno e externo.

O gerenciamento de todos os blocos de memória (MemoryPool) de todos os Grupos de Execução é realizado pela classe ExportAreas. Esta classe cria um par de blocos de memória para cada Grupo de Execução, e faz a cópia entre eles durante o período de Sincronização de Dados.

As classes InputPort e OutputPort são implementações das portas de entrada e saída respectivamente. Elas herdam das classes abstratas InputPort e OutputPort do componente Aplicação da biblioteca. 
Todo este sistema é coordenado pelo singleton PortManager. Esta classe cria portas, estabelece conexões entre elas e gerencia os blocos de memória com o auxílio da classe ExportAreas.

O processo de conexão entre portas consiste em atribuir o endereço de memória compartilhado para o local onde o dado deverá ser escrito ou lido. Porém estes locais dependem do Grupo de Execução em que os componentes de origem e destino se encontram. Como, no momento da definição da rede de fluxo de dados os componentes podem não estar distribuído entre os Grupos de Execução, a solicitação de uma conexão entre portas de dois componentes consiste no registro nas estruturas internas das portas, deixando pendente a alocação de memória para elas. Quando a simulação inicia, os blocos de memória de cada Grupo de Execução são alocados e particionados, e o endereço de cada região é atribuído para as portas corretas de acordo com as conexões.

\subsubsection{Propriedades}

Propriedades, cujo diagrama de classes é apresentado na figura 5.7 representam atributos de um objeto que podem ser acessados e alterados em tempo de execução. Internamente a propriedade associa uma identificação (nome) a uma região de memória nativa, a um par de métodos de atribuição e recuperação de valores, ou uma outra propriedade.

Conforme descrito no capítulo 4, as propriedades serão utilizadas para parametrização dos componentes, possibilitando a reutilização em diversas aplicações. Este mecanismo, assim como o RTOM, fornece também uma base para futuro desenvolvimento de ferramentas para controle, monitoramento e desenvolvimento de simuladores (consoles de comando, ferramentas gráficas, entre outros).

A classe abstrata Property é genérica ao tipo de dado (template) e representa uma propriedade. As classes PointerProperty, ClassMethodProperty e LinkProperty implementam propriedades associadas à um ponteiro, à métodos de atribuição e recuperação, e à outra propriedade, respectivamente.

As propriedades são agrupadas em listas (PropertyList). Como em tempo de compilação as classes genéricas são especializadas, assumindo assinaturas diferentes, foi adicionado a classe não genérica BaseProperty para possibilitar o agrupamento das propriedades.

Todos os objetos da aplicação (herdeiros da classe Object) podem possuir uma lista de propriedades. 


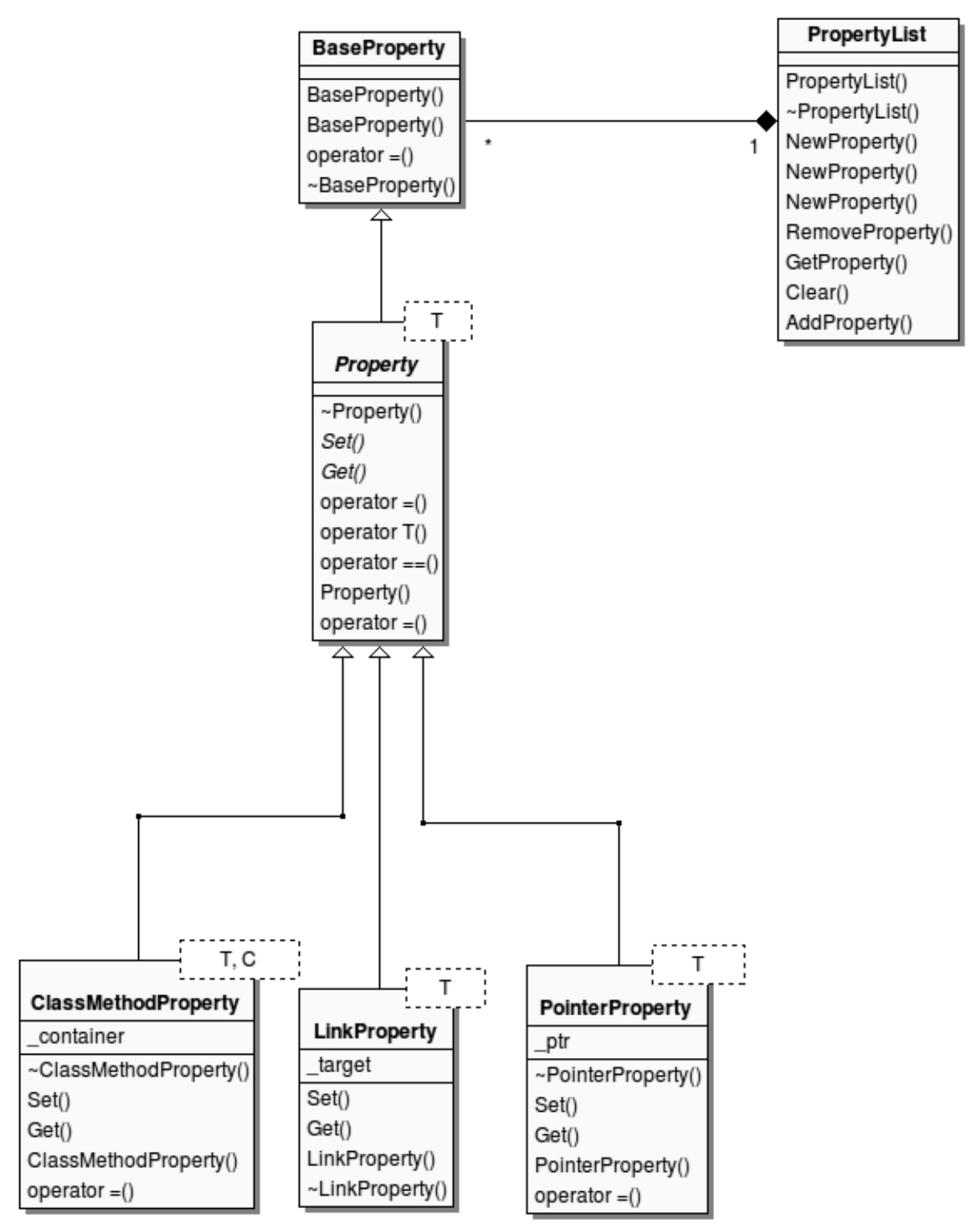

Figura 5.7: Diagrama de classes do sistema de propriedades.

\subsubsection{Motor de Simulação}

A classe SimulationEngine é um Singleton de interface para o sistema de execução e de distribuição de dados. O propósito desta classe é fornecer uma interface única para efetuar as conexões entre elementos de simulação, criação de Grupos de Execução e controle da simulação (inicio, término, pausa entre outros).

\subsection{Aplicação}

Este componente da biblioteca fornece o conjunto de classes abstratas e de interface para a implementação da aplicação (simulador). A figura 5.8 contém o 
diagrama de classes deste componente.

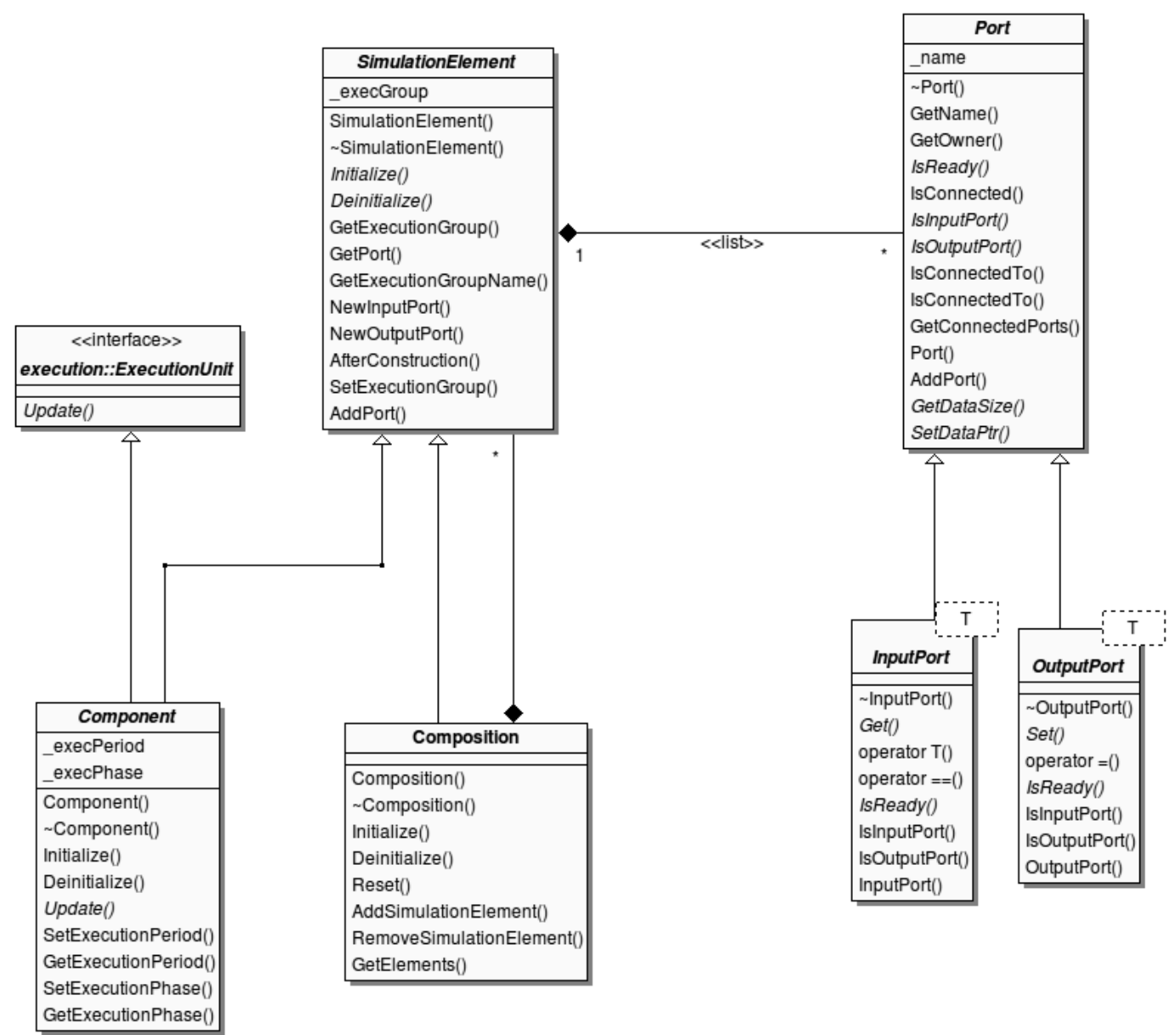

Figura 5.8: Diagrama de classes do componente aplicação.

A classe SimulationElement representa um elemento no simulador. As classes derivadas Component e Composition representam os Componentes e Composições respectivamente, conforme descrito no capítulo 4. Para pode ser atualizado pelo Sequenciador (classe Sequencer do componente Executor), a classe Component implementa a interface ExecutionUnit.

Os métodos virtuais Initialize e Deinitialize poderão ser sobrecarregados para implementar rotinas para alocar e desalocar os recursos necessários à execução de um Componente.

As portas de entrada e saída são representadas pelas interfaces (classes abstratas) genéricas InputPort e OutputPort respectivamente. O conjunto destas portas são agregadas aos Elementos de Simulação. 


\subsection{Serviços}

Como descrito no capítulo 4, serviços são módulos que auxiliam a simulação mas que não fazem parte do modelo. Nesta implementação referência foi implementado o serviço de registro de eventos $(\log )$ com o objetivo de facilitar a depuração e o monitoramento de simuladores e do SimFlow.

Este serviço classifica os eventos nas seguintes categorias:

- Depuração - Utilizado na etapa de desenvolvimento;

- Informação - Eventos informativos, em condições normais de execução;

- Aviso - Eventos que afetam a execução, mas não tem gravidade suficiente para finalizar a aplicação;

- Erro - Eventos que interrompem a simulação;

- Pânico - Erros graves internos do sistema SimFlow.

\subsection{Utilitários}

Utilitários é um conjunto de funções e classes que auxiliam internamente o desenvolvimento dos componentes e da própria biblioteca. Esta implementação contém os seguintes utilitários:

- manipulador de arquivos (classes para acesso e operações em arquivos em diferentes formatos);

- operação na entrada e saída padrão;

- programação multi-thread (barreira, mutex, eventos, condições entre outros);

- cronômetro (para medição de performance);

- comunicação por rede TCP/IP.

Estes utilitários foram implementados para auxiliar o desenvolvimento do SimFlow e podem também ser utilizados no desenvolvimento de Componentes de Simulação. 


\subsection{Utilização}

O desenvolvimento de uma aplicação utilizando o SimFlow consiste nas etapas de implementação dos Componentes de simulação e implementação da rede de fluxo de dados (instanciação e conexão entre os componentes). Estas etapas são descritas nas seções seguintes.

\subsubsection{Implementação de Componentes de Simulação}

Nesta etapa os Componentes de Simulação são desenvolvidos individualmente. Cada componente deve ser implementado em uma classe herdeira (diretamente ou indiretamente) da classe Componet. A listagem 5.1 contém um exemplo de um Componente soma com duas entradas do tipo inteiro (inputA e inputB) e uma saída (output). 
Listagem 5.1: Exemplo de componente (Soma).

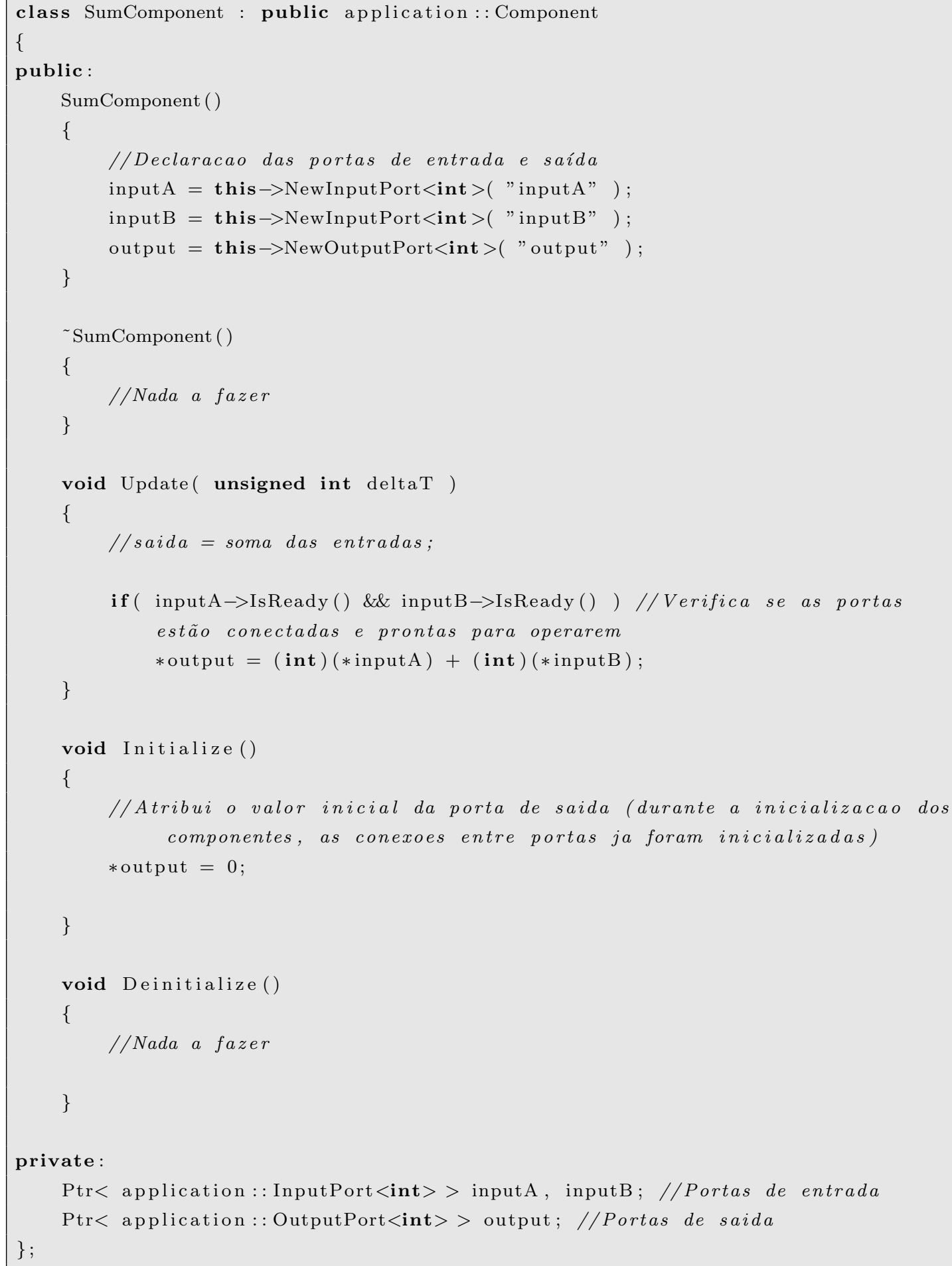

O construtor desta classe instancia as portas deste componente através dos métodos NewInputPort() e NewOutputPort(). O retorno destes métodos é o ponteiro inteligente ${ }^{3}$ para a nova porta.

O método virtual Update( unsigned int deltaT ) deve implementar o algoritmo de atualização do Componente. Neste exemplo, somar os valores das entradas e atribuir à porta de saída. Este método é chamado pelo SimFlow durante a

\footnotetext{
${ }^{3}$ A classe genérica Ptr implementa o ponteiro inteligente.
} 
atualização do componente, passando como parâmetro (deltaT) o tempo, em microsegundos, entre o ciclo anterior e atual.

Os métodos virtuais Initialize () e Deinitialize () são chamados durante a inicialização e a finalização da simulação. Os Componentes devem utilizar estes métodos para alocar e desalocar os recursos necessários para a execução, e atribuir os valores iniciais nas portas de saída.

\subsubsection{Implementação da Rede de Fluxo de Dados}

A implementação da rede de fluxo de dados é a etapa na qual os Componentes ou Composições já implementados são utilizados para compor a aplicação final, estabelecendo as conexões entre as portas. As seguintes atividades podem ser realizadas nesta etapa:

- Instanciação dos Componentes e Composições pré-definidas;

- Criação de novas composições;

- Agrupamento dos elementos de simulação (Componentes e Composições) em Grupos de Execução;

- Estabelecimento das conexões entre os elementos de simulação.

A listagem 5.2 implementa a rede de fluxo de dados do exemplo ilustrado na figura 5.9.

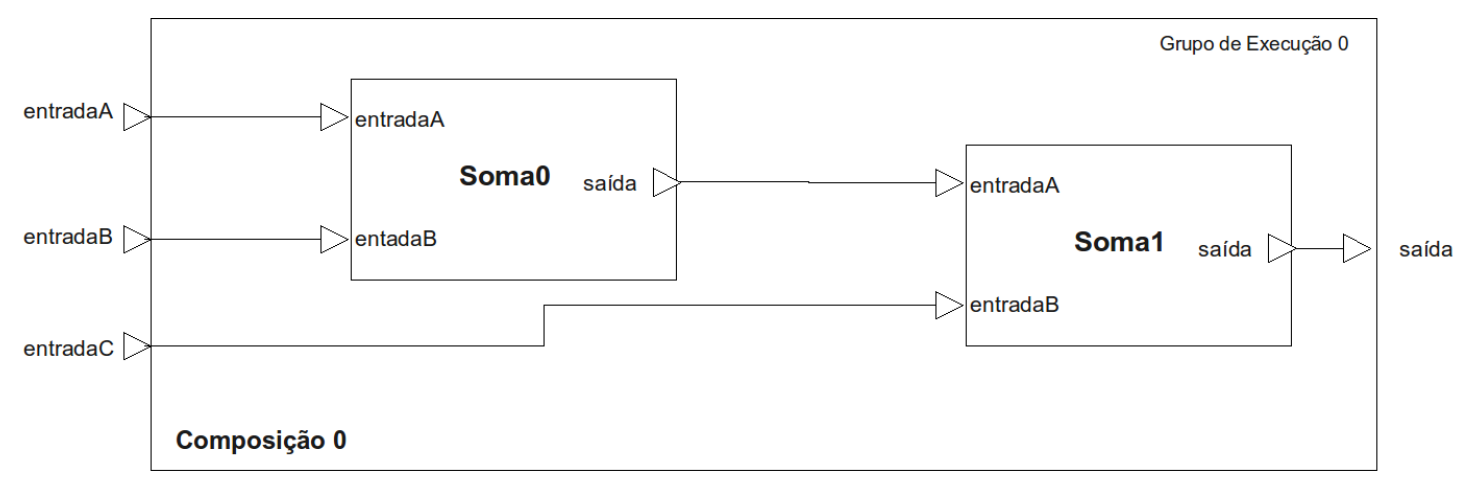

Figura 5.9: Exemplo de fluxo de dados. 
Listagem 5.2: Exemplo de implementação de rede de fluxo de dados.

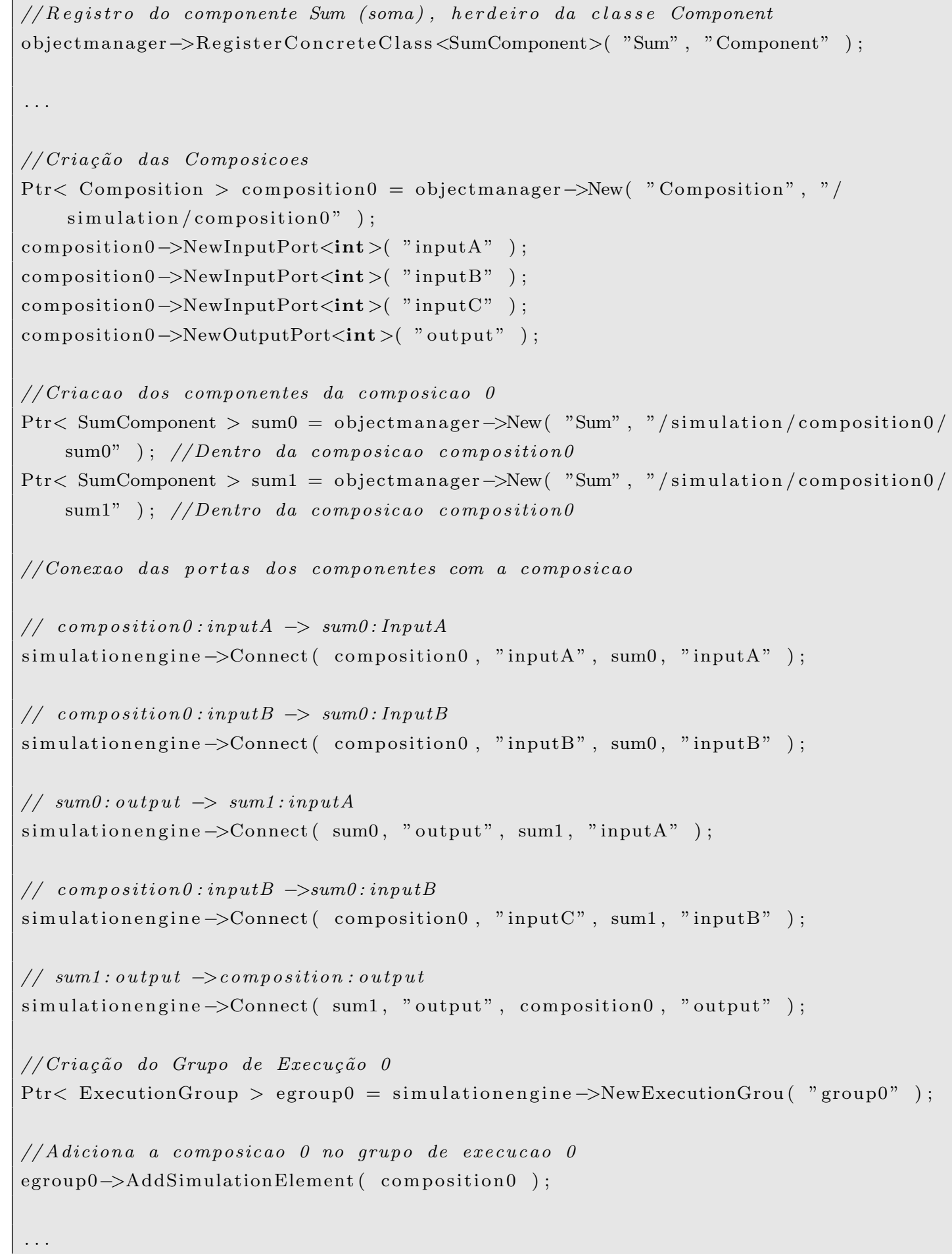

Os objetos objectmanger e simulationengine são instâncias das classes ObjectManager (seção 5.2.1) e SimulationEngine (seção 5.2.5) respectivamente, e já estão construídos neste exemplo.

Inicialmente é registrado no RTOM a classe do componente soma (linha 5) com o nome Sum, herdeira da classe Component. 
Em um momento posterior, é criada a composição, especificando as suas portas de entrada e saída (linhas 11 à 15). Em seguida são instanciados os componentes soma (linhas 17 e 18), abaixo da composição na hierarquia de objetos (ou seja, o objeto composition0 é pai dos objetos sum0 e sum1).

As linhas 21 à 36 estabelecem as conexões entre as portas dos componentes e composições.

Finalmente, é criado um grupo de execução para a composição.

\subsection{Controle da Simulação}

Através da classe SimulationEngine é possível iniciar, finalizar, pausar e retomar a simulação.

Durante a operação de inicio da simulação, o SimulationEngine executa os seguintes passos:

- Inicialização das conexões (inicialização do PortManager);

- Inicialização dos elementos de simulação (método virtual Initialize () dos componentes);

- Operação de início da simulação no Gerenciador de Execução ${ }^{4}$ (método Start() da classe ExecutionManager).

\subsection{Síntese}

Este capítulo apresentou a ferramenta SimFlow, uma implementação referência da arquitetura proposta no capítulo 4. Nesta implementação a aplicação final (simulação) é organizada em uma hierarquia de elementos de simulação, onde os componentes básicos são agrupados sucessivamente em composições. Estes elementos são então interligados através de portas de entrada e saída, formando uma rede de fluxo de dados.

O sistema de Gerenciamento de Objetos em Tempo de Execução (RTOM) e o mecanismo de Propriedades permitem que novas funcionalidades sejam futuramente adicionadas à biblioteca, além de fornecer uma interface de alto nível para

\footnotetext{
${ }^{4} \mathrm{O}$ Gerenciador de Execução, por sua vez, dispara os threads dos Grupos de Execução e o gerenciador de tempo.
} 
implementações futuras de ferramentas gráficas (editores) para o desenvolvimento de simuladores.

O módulo de execução foi projetado de forma a explorar as atual tecnologia multi-core, fornecendo ao desenvolvedor mecanismos simples para paralelizar a execução da simulação. O paralelismo é alcançado através de técnicas de mutithreading.

O Sistema de Distribuição de Dados implementa a infra-estrutura de Portas de forma transparente e com baixo overhead. 


\section{Estudo de Caso}

A partir da implementação apresentada no capítulo 5 foi realizado um estudo de caso como prova de conceito da utilização da ferramenta proposta. O estudo consistiu na adaptação parcial do software de um simulador da aeronave de asas rotativas Bell Jet Ranger III para a arquitetura proposta.

Este simulador desenvolvido na década de 80 pela empresa inglesa Redffusioné propriedade do Centro de Instrução e Adestramento Aero-Naval (CIAAN) da Marinha do Brasil. Este equipamento consiste de uma réplica fiel do cockpit montada sobre uma plataforma hidráulica com quatro graus de liberdade, sendo três utilizados para rotação (pitch, roll, yaw) e um para a translação vertical. A simulação original é executada por um supercomputador Gould/SEL 32, com sistema operacional MPX-32, cujo software foi desenvolvido nas linguagens Fortran 77 (aplicação) e assembly (executivo).

Neste capítulo são apresentados a organização original do Software, o processo de adaptação e os resultados obtidos.

\subsection{Arquitetura de Software Original}

O software é dividido em aplicação e sistema executivo. A aplicação consiste em um conjunto de programas escritos em linguagem Fortran 77 que simulam todos os componentes da aeronave. Já o sistema executor tem a finalidade de carregar e coordenar a execução das rotinas do simulador.

\subsubsection{Aplicação}

A aplicação consiste em um conjunto de rotinas responsável pela simulação de aspectos específicos da aeronave. Estas rotinas são agrupadas em subsistemas, no nível de sistema de arquivos e binários.

Esta organização é semelhante ao AVSM, porém neste caso, o nível de sub- 
sistema não faz parte da arquitetura, sendo apenas um agrupamento durante a compilação. Os subsistemas deste simulador são descritos na tabela 6.1.

Com exceção do SOND, todos os subsistemas representam sistemas reais da aeronave.

Tabela 6.1: Subsistemas do simulador Bell Jet Ranger III.

FLYT Simulação da aerodinâmica da aeronave

RAID Sistemas de comunicação e radio navegação (ILS, VOR, NDB, etc)

ENGS Motor

FUEL Sistema de combustível

ELEC Sistema elétrico

HYDS Sistema hidráulico

AFCS Sistema de Controle de Voo Automático

SOND Síntese de sons da aeronave

A comunicação entre rotinas e com o hardware de Entrada e Saída é realizada através de um ambiente de variáveis compartilhadas gerenciadas pelo sistema operacional, denominada datapool. As variáveis registradas no datapool são automaticamente visíveis por qualquer programa em execução.

Através do datapool é estabelecido uma malha de fluxo de dados entre as entidades do software. Por convenção, somente uma rotina atua uma determinada variável, mas as demais podem acessá-la. Essa malha de fluxo de dados representa as conexões entre os diversos sistemas da aeronave real, conforme apresentado na figura 6.1.

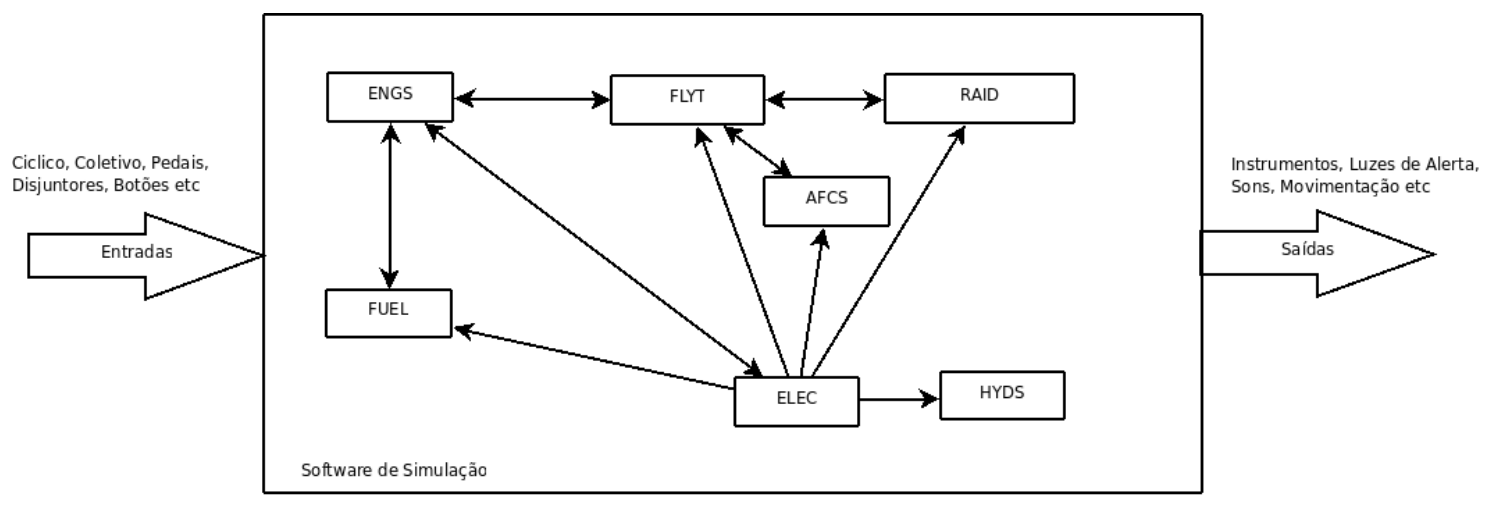

Figura 6.1: Fluxo de dados entre subsistemas do Bell Jet Ranger III.

Cada sistema é compilado separadamente formando um overlay independente. Overlay é um recurso comum nos sistemas operacionais antigos, que permite o programador criar vários grupos de objetos (rotina já compilada) em um mesmo programa. Estes grupos podem ser alocados ou desalocados da memória durante a execução do programa. Desta forma era possível desenvolver softwares 
maiores que a memória disponível. Atualmente as unidades de gerenciamento de memória (Memory Management Unit (MMU)) fornecem o recurso de paginação, tornando esta técnica desnecessária.

\subsubsection{Sistema Executivo}

O sistema executor é responsável por carregar o software e coordenar a execução das rotinas de simulação dentro de cada iteração. Durante a carga da simulação são inicializados o datapoole as tarefas vazias (uma para cada CPU) com prioridade de tempo real. Cada uma destas tarefas é preenchida com os overlays que irá executar.

Após a inicialização, o executor presente em cada uma das tarefas entra em um laço infinito (loop) de tempo fixo (33.3 ms ou $30 \mathrm{~Hz}$ entre cada iteração), controlado por uma interrupção proveniente do hardware de tempo real.

No inicio de cada iteração, a tarefa principal (mestre) entra no modo síncrono que. executa as rotinas de maior prioridade e aquelas que necessitam de um tempo preciso entre uma chamada e outra. Nesta etapa são iniciadas as transferências de dados entre o software de simulação e o hardware de entrada e saída.

Após a execução de todas as rotinas síncronas, o executor entra no modo assíncrono, sinalizando as demais tarefas que executam as rotinas assíncronas de acordo com uma tabela de escalonamento.

Caso ocorra uma nova interrupção, as tarefas são suspensas imediatamente, e a tarefa principal entra no modo síncrono novamente. Ao final da execução de todas as tarefas, o executor inicia uma nova iteração da simulação, repetindo o ciclo.

\subsection{Descrição dos Subsistemas Utilizados}

Como prova de conceito, somente alguns dos subsistemas do software do simulador foram adaptados para a ferramenta SimFlow. São eles:

- ELEC - Sistema Elétrico

- FUEL - Sistema de Combustível

- ENGS - Sistema de Motores

Os subsistemas em questão são apresentados na figura 6.2. 


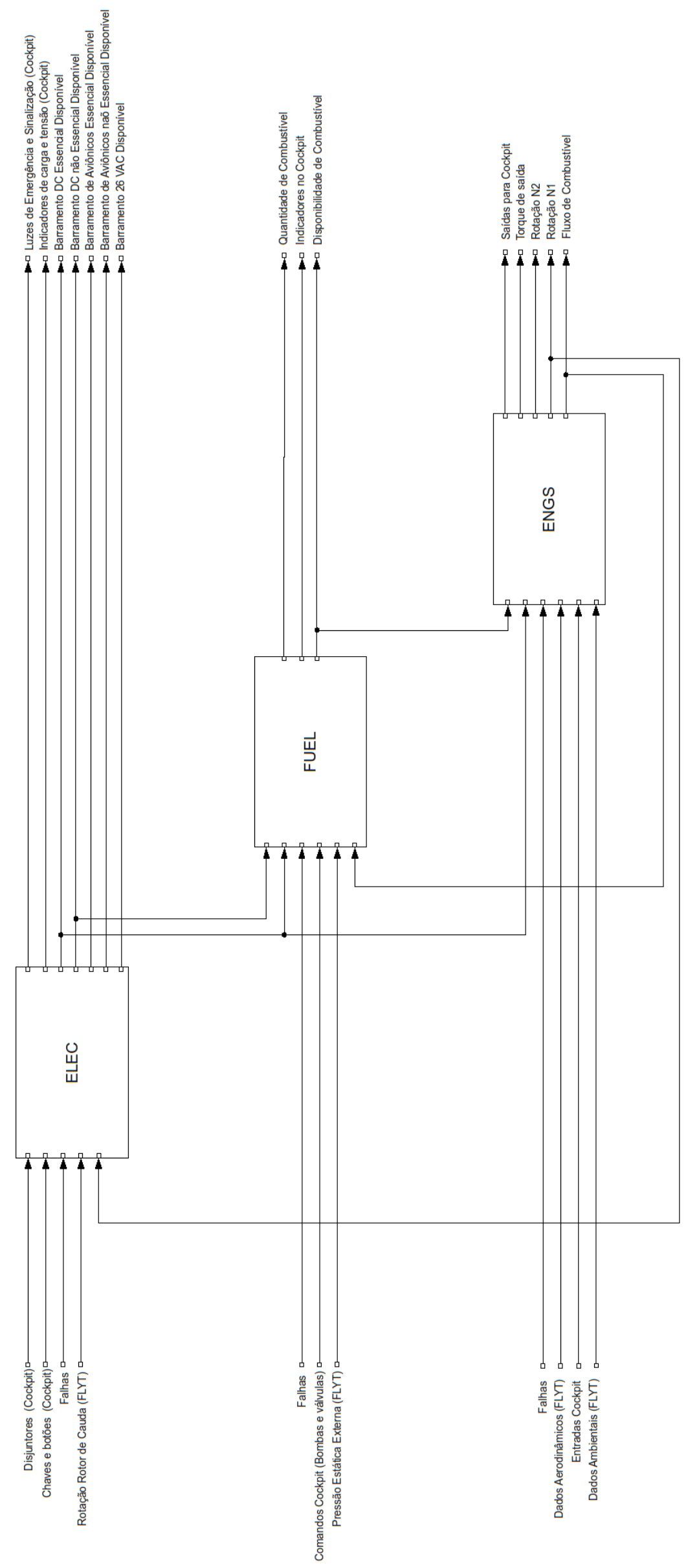

Figura 6.2: Fluxo de dados entre os subsistemas ELEC, FUEL e ENGS. 
Cada subsistema e suas rotinas são detalhados a seguir.

\section{Combustível (FUEL)}

Este subsistema é composto por uma única rotina que simula todo o sistema de combustível da aeronave. Os principais aspectos simulados são reabastecimento, pressão e a quantidade do combustível, disponibilidade para os motores, além de controlar os indicadores e alarmes associados. Utiliza entradas dos seguintes subsistemas:

- FLYT: informação de pressão estática;

- ENGS: fluxo de combustível devido à operação da turbina;

- ELEC: estado dos barramentos elétricos

- cockpit: Disjuntores e chaves das bombas e válvulas de combustível.

\section{Motores (ENGS)}

Este subsistema simula a operação das turbinas do Bell Jet Ranger III. Utilizando a posição do acelerador e os comandos de partida e associados, calcula as temperaturas, torques e rotações nos diferentes estágios da turbina, enviando os resultados para os indicadores no cockpit e para outros subsistemas. A maioria dos parâmetros é calculada através da interpolação de curvas de comportamento da turbina.

A simulação é dividida entre as seguintes rotinas:

EM04ENG1: Esta rotina implementa as funções matemáticas para os principais parâmetros da turbina. As principais entradas são a rotação do primeiro estágio (N1) normalizada (proveniente de EM04ENG2), fluxo de combustível (proveniente de EM04ENG3) e comandos de ignição (proveniente do cockpit). Os resultados são os valores normalizados de diversos parâmetros, como aceleração do fluxo de combustível, torque de saída, torque de resistência entre outros.

EM04ENG2: Calcula a velocidade de rotação da turbina, o torque de saída, integração com o segundo estágio (N2), efeitos do sistema de degelo (anti-ice), temperaturas dos gases expelidos, engate com o rotor e simulação da ignição. Recebe entradas do subsistema FLYT (pressão estática, temperatura e velocidade do rotor), do subsistema FUEL (disponibilidade de combustível), do cockpit (comandos de ignição e degelo). Também utiliza os valores normalizados calculados pelo módulo EM04ENG1, como o torque de ignição, fluxo de ar, fluxo de 
combustível entre outros. As saídas são enviadas para os mostradores no cockpit, para o subsistema FLYT (torque de saída) e para os outros módulos.

EM04ENG3: Simula o consumo de combustível e o sistema de governor (controle automático da velocidade de rotação da turbina). As entradas provenientes do cockpit são principalmente a posição do acelerador e os comandos do governor. Utiliza também a rotação N1 (proveniente de EM04ENG2) e os parâmetros calculados EM04ENG1. A principal saída desta rotina é o fluxo de combustível normalizado.

EM04OIL: Esta rotina simula o controle do sistema de lubrificação do motor e transmissão. Utiliza entradas do subsistema FLYT (Rotação do rotor principal e temperatura ambiente) e das rotinas EM04ENG1 e EM04ENG1 (torques, rotação N1 e N2). As pressões e temperaturas calculadas são enviadas aos indicadores no cockpit, e os sinalizadores de temperatura elevada e baixa pressão, para o subsistema ELEC (para acionamento dos alarmes).

A figura 6.3 apresenta de forma geral as principais conexões do subsistema de Motores.

\section{Elétrico (ELEC)}

Este subsistema simula o sistema elétrico da aeronave. Nesta simulação são computadas a carga consumida por outros sistemas da aeronave, a tensão de saída dos geradores e a carga da bateria (que pode descarregar ou recarregar).

As entradas provenientes do cockpit são os disjuntores e chaves relacionados ao sistema (bateria, gerador principal, gerador reserva, aviônicos entre outros). Através de equações booleanas, são estabelecidos os estados dos barramentos elétricos do helicóptero (barramento essencial, não essencial, aviônicos e 26VAC).

Utilizando as informações de rotação da turbina (subsistema ENGS) e rotor de cauda (subsistema FLYT), são calculadas as tensões fornecidas pelos geradores. É simulado também o processo de descarga ou recarga da bateria.

As saídas para cockpit são, principalmente as luzes de emergência e avisos, e indicadores de carga. Já as saídas para os demais subsistemas incluem sinalizadores que indicam se um determinado barramento está energizado ou não. 


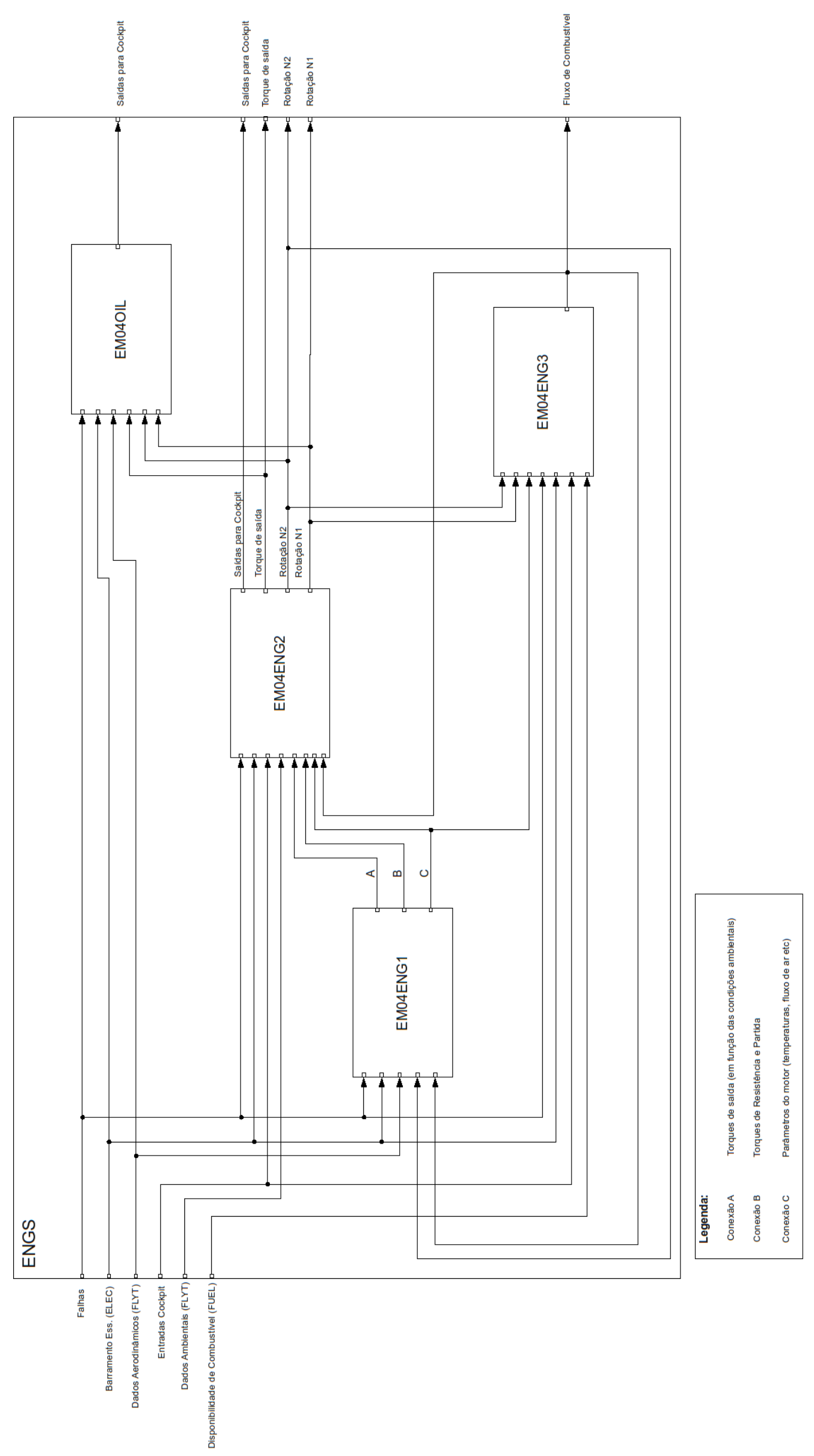

Figura 6.3: Fluxo de dados do subsistema de motores (ENGINES). 


\subsection{Adaptação do Simulador}

A adaptação parcial foi realizada utilizando o seguinte procedimento:

1. Tradução do código fonte da aplicação da linguagem Fortran 77 para linguagem $\mathrm{C}$.

2. Conversão das rotinas em Componentes.

3. Conversão das variáveis globais (datapool) em portas de entrada e saída.

4. Agrupamento dos Componentes em Subsistemas (Composições), e estabelecimento de conexões internas.

5. Conexões entre Subsistemas.

6. Separação dos Subsistemas em Grupos de Execução.

7. Testes e análises.

As rotinas do subsistema ENGS (EM04ENG1, EM04ENG2, EM04ENG3 e EM04OIL) foram convertidas em componentes e agrupadas em uma Composição que representa todo o subsistema (Composição Engines). Já os subsistemas ELEC e FUEL, por serem compostos por uma única rotina cada, foram convertidos diretamente nos Componentes Electrics e Fuel respectivamente. A árvore de objetos da aplicação adaptada é apresentada na figura 6.4.

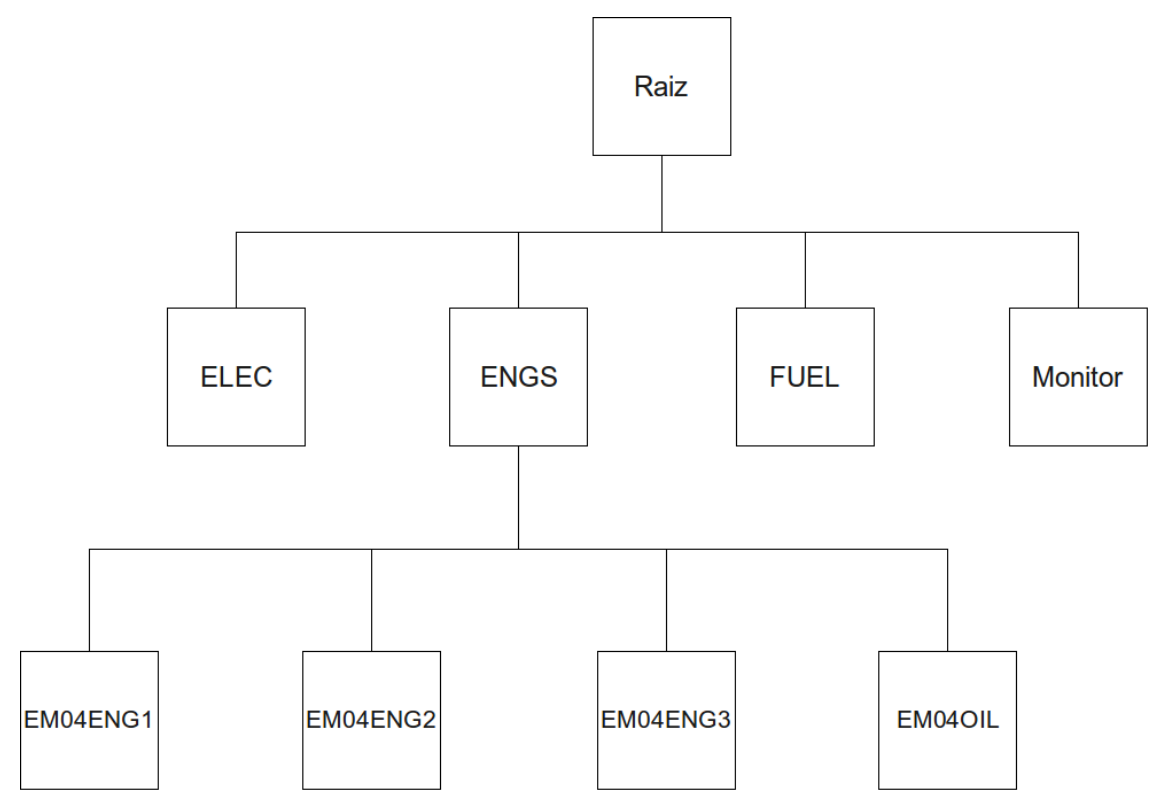

Figura 6.4: Árvore de objetos do estudo de caso. 
O componente Monitor fornece uma interface para monitoramento e a modificação de valores das portas externas de entrada e saída, em tempo de execução. Durante a execução deste estudo de caso é possível emular as entradas de outros subsistemas ou do cockpit através de comandos de console. A cada passo da simulação, este componente armazena em um arquivo os valores de todas as conexões relevantes para análise posterior.

Para explorar e avaliar as características de execução paralela da ferramenta SimFlow, os elementos deste estudo de caso foram divididos em cinco Grupos de Execução, conforme ilustrado na figura 6.5.

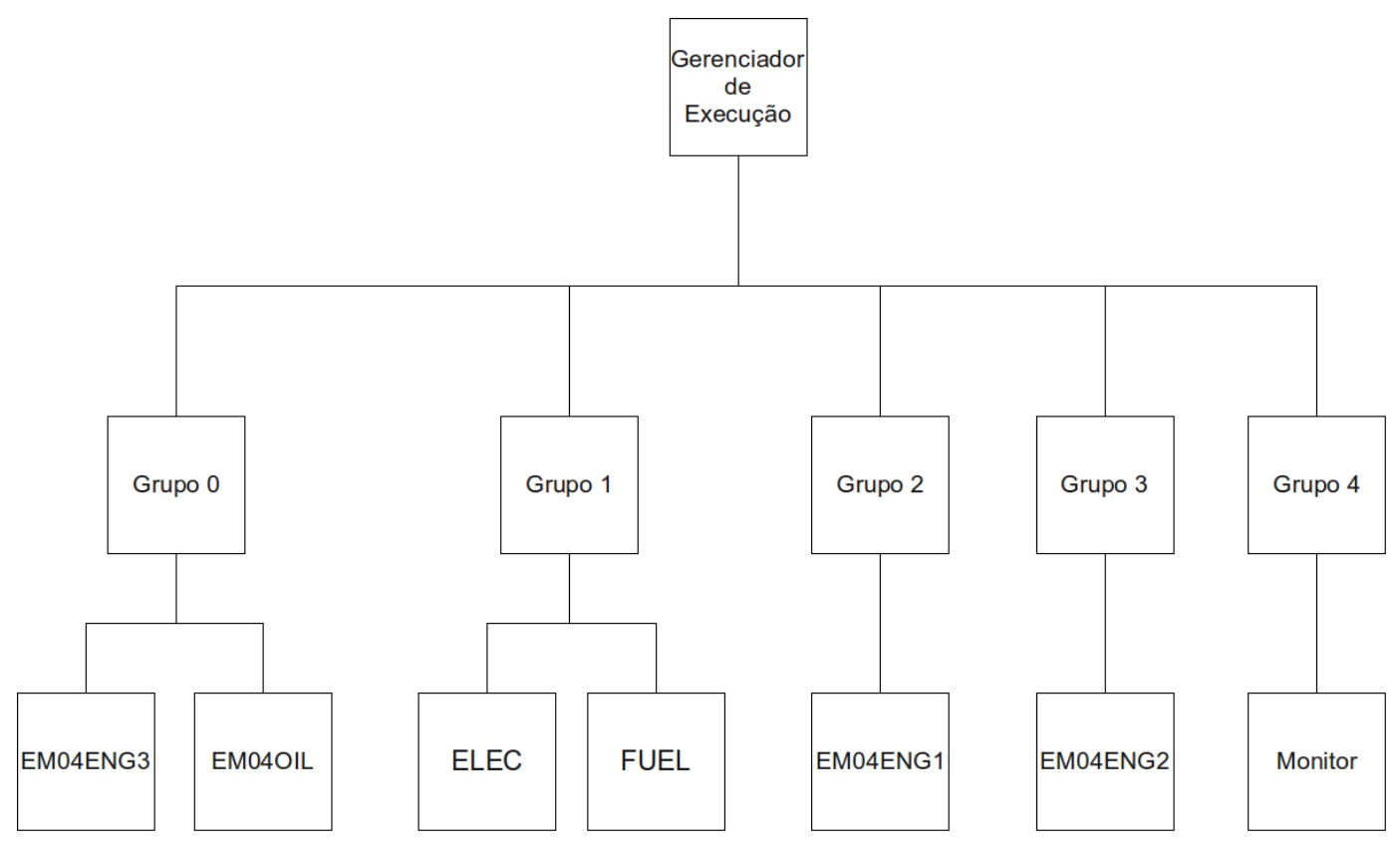

Figura 6.5: Divisão dos componentes em grupos de execução.

A implementação do fluxo de dados da Composição dos motores e a rede final deste estudo de caso é listada no apêndice B.

\subsection{Síntese}

Este capítulo descreveu a arquitetura e o funcionamento do simulador de aeronave de asa rotativa Bell Jet Ranger III, desenvolvido pela empresa Redffusion na década de 80. Este estudo de caso tem como objetivo final testar o protótipo implementado no capítulo 5. 


\section{$7 \quad$ Testes e Resultados Obtidos}

Este capítulo é dedicado a apresentação dos testes realizados e dos resultados obtidos no estudo de caso, verificando a correta execução do software de simulação, e analisando o desempenho do protótipo. Como o estudo de caso foi baseado na adaptação do software original escrito em linguagem Fortran 77, não foi considerado no escopo deste trabalho a validação quantitativa dos modelos matemáticos e comportamentais.

Devido à inacessibilidade dos dados do simulador original, não foi possível obter resultados numéricos para comparação. Desta forma a análise dos resultados foi baseada na execução de procedimentos de operação da aeronave real, e na comparação das saídas obtidas com as esperadas, baseadas nos modelos implementados no código original.

A seguir são apresentados os testes de procedimentos normal de operação, as comparações com os modelos originais e a análise de desempenho do Simflow.

\subsection{Execução Paralela}

Com a finalidade de verificar a consistência dos dados em um ambiente paralelo, os componentes foram divididos em cinco Grupos de Execução, conforme a tabela 7.1 .

Tabela 7.1: Divisão dos componentes nos grupos de execução.

\begin{tabular}{cl}
\hline Grupo de Execução & Componentes \\
\hline Grupo 0 & EM04ENG3, EM04OIL \\
Grupo 1 & ELEC, FUEL \\
Grupo 2 & EM04ENG1 \\
Grupo 3 & EM04ENG2 \\
Grupo 4 & Monitor \\
\hline
\end{tabular}




\subsection{Testes de Procedimentos Normais de Operação}

Visando uma maior segurança, cada modelo de aeronave possuí um manual de operações bem detalhado que inclui procedimentos para as diversas etapas de um voo em diferentes condições. Para auxiliar os pilotos, para cada procedimento existe uma lista de checagem (checklist) que devem ser seguidos durante o voo. O anexo A contém a lista de checagem dos procedimentos normais de preparo, acionamento e desligamento da aeronave, semelhante à utilizada pelo Centro de Adestramento Aero-Naval da Marinha do Brasil.

O objetivo deste teste é verificar o comportamento do estudo de caso durante a execução do procedimento normal de partida e desligamento. Como somente os subsistemas de Motores, Elétrico e Combustível foram adaptados, somente os passos relacionados foram executados. A lista de checagem do utilizada neste teste é apresentada nas tabelas 7.2 e 7.3.

Tabela 7.2: Lista de checagem de acionamento.

\begin{tabular}{cl}
\hline Acelerador & Fechado \\
Válvula de Combustível & Ligado \\
Bateria & Ligado \\
Luzes de Aviso & Eng Out aceso \\
Bombas de Combustível & Ligado \\
Ignição & Acionada \\
N1 15\% & Abrir combustível (Acelerador em ponto morto) \\
T.O.T & Aumentando \\
Ignição & Parar com $58 \% \mathrm{~N} 1$ \\
Estabilização em ponto morto (60\% - $62 \% \mathrm{~N} 1$ ) \\
Acelerador & Aberto até $70 \% \mathrm{~N} 1$ \\
Gerador & Ligado \\
Aviônicos & Ligado \\
Acelerador & Todo aberto \\
\hline
\end{tabular}

Tabela 7.3: Lista de checagem de desligamento.

\begin{tabular}{cl}
\hline Acelerador & Em ponto morto, manter até estabilizar N1 \\
Bombas de Combustível & Desligado \\
Acelerador & Fechado \\
TOT & Reduzindo \\
N1 & Reduzindo \\
Válvula de Combustível & Desligado \\
Gerador & Desligado \\
Aviônicos & Desligado \\
N1 & $0 \%$ \\
Bateria & Desligado \\
\hline
\end{tabular}




\subsubsection{Detalhamento do Procedimento de Acionamento e Desligamento}

A interação com o software foi realizado através de comandos de console interpretados pelo componente Monitor. As saídas dos subsistemas foram gravadas em arquivos e plotadas em gráficos.

O parâmetro N1 indica a porcentagem da rotação do primeiro estágio da turbina da aeronave em relação à rotação ideal de operação (50970 RPM). Este é o principal indicador que auxilia o piloto durante a partida da aeronave.

A partida da turbina inicia com o acionamento do motor elétrico de arranque e do ignitor e, neste momento, a rotação N1 aumenta e estabiliza em aproximadamente $17 \%$ devido ao torque de arranque.

No estágio seguinte, ao abrir o acelerador em ponto morto, a turbina entra em combustão e o N1 sobe até estabilizar em aproximadamente 61\%. Neste momento a luz de indicação de turbina desligada (Eng Out) se apaga. Durante a partida, a temperatura de saída da turbina ( T.O.T - Turbine Outlet Temperature) se eleva junto com N1.

Após a estabilização dos parâmetros da turbina, o piloto posiciona o acelerador para manter N1 em 70\% permitindo o acionamento os geradores elétricos, e inicia o preparo do cockpit para o voo.

Antes da decolagem, o piloto posiciona o acelerador em abertura máxima, elevando a rotação N1 para $100 \%$ e o T.O.T para região de regime. Durante todo o voo, a rotação da turbina é mantida constante pelo sistema de controle, sendo ajustado pelo piloto apenas o passo das pás dos rotores principal e de calda, aumentando ou diminuindo o torque.

Após o pouso, o acelerador é posicionado em ponto morto, reduzindo N1 para $61 \%$ e, consequentemente o T.O.T. Após a estabilização dos parâmetros, o piloto desliga os equipamentos elétricos e o gerador, e a turbina é então desligada, através do corte do combustível. O N1 diminui até rotação zero, e o T.O.T até a temperatura ambiente.

O procedimento é finalizado quando o piloto desliga as bombas elétricas de combustível e a bateria da aeronave, assim que N1 atingir rotação nula. 


\subsubsection{Resultados da Simulação dos Procedimentos}

O procedimento apresentado na seção anterior foi simulado no estudo de caso cujos gráficos da figura 7.1 mostram os valores de entrada e saída para o cockpit ao longo do tempo de simulação (em segundos), representando as entradas de um piloto em treinamento e as leituras dos instrumentos, a saber:.

- Os comandos da aeronave, como botões e chaves, têm seus valores representados como zero ou um, representando os estados desligado e ligado respectivamente. Já nos comandos analógicos, como a posição do acelerador, o valor em um determinado tempo representa a posição do comando em porcentagem.

- As saídas digitais, como as luzes indicativas, são também representadas por zero ou um, enquanto que nas saídas analógicas, os valores estão nas escalas e unidades representadas nos respectivos gráficos.

- Os Comandos de Bateria, Bombas de Combustível e Gerador representam as entradas do piloto para o acionamento ou desligamento destes dispositivos.

- O Comando de Ignição indica o tempo que o piloto mantem acionado o motor de arranque e o ignitor para acionamento da turbina.

- Os gráficos de saída mostram a leitura dos instrumentos no cockpit.

Observando os já citados gráficos, constata-se que o processo de ignição é iniciado com o comando do piloto 55 segundos aproximadamente após o início da simulação. Neste momento é observado pelo gráfico de N1 o aumento deste parâmetro e uma tendencia de estabilização em $17 \%$ no instante $t=58$ s. Após 60 segundos do início da simulação, o acelerador é posicionado em ponto morto (aproximadamente 7\%), iniciando a combustão. Neste momento N1 inicia a fase de crescimento acelerado até $\mathrm{t}=70 \mathrm{~s}$, seguido de crescimento desacelerado ate estabilizar em $60 \%$ aproximadamente no instante $t=77 \mathrm{~s}$. O comando de ignição é interrompido 20 segundos após o inicio da partida.

Durante a partida, o parâmetro T.O.T cresce após a abertura do acelerador, atingindo o valor máximo de aproximadamente 650 graus Celsius no instante $\mathrm{t}=$ 70 s, seguido de uma redução e estabilização em 520 graus Celsius.

Quando N1 atinge 55\%, a luz indicativa de turbina desligada (Eng Out) é apagada. 

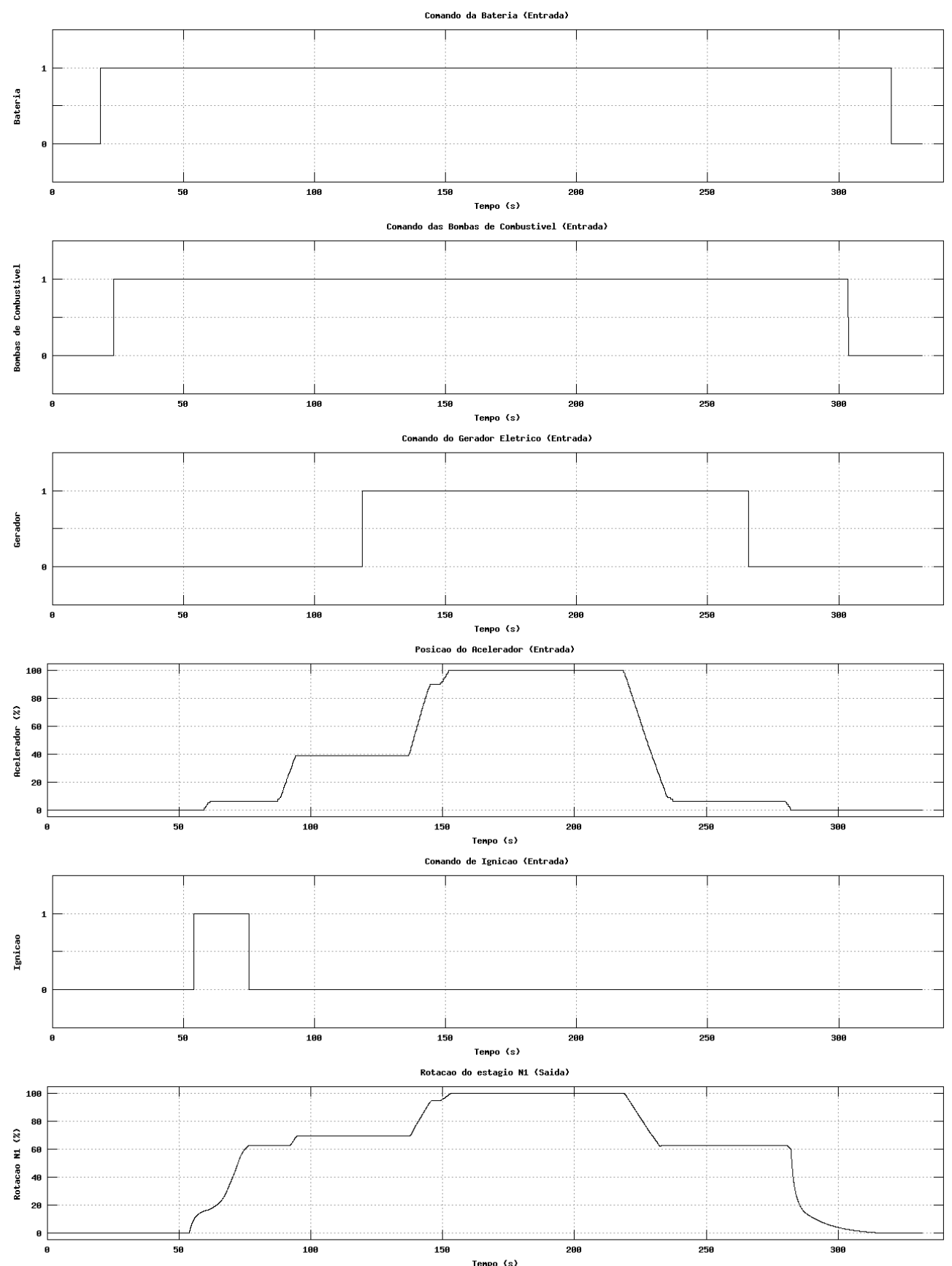

Tenpo (s)
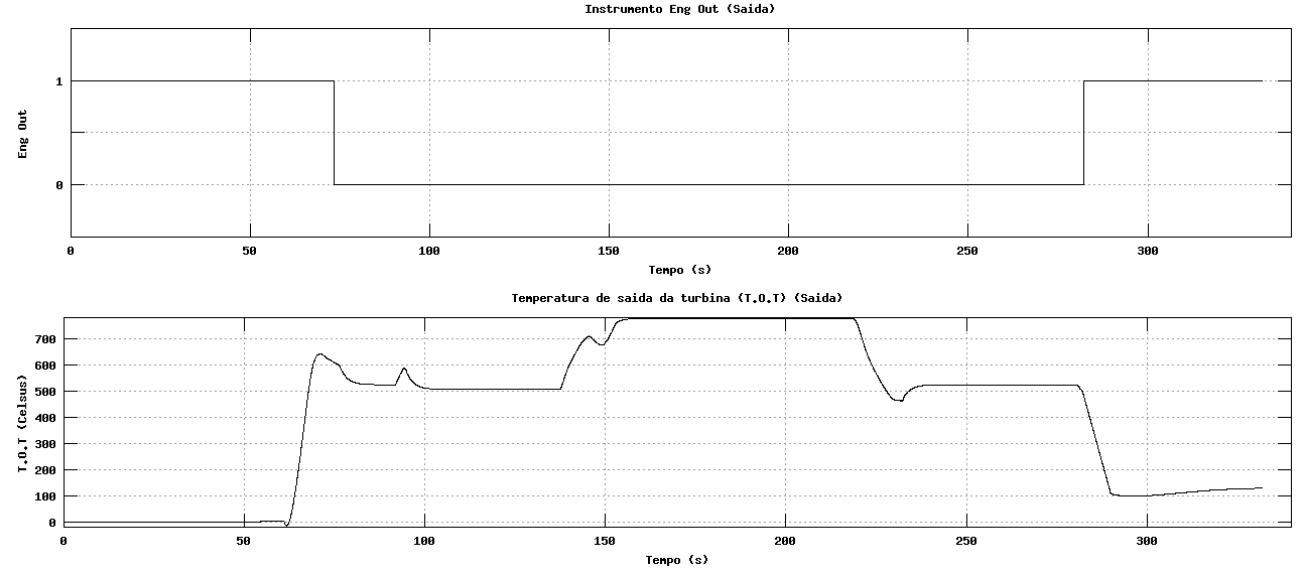

Figura 7.1: Entradas e saídas em função do tempo de simulação para o procedimento padrão de partida e desligamento. 
No instante $\mathrm{t}=87 \mathrm{~s}$, o acelerador é posicionado em $40 \%$, elevando N1 para $70 \%$, conforme o procedimento normal de acionamento. É observado que N1 inicia o aumento após a posição do acelerador passar de $25 \%$. Isto ocorre pois, o modelo matemático considera as posições entre $5 \%$ e $25 \%$ como ponto morto, não alterando o fluxo de combustível.

Após 135 segundos do início da simulação, o acelerador é posicionado em 100\%, elevando N1 para 100\% e T.O.T para aproximadamente 770 graus Celsius.

O procedimento de desligamento tem início no instante $\mathrm{t}=220 \mathrm{~s}$, com o posicionamento do acelerador em $5 \%$ (ponto morto). Como consequência, N1 e T.O.T reduzem e estabilizam nos valores normais para a condição de ponto morto. Em $\mathrm{t}=280 \mathrm{~s}$, o acelerador é colocado em corte $(0 \%)$, encerrando a combustão da turbina. N1 então reduz até a parada total (0\%), e T.O.T até a temperatura ambiente.

Após a parada de N1, o piloto desliga as bombas de combustível e a bateria, finalizando o procedimento.

Comparando estes resultados com o procedimento descrito na seção 7.2.1, verifica-se que a execução do estudo de caso apresentou saídas compatíveis com as esperadas durante procedimentos normais de operação da aeronave, dentro das limitações dos modelos matemáticos implementados no programa original. Nesta análise não foi observada nenhuma divergência considerável devido à execução paralela das rotinas que originalmente eram executadas sequencialmente.

\subsection{Comparação com as Rotinas Originais}

Devido principalmente à incompatibilidade tecnológica com as tecnologias atuais, é inviável, no escopo deste trabalho, a comparação dos resultados do estudo de caso com o simulador original. Porém, é possível extrair o modelo matemático do código fonte original (escrito na linguagem Fortran77), utilizando como base para comparação.

Para esta análise foi escolhida a simulação da rotação da turbina (parâmetro N1) em decorrência do acionamento do motor de arranque, antes do início da combustão.

O parâmetro N1 (porcentagem da rotação do primeiro estágio) em cada ciclo é obtido através do torque resultante do primeiro estágio da turbina. No inicio do arranque, o torque resultante é composto por uma componente proveniente do 
motor de arranque (torque de arranque) e outra devido às resistências mecânicas (torque de resistência). O torque de arranque é descrito em função de N1. Já o torque de resistência é em função de N1 ajustado pela temperatura externa $\left(T_{a m b}\right)$. A equação do torque resultante é apresentada em 7.1, onde $N$ é a porcentagem da rotação N1, $N_{\text {corr }}$ é o parâmetro N1 ajustado (definido pela equaçõe 7.2 ), $\tau_{r}$, o torque resultante, $\tau_{a r}$, o torque de arranque e $\tau_{r e s}$, o torque de resistência.

$$
\begin{gathered}
\tau_{r}(N)=\tau_{a r}(N)-\tau_{\text {res }}\left(N_{\text {corr }}\right)-0.1 \\
N_{\text {corr }}=\frac{N}{\sqrt{\frac{T_{a m b+273.0}}{288.0}}}
\end{gathered}
$$

No modelo original, os torques de arranque e resistência são obtidos através da interpolação linear dos valores da tabela 7.4. Os valores do torque de arranque são absolutos, enquanto o torque de resistência é em razão à pressão do ambiente (em PSI). Não foi possível obter através do código fonte original a unidade de torque utilizada.

Tabela 7.4: Valores das componentes do torque resultante.

(a) Valores para torque de arranque

\begin{tabular}{cl}
\hline N1 (\%) & Torque \\
\hline 0.00 & 6.0 \\
13.33 & 2.0 \\
26.66 & 2.5 \\
40.00 & 1.0 \\
53.33 & 0.0 \\
\hline
\end{tabular}

(b) Valores para torque de resistência

\begin{tabular}{cl}
\hline N1 ajustado(\%) & Torque \\
\hline 0.00 & 0.00 \\
13.33 & 0.06 \\
26.66 & 0.34 \\
40.00 & 0.82 \\
45.55 & 1.40 \\
66.65 & 1.90 \\
80.00 & 2.50 \\
93.30 & 3.56 \\
106.64 & 4.50 \\
\hline
\end{tabular}

As curvas do torque de arranque, de resistência e resultante, em função de 
N1, considerando a pressão ambiental de 14.7 PSI e temperatura de $25^{\circ} \mathrm{C}$, são apresentadas na figura 7.2.

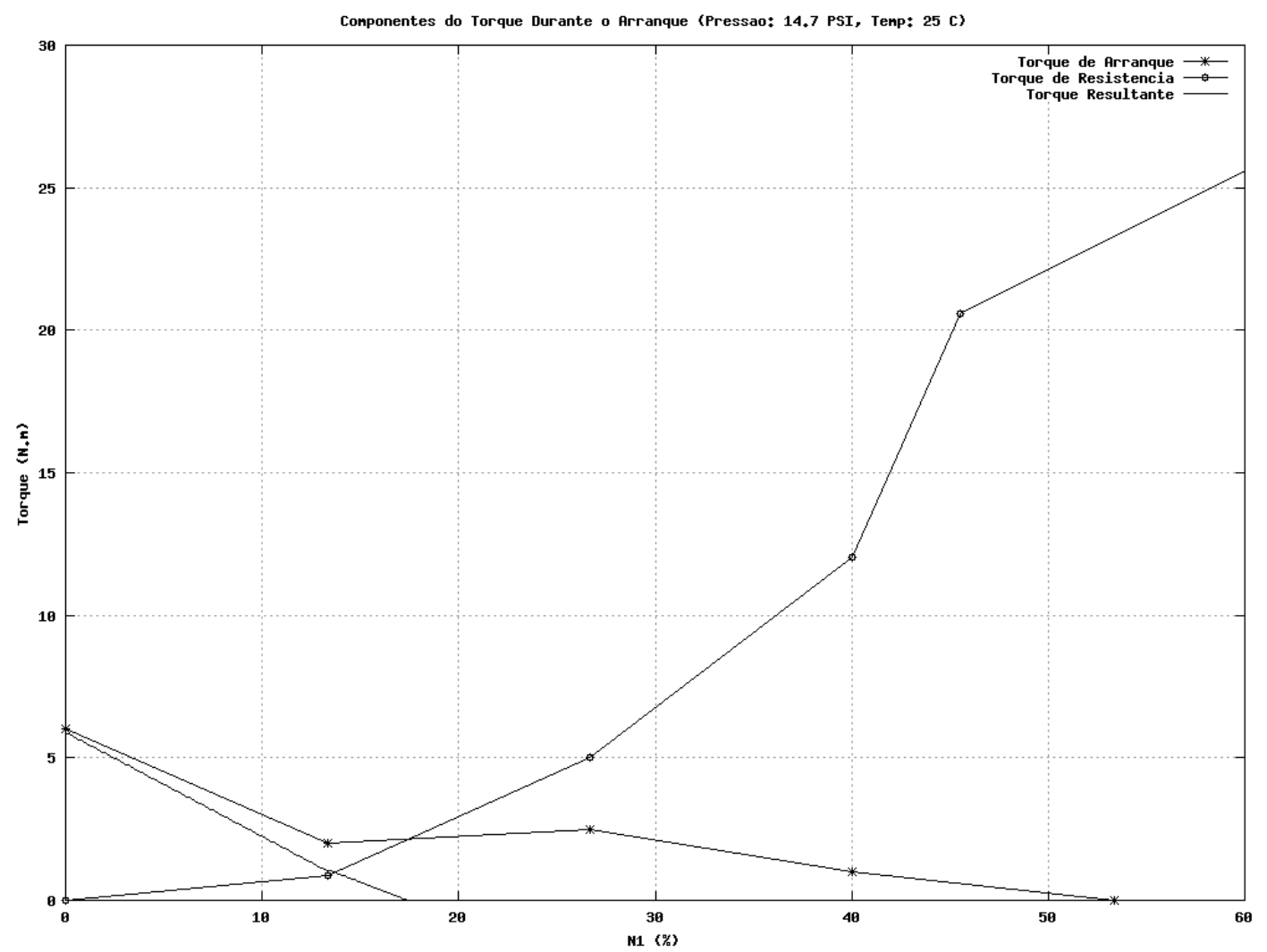

Figura 7.2: Curvas de torque em função de N1 (Pressão = 14.7 PSI).

Como pode ser observado, o torque de arranque decresce com o aumento de N1, enquanto o torque de resistência aumenta. As duas componentes são iguais para $N 1 \approx 17 \%$, anulando o torque resultante.

A partir do torque resultante é calculado a aceleração angular utilizando a equação 7.3, onde $a_{a n g}$ é aceleração angular, $n$, o ciclo atual e $I$ é o momento de inércia (unidade desconhecida), cujo valor é 0.45. A unidade de $a_{a n g}$ é $R P M / s$.

$$
a_{\text {ang }}(n)=307.2 * \frac{\tau_{r}(N(n-1))}{I}
$$

O valor de N1 do ciclo atual então calculado a partir de $a_{a n g}$ e normalizado em relação à rotação ideal de operação (50970 RPM), conforme as equações 7.4 e 7.5 .

$$
N_{r p m}(n)=N_{r p m}(n-1)+a_{a n g} * \Delta t .
$$




$$
N(n)=100 * \frac{N_{r p m}(n)}{50970}
$$

A figura 7.3 apresenta as curvas de N1 ao longo do tempo obtidas do modelo original e da execução do estudo de caso, assumindo taxa de atualização de 30 ciclos por segundo.

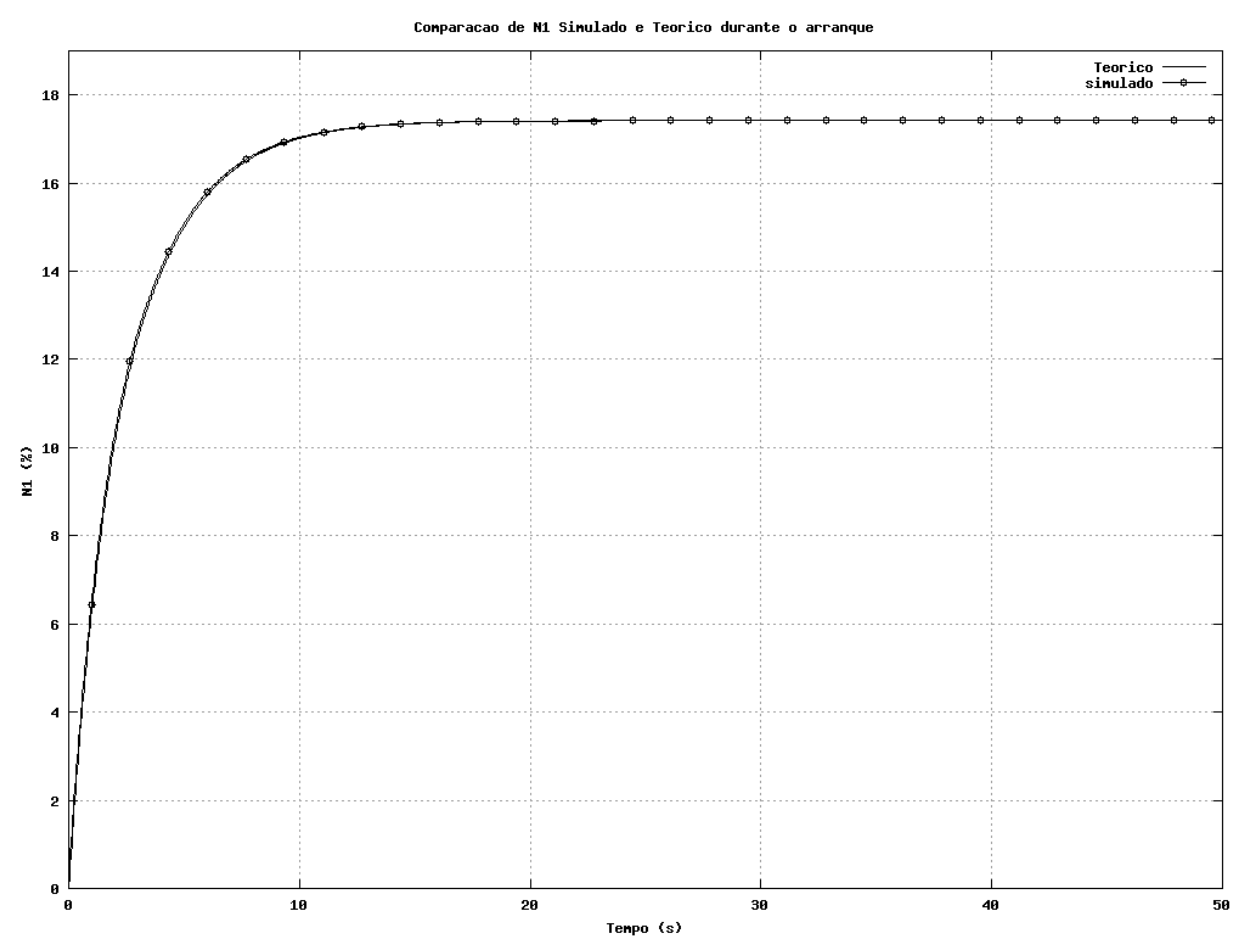

Figura 7.3: Evolução de N1 (30 ciclos por segundo).

Como pode ser observado, o resultado obtido pelo SimFlow é muito próximo, apresentando uma diferença durante o transitório, mas estabilizando no valor esperado $(\mathrm{N} 1=17.4182 \%)$. Analisando numericamente a diferença durante o transitório, é constatado diferenças no domínio do tempo. Como os componentes do estudo de caso foram distribuídos em diversos Grupos de Execução, variações de um ou dois ciclos são esperados devido ao mecanismo de duplo Buffer para manter a consistência dos dados.

Estes resultados mostram que mesmo em um ambiente paralelo, o protótipo SimFlow executou a simulação originalmente sequencial do estudo de caso de maneira satisfatória, apresentando resultados corretos, porém com atrasos previstos e toleráveis, que não prejudicariam o processo de treinamento. 


\subsection{Desempenho da Ferramenta SimFlow}

Para a análise de desempenho do protótipo, foi aferido o tempo em diversas etapas da execução do estudo de caso. Foi utilizado a chamada gettimeofday (padrão POSIX) em ambiente Linux 64bits. Esta chamada apresenta acurácia média de $1.3 \mu s$, sendo suficiente para esta análise.

As medidas foram realizadas nos níveis de executor e aplicação. No executor, para cada Grupo de Execução foram medidos os tempos em cada uma das fases de um ciclo (figura 5.4 do capítulo 5). No nível da aplicação, foram monitorado os tempos de atualização de cada Componente da simulação.

No ensaio analisado, a simulação foi executada durante 50615 ciclos à $30 \mathrm{~Hz}$ (aproximadamente 28 minutos), em um computador Intel Core 2 Duo, modelo T7700, em ambiente Ubuntu 9.04 (Kernel 2.6.28, 64 bits). A tabela 7.5 apresenta os resultados agrupados por Grupo de Execução.

As fases Sinc. Dados e Sinc. Exec. são as barreiras de sincronismo para o início do ciclo (início da atualização das áreas de memória externas) e início da fase de atualização dos componentes, respectivamente. A medida Total Sinc. representa o tempo total entre o inicio do inicio do ciclo até o inicio da fase de atualização dos componentes, representado pela medida Total Atual. Neste cenário, o grupo 4 foi descartado pois o componente Monitor apresenta tempos muito acima da média devido as operações de entrada e saída com o console.

Como pode ser observado na tabela 7.5, neste estudo de caso a atualização dos Componentes consome menos de $1 \%$ do tempo total do ciclo, sendo que em mais de $99 \%$ o Grupo de Execução permanece ocioso. O tempo adicional devido a utilização do SimFlow (overhead) por Grupo de Execução é calculado segundo a equação 7.6 .

$$
t_{\text {overhead }}=t_{\text {buffer }}+t_{\text {atual }}-\sum t_{\text {componentes }}
$$

Considerando $5 \mu$ s o tempo médio de execução de cada Componente, e 1.5 componentes por Grupo, então o tempo adicional médio é $t_{\text {overhead }} \approx 6 \mu$ s. Deste tempo, $4 \mu s$ são referentes à atualização dos componentes, utilizados pelo Sequênciador. Desta forma o tempo de atualização é proporcional ao número de Componentes no Grupo de Execução. Portanto o tempo adicional por Componente é $t_{\text {CompOver }} \approx$ $3 \mu s$, independente da complexidade do Componente.

O software de simulação original é composto por 50 rotinas, e aproximada- 
Tabela 7.5: Tempos médios e máximos por grupo de execução.

\begin{tabular}{|c|c|c|c|}
\hline Grupo & Fase & Tempo Médio $(\mu s)$ & Tempo Máximo $(\mu s)$ \\
\hline \multirow[t]{8}{*}{ grupo 0} & Sinc. Dados & 118 & 4362 \\
\hline & Troca Buffers & 2 & 204 \\
\hline & Sinc. Exec. & 33320 & 52781 \\
\hline & Total Sinc. & 33447 & 52997 \\
\hline & EM04ENG2 & 7 & 99 \\
\hline & EM04OIL & 3 & 49 \\
\hline & Total Atual. & 16 & 107 \\
\hline & Total Grupo & 33467 & 53017 \\
\hline \multirow[t]{8}{*}{ grupo 1} & Sinc. Dados & 113 & 4454 \\
\hline & Troca Buffers & 2 & 68 \\
\hline & Sinc. Exec. & 33326 & 52797 \\
\hline & Total Sinc. & 33447 & 52980 \\
\hline & ELEC & 6 & 42 \\
\hline & FUEL & 5 & 44 \\
\hline & Total Atual. & 16 & 76 \\
\hline & Total Grupo & 33467 & 53002 \\
\hline \multirow[t]{7}{*}{ grupo 2} & Sinc. Dados & 120 & 2692 \\
\hline & Troca Buffers & 2 & 44 \\
\hline & Sinc. Exec. & 33327 & 52775 \\
\hline & Total Sinc. & 33455 & 53020 \\
\hline & EM04ENG1 & 5 & 53 \\
\hline & Total Atual. & 8 & 56 \\
\hline & Total Grupo & 33467 & 53030 \\
\hline \multirow[t]{7}{*}{ grupo 3} & Sinc. Dados & 115 & 4348 \\
\hline & Troca Buffers & 2 & 28 \\
\hline & Sinc. Exec. & 33332 & 52769 \\
\hline & Total Sinc. & 33456 & 53033 \\
\hline & EM04ENG3 & 4 & 41 \\
\hline & Total Atual. & 7 & 57 \\
\hline & Total Grupo & 33467 & 53044 \\
\hline \multirow[t]{7}{*}{ grupo 4} & Sinc. Dados & 86 & 4381 \\
\hline & Troca Buffers & 2 & 37 \\
\hline & Sinc. Exec. & 33296 & 52712 \\
\hline & Total Sinc. & 33390 & 52729 \\
\hline & Monitor & 70 & 327 \\
\hline & Total Atual. & 72 & 330 \\
\hline & Total Grupo & 33467 & 52789 \\
\hline
\end{tabular}


Tabela 7.6: Tempos médios.

\begin{tabular}{lr}
\hline Fase & Tempo Médio $(\mu s)$ \\
\hline Sinc. Dados & 116 \\
Troca Buffers & 2 \\
Sinc. Exec. & 33326 \\
Total Sinc. & 33451 \\
Total Atual. & 11 \\
Total Grupo & 33467 \\
\hline
\end{tabular}

mente 2600 variáveis globais (datapool). O tempo estimado de atualização é de aproximadamente $400 \mu \mathrm{s}$. O tempo para a troca de buffers pode ser estimado através da curva 7.4 (obtida através de testes no mesmo ambiente), para um tamanho de memória de aproximadamente 10400 bytes ( 4 bytes por variável), resultando em um valor entre 2 e $4 \mu s$. O tempo de processamento médio estimado por ciclo é de $404 \mu \mathrm{s}$, representando aproximadamente $1 \%$ do tempo total do ciclo $(30 \mathrm{~Hz})$ de um Grupo de Execução.

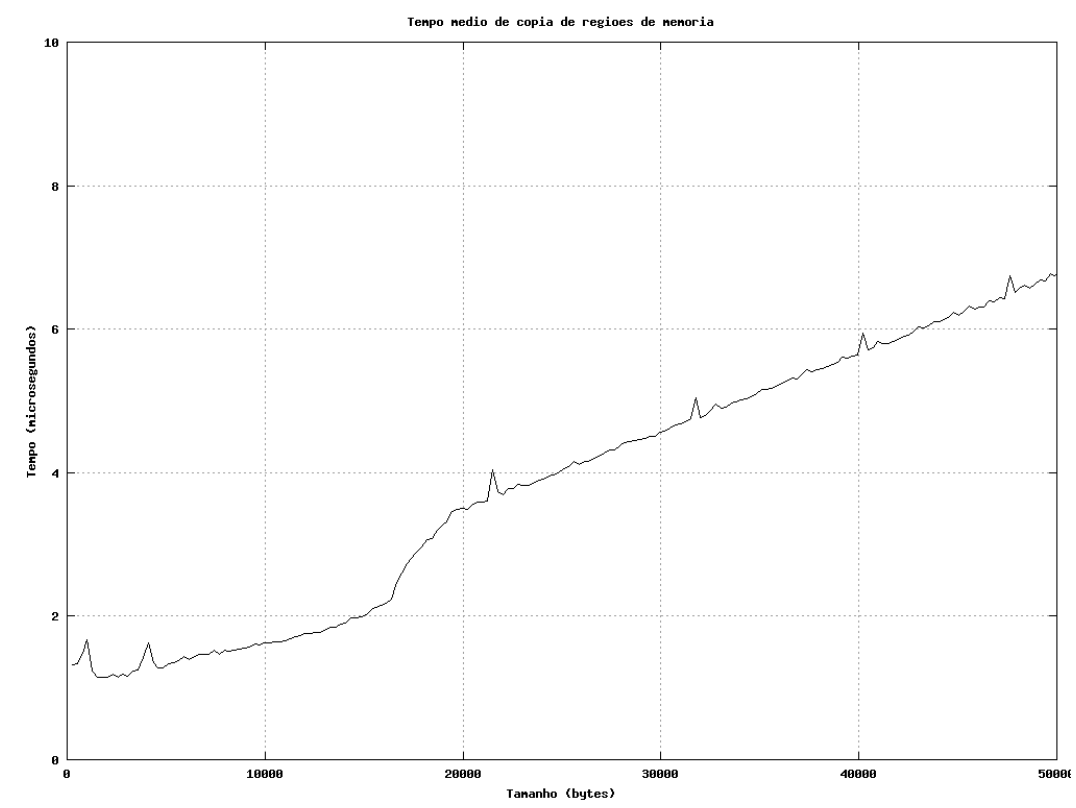

Figura 7.4: Tempo de cópia de regiões de memória.

Com as tecnologias atuais, a frequência de atualização adotada nos simuladores é de $60 \mathrm{~Hz}$. Desta forma, a ferramenta proposta SimFlow permite a implementação de simulações mais complexas, sobrando margem para operações de entrada e saída e síntese de áudio e imagens em tempo real. 


\subsection{Síntese}

Este capítulo apresentou os resultados obtidos do estudo de caso, analisando de forma qualitativa e quantitativa as saídas do simulador, e o desempenho da ferramenta.

A análise qualitativa foi realizada a partir do procedimento normal de partida e desligamento da turbina da aeronave, monitorando as saídas para os instrumentos disponíveis no cockpit. Os resultados foram satisfatórios uma vez que as leituras foram conforme o esperado pelo procedimento normal.

Como base de comparação para a análise quantitativa foi utilizado o modelo matemático da simulação do arranque da turbina, extraído do código fonte original. Foi constatado que as diferenças entre as simulações são atrasos de um a dois ciclos, devido ao algoritmo de duplo buffer utilizado para garantir a consistência dos dados em uma simulação paralela. Porém estas diferenças são toleráveis em um simulador para treinamento.

A análise de desempenho mostrou que o estudo de caso utiliza menos de $1 \%$ do tempo total de ciclo para processamento, e que tempo adicionado da ferramenta (overhead) não é crítico para a simulação.

O protótipo SimFlow apresentou resultados satisfatórios em todas as análises, apresentando um potencial para ser utilizado no desenvolvimento de simuladores de treinamento mais complexos. 


\section{Conclusões}

Simuladores são utilizados para treinamento desde 1910, utilizando sistemas elétricos e mecânicos para criar um ambiente virtual. Atualmente simuladores de treinamento são aplicados intensivamente em várias áreas, visando principalmente redução de custos e riscos no treinamento.

Apesar da crescente demanda nesta área, no Brasil existem poucos trabalhos direcionados para o desenvolvimento de uma ferramenta específica para simuladores de treinamento, possibilitando a redução de custos e o tempo de desenvolvimento destes softwares.

É nesse contexto que foi proposta e avaliada quanto à aplicabilidade uma ferramenta de software para auxiliar o desenvolvimento destes simuladores, baseado na decomposição em uma hierarquia de blocos funcionais inter-conectados através de suas entradas e saídas.

Foi concebida uma nova arquitetura de software destinada a explorar a paralelização do desenvolvimento e a reutilização de componentes. Esta arquitetura foi utilizada como base para o projeto e implementação de um protótipo denominado SimFlow.

Com o objetivo de testar e avaliar a arquitetura e o protótipo, foi realizado, como estudo de caso, a adaptação parcial de um simulador da aeronave Bell Jet Ranger III, desenvolvido na década de 80, mas ainda em operação na Marinha do Brasil.

A execução de procedimentos de operação reais da aeronave simulada no estudo de caso mostrou que a ferramenta SimFlow foi capaz de executar adequadamente os componentes adaptados do código fonte original. A análise numérica comprovou que os resultados são compatíveis com o modelo original, apesar das mínimas diferenças de tempo previstas devido à técnica adotada para manter a consistência dos dados em um ambiente paralelo.

Por meio da análise de desempenho do SimFlow foi observado um pequeno tempo adicional de processamento devido à utilização da ferramenta, mostrando 
que é possível implementar modelos matemáticos mais complexos e acrescentar recursos como síntese de áudio e imagem em tempo real. Como se trata de um protótipo, outras otimizações poderão ser adicionadas futuramente, reduzindo ainda mais os tempos adicionais.

Desse modo, a ferramenta proposta mostrou-se eficiente e com desempenho adequado no processo de adaptação parcial de um simulador real e na execução do estudo de caso proposto. Este protótipo da ferramenta também foi projetado de forma a facilitar o acréscimo futuro de novas funcionalidades sem a necessidade de modificações no núcleo da ferramenta.

\subsection{Principais Contribuições}

Na área acadêmica são poucos os trabalhos disponibilizados que tratam sobre ferramentas genéricas destinadas para o desenvolvimento de simuladores de treinamento. Da mesma forma, na área de aplicação não foram encontrados produtos com esta finalidade.

Portanto, a arquitetura de software proposta, a ferramenta concebida com a sua implementação através de um protótipo são contribuições deste trabalho para o desenvolvimento de novos simuladores para treinamento.

A implementação do estudo de caso mostrou que o protótipo desenvolvido pode ser utilizado de fato para o desenvolvimento de simuladores de treinamento, comprovando a hipótese de que é viável o emprego de ferramentas genéricas neste tipo de aplicação.

\subsection{Trabalhos Futuros}

Como continuidade deste trabalho, é sugerido o aperfeiçoamento e a otimização do núcleo do protótipo, e a implementação de novas funcionalidades como:

- suporte à execução em ambiente distribuído;

- suporte ao carregamento de componentes e serviços em tempo de execução (Plug-ins);

- incorporação de protocolos de integração (HLA e DIS), permitindo o desenvolvimento de treinamentos conjuntos; 
- facilidades de desenvolvimento, como interfaces para controle e depuração da simulação;

- serviços para geração de áudio e imagem em tempo real;

- suporte a linguagens de scripts, permitindo a prototipagem de Componentes.

Além da ferramenta na forma de biblioteca de software, é sugerido o desenvolvimento de editores gráficos para a configuração das conexões entre componentes e testes do simulador, consolidando um ambiente de produtividade nesta área. 


\section{Referências Bibliográficas}

[1] FUJimoto, R. M. Parallel and Distributed Simulation Systems. [S.l.]: John Wiley and Sons, 2000.

[2] ROLFE, J. M.; STAPLES, K. J. Flight Simulation. [S.l.]: Cambrige University Press, 1986.

[3] AUGUSTO, R. L. et al. Gp brasil vr: uma corrida de carros em realidade virtual. In: SBGames: Proceedings of the V Brazilian Symposium on Computer Games and Digital Entertainment. Recife, PE, Brazil: Brazilian Computing Society, 2006.

[4] ABOWD, G. D. et al. Structural Modeling: An Application Framework and Development Process for Flight Simulators. Pittsburgh, Pennsylvania, August 1993.

[5] THE BOEING COMPANY. System Segment Specification for the Generic Modular Simulator System. [S.1.], 1991. Volumes I-XIV, n. S495-10400.

[6] CRISPEN, R. G.; STUCKEY JR., L. D. Structural model: architecture for software designers. In: TRI-Ada '94: Proceedings of the conference on TRI-Ada '94. New York, NY, USA: ACM, 1994. p. 272-281. ISBN 0-89791-666-2.

[7] CRISPEN, R. G. et al. Darts: A domain architecture for reuse in training systems. In: I/ITSEC '93: Proceedings of the 15th Interservice/Industry Training, Simulation and Education Conference. Huntsville, Alabama: [s.n.], 1993.

[8] GAMMA, E. et al. Design Patterns: Elements of Reusable Object-Oriented Software. [S.1.]: Addison-Wesley, 1995.

[9] STROUSTRUP, B. The $C++$ Programming Language. 2nd. ed. [S.l.]: Addison-Wesley, 1991.

[10] EDELSON, D. R. Smart pointers: They're smart, but they're not pointers. In: In $C++$ Conference. [S.l.]: Usenix, 1992. p. 1-19.

[11] BLAIS, C. Prototyping advanced warfare gaming capabilities for the 21st century warfighter. In: Proc. Winter Simulation. [S.l.: s.n.], 1998. v. 1, p. 841-848.

[12] BOUKERCHE, A.; LU, K. A novel approach to real-time rti based distributed simulation system. In: ANSS '05: Proceedings of the 38th annual Symposium on Simulation. Washington, DC, USA: IEEE Computer Society, 2005. p. 267-274. ISBN 0-7695-2322-6.

[13] CHASTEK, G.; BROWNSWORD, L. A Case Study in Structural Modeling: [S.l.], 1996. 
[14] FUJIMOTO, R. Distributed simulation systems. In: Proc. Winter Simulation Conference. [S.1.: s.n.], 2003. v. 1, p. 124-134.

[15] HAMILTON, J. Montana smart pointers: They're smart, and they're pointers. In: Usenix Association, Berkeley, Calif. [S.l.: s.n.], 1997.

[16] HARMONOSKY, C. Simulation-based real-time scheduling: review of recent developments. In: Proc. Winter Simulation. [S.l.: s.n.], 1995. p. 220-225.

[17] HATCHERSON, R.; HOLT, K.; TARTER, S. A Container-Based Architecture for Simulation, ZedaSoft. January 2004. Technical White Paper.

[18] JAIN, S.; MCLEAN, C. R. Integrated simulation and gaming architecture for incident management training. In: WSC'05: Proceedings of the 37th conference on Winter simulation. [S.1.]: Winter Simulation Conference, 2005. p. 904-913. ISBN 0-7803-9519-0.

[19] JúNIOR, A. M. G. Um Ambiente de Execução para um Sistema de Memória Compartilhada Distribuida Utilizando Plataforma Windows. Dissertação (Mestrado) — Escola Politécnica da Universidade de São Paulo, São Paulo, 2005.

[20] KAZMAN, R. Handbook of parallel and distributed computing. In:

[S.l.]: McGraw-Hill, 1995. cap. Distributed Flight Simulation: A Challenge for Software Architecture.

[21] MCLEAN, T.; FUJIMOTO, R. Predictable time management for real-time distributed simulation. In: PADS '03: Proceedings of the seventeenth workshop on Parallel and distributed simulation. Washington, DC, USA: IEEE Computer Society, 2003. p. 89. ISBN 0-7695-1970-9.

[22] MONSERRAT, D. S. Modelos de Analisis Orientado a Objetos Aplicados en el Dominio Aeronautico. Dissertação (Mestrado) - Universidad Nacional de La Plata, La Plata, Buenos Aires, Argentina, 2005.

[23] PAGE, E. H.; SMITH, R. Introduction to military training simulation: a guide for discrete event simulationists. In: WSC '98: Proceedings of the 30th conference on Winter simulation. Los Alamitos, CA, USA: IEEE Computer Society Press, 1998. p. 53-60. ISBN 0-7803-5134-7.

[24] PRAEHOFER, H.; SCHOEPPL, A. A continuous and combined simulation platform in java and its application in building paper mill training simulators. In: Proceedings of WebSim 2000. San Diego, CA: [s.n.], 2000.

[25] RODRIGUES, F. et al. Coupling virtual reality open source software using message oriented middleware. In: SEARIS'09: Proceeding of the second workshop on Software Engineering and Architecture for Realtime Interactive Systems. [S.l.]: IEEE VR, 2009.

[26] CRAVEIRO, G. da S. Um ambiente de execução para suporte à programação paralela com variáveis compartilhadas em sistemas distribuídos heterogêneos. Dissertação (Mestrado) — Escola Politécnica da Universidade de São Paulo, São Paulo, 2003. 
[27] SJöQUIST, K. Design of a Flight Simulator Software Architecture. Dissertação (Mestrado) - School of Mathematics and Systems Engineering, Växjö University, Vöxjö, Sweden, 2002.

[28] STEINMAN, J. The warpiv simulation kernel. In: Proc. Workshop on Principles of Advanced and Distributed Simulation PADS 2005. [S.l.: s.n.], 2005. p. 161-170. ISSN 1087-4097.

[29] STEINMAN, J.; WONG, J. The speedes persistence framework and the standard simulation architecture. In: Proc. Seventeenth Workshop on Parallel and Distributed Simulation (PADS 2003). [S.l.: s.n.], 2003. p. 11-20. ISSN 1087-4097.

[30] TEUBL, F. et al. Passeio digital: Um sistema de multiprojeção de baixo custo voltado às aplicações educacionais. In: In XI Symposium on Virtual and Augmented Reality SVR2009. [S.1.: s.n.], 2009.

[31] WORD, D. et al. Multi-rate real-time simulation techniques. In: SCSC: Proceedings of the 2007 summer computer simulation conference. San Diego, CA, USA: Society for Computer Simulation International, 2007. p. 195-198. ISBN 1-56555-316-0. 


\section{Apêndice A - Descrição dos Subsistemas e Rotinas do Simulador da Aeronave Bell Jet Ranger III}

\section{A.1 Subsistema de Aerodinâmica (FLYT)}

As rotinas deste subsistema são responsáveis pelos cálculos aerodinâmicos da simulação. As principais entradas externas são dos controles aerodinâmicos da aeronave (coletivo, pedais e cíclico), e comandos do instrutor (congelamento da simulação, falhas etc). Enquanto as saídas são as leituras dos instrumentos primários (altímetro, altímetro radar, atitude, velocidade vertical, split ball, indicador de curva, velocímetro etc) e outras utilizadas por outros subsistemas (Latitude e longitude da aeronave, altitude, velocidades lineares e angulares etc). São utilizadas também saídas de outros subsistemas, como o torque de saída das turbinas, estado dos barramentos elétricos etc.

O subsistema FLYT é composto pelas seguintes rotinas:

- AMATMOS: Utilizando saídas do subsistema RAID (informações de terreno) e das equações de movimentação (altitude, velocidade etc), esta rotina calcula as condições atmosféricas como temperaturas e pressões.

- AMCOEFX: Esta rotina computa os termos de inércia para as outras equações e atribui algumas constantes do Rotor. Como entrada, utiliza principalmente informações de posições do centro de gravidade (proveniente do AMMASS), ângulo de ataque e de curva (proveniente do AMEOM) e de constantes aerodinâmicas. As principais saídas são as distâncias de componentes (como rotor, rotor de calda, distribuidor etc) em relação ao centro de gravidade.

- AMCRASH: Através de informações como a posição da aeronave, distância do terreno, velocidade, ângulos de pitch e roll e razões de subida ou descida 
(fornecidos pelo AMEOM e AMINST1), determina possíveis condições de acidentes (Crash). Os motivos considerados incluem o excesso de velocidade (overspeed), colisão com o terreno, razões de descidas inapropriadas, colisão em solo etc.

- AMEOM: Implementa as equações de movimento. Utiliza como entradas todas as informações de forcas que atuam sobre a aeronave (AMFORCE), forças do vento (AMWIND) rajadas de ar e turbulências (AMRUFAIR), dados de massas, centro de gravidade etc. Os resultados são as forças resultantes, acelerações (lineares e angulares), velocidades (angulares e lineares) e posição da aeronave.

- AMFORCE: Este módulo soma as forças e momentos aerodinâmicos que atuam no rotor principal e de cauda (AMROTOR) e na fuselagem (AMFUSX). As forças resultantes então são ajustadas para considerar os efeitos de vortex na performance das pás, e de proximidade com o solo.

- AMFUSX: Calcula os momentos e forças aerodinâmicas sobre a fuselagem da aeronave. As equações consideram o modelo simplificado da área do corpo da aeronave, informações de gelo (AMICE), e o estado atual da aeronave (velocidades, ângulo de ataque, de curva, variações de pitch, roll e yaw, momentos etc, provenientes do AMEOM).

- AMGEAR: Computa as forças e momentos que atuam nos pontos de contato do esqui do helicóptero. Utiliza informações de massa (AMMASS) e do estado da aeronave (AMEOM).

- AMICE: Este módulo resulta nas condições de gelo durante o voo, sendo utilizada nos cálculos de forças e no sistema pitot-static. As entradas são informações fornecidas pelo sistema do instrutor e o estado atual da aeronave (AMEOM).

- AMINST1: Baseado nas saídas dos módulos AMEOM, AMMASS e AMICE, esta rotina calcula as saídas para os seguintes instrumentos (piloto e co-piloto): Indicador de Velocidade do Ar, Altímetro, Indicador de velocidade vertical (VSI), medidor Hover e Indicador OAT.

- AMINST2: Calcula as saídas para os seguintes instrumentos do piloto e co-piloto: Indicadores de curva e coordenação (slip ball), horizonte artificial e do tacômetro do rotor. Utiliza como entradas valores calculados no 
módulo AMEOM (como os ângulos de pitch, roll e yaw, e as acelerações lineares e angulares de cada eixo) e AMROTOR (como a velocidade do rotor em RPM).

- AMMAGGS: Este componente verifica a validade e executa os comandos de reposicionamento da aeronave, congelamento da simulação e parâmetros das condições atmosféricas, enviadas pelo console do instrutor (subsistema TASC).

- AMMASS: Recebe como entrada propriedades de carga extra na aeronave (AMMAGGS), quantidade de combustível (subsistema FUEL) e informações de gelo (AMICE); e computa as massas total do helicóptero, as coordenadas do centro de gravidade e os momentos de inércia.

- AMMOTiON: Gera os sinais de controle de posição, velocidade, aceleração e vibração para os pistões do sistema de movimentação de 4 eixos. As principais entradas deste módulo são: posicionamento, velocidades e acelerações, angulares e lineares, da aeronave nos três eixos (AMEOM), momentos angulares nos esquis, caso em solo (AMGEAR), velocidade da turbulência (AMRUFAIR), coordenadas do centro de gravidade (AMMASS), além dos sinais de realimentação provenientes da plataforma.

- AMRADALT: Este módulo gera as saídas para o instrumento rádio altímetro do piloto e co-piloto. Recebe como entrada os ângulos e posições da aeronave (AMEOM), informações sobre o barramento elétrico (subsistema elétrico) e dos controles dos pilotos (botão de teste do instrumento).

- AMREPOS: Recebe informações do estado atual da aeronave (AMEOM, AMGEAR, AMMASS, AMCRASH) e dos comandos do instrutor (AMMAGGS) e utiliza para o reposicionamento da aeronave após uma quebra (Crash) ou para o inicio de uma nova simulação.

- AMROTOR: Calcula o torque e a velocidade do rotor principal e de cauda. Suas principais entradas são: velocidade, aceleração no eixo z (AMEOM), informações de quebra (AMCRASH), torque aerodinâmico dos rotores de cauda e principal (AMROTRX), estado do barramento elétrico (sistema elétrico), estado dos motores (subsistema motores) e a posição do controle de coletivo.

- AMROTRX: Simula a aerodinâmica dos rotores principal e de cauda. Este módulo recebe em sua entrada informações de velocidades, acelerações 
e ângulos (AMEOM), torque e velocidade dos rotores (AMROTOR), coeficientes inerciais (AMCOEFX), condições atmosféricas (AMTMOS), estado do sistema elétrico, torque da turbina (subsistema motores). Também faz a leitura das posições dos controles de coletivo, cíclico e pedais. As saídas são as forças devido à rotação dos rotores.

- AMRUFAIR: Provê variações aleatórias na velocidade do vento. Os cálculos deste módulo consideram fatores de turbulência fornecidos pelo instrutor (AMMAGGS), altura em relação ao relevo (AMEOM), efeitos de vortex (AMFORCE).

- AMWIND: Computa a velocidade e direção do vento, conforme requisitado pelo instrutor (através do módulo AMMAGGS). Recebe como entradas a altitude da aeronave (AMEOM) e sua proa (subsistema de auxílio por rádio).

- INITFLYT: Diferente dos outros módulos, este é executado uma única vez durante a inicialização do software de simulação. Sua função é inicializar variáveis de constantes e coeficientes no datapool.

\section{A.2 Subsistema Auxílio por Rádio (RAID)}

Este subsistema simula os transmissores e receptores de rádio (comunicação, ADF, VOR, ILS etc) e os instrumentos de navegação associados (RMI, HSI, Glideslope etc).

As simulações são auxiliadas por um banco de dados com as informações das estações radio transmissoras em solo (NDB, VOR, ILS etc) e do terreno ao redor. Estes dados são gerenciados pelo sistema GSD (Ground Station Data).

As rotinas que compõem este subsistema são:

- RMADF: Este módulo simula o receptor Collins ADF (Automatic Direction Finder) 650A, os instrumentos que indicam o rumo da estação (RMI) e os níveis de áudio. Os cálculos são baseados na posição da aeronave relativa a estação NDB sintonizada, e das posições das chaves (switchs) de controle. O posicionamento do helicóptero (latitude, longitude, altitude e ângulo yaw) é enviado pelo módulo AMEOM (subsistema FLYT). Utiliza também como entrada o estado dos barramentos elétricos (subsistema ELEC) e as informações do GSD. 
- RMAUDIO: Gera os sinais de áudio de identificação dos receptores de marcadores de aproximação (Land Marker Beacon), ADF, navegação VHF e DME. Utiliza como entradas os sinais de identificação calculados no módulo RMKEYING.

- RMCLOST: Procura no GSD as duas estações terrestres mais próximas da aeronave retornando os valores das distâncias, variação magnética e a altura do terreno de cada uma delas.

- RMCOMCAT: Simula os receptores de áudio do piloto, co-piloto e instrutor, como os transdutores UHF, VHF, HF, o Transponder e o sistema de comunicação interna (ICS). Baseado nas chaves e botões de seleção do cockpit, este módulo computa a freqüência selecionada em cada equipamento e processa o áudio para cada uma delas, adicionando ruído e habilitando os fones de microfones. Utiliza também informações dos barramentos elétricos (subsistema ELEC).

- RMCOMIN: Calcula as indicações dos indicadores de proa (heading indicator), utilizado nos instrumentos HSI e RMI. São considerados os erros de precisão do giroscópio. As principais entradas são a posição da aeronave (latitude, longitude e altitude) e o ângulo yaw, provenientes do subsistema FLYT, e os estados dos barramentos elétricos (subsistema ELEC).

- RMDME: Este módulo simula o receptor/transmissor DME (Distance Measuring Equipment) Collins 451 e seu indicador Collins 450. Computa a validade do DME, sua distancia e tempo de interceptação da estação. Utiliza como entrada a posição da aeronave (subsistema FLYT), posicionamento e validade da estação DME sintonizada (RMTUNING) e informações do sistema elétrico (subsistema ELEC).

- RMFREQS: Decodifica as freqüências selecionadas nos receptores e transmissores. As entradas são as chaves seletoras de freqüência. As saídas são os valores decodificados e os sinais elétricos para os displays de 7 segmentos indicadores.

- RMKEYING: Processa o sinal de identificação de cada estação sintonizada (NDB, VOR, DME, Land Markers Beacon etc). As entradas são provenientes do módulo RMTUNNING e do subsistema ELEC.

- RMMKRRCV: Simula o receptor de marcadores (Land Marker Beacon). Para calcular o nível de áudio e validade do marcador, são levados em consideração a distancia, orientação e altura da aeronave em relação à estação. 
As entradas são a posição da aeronave (subsistema FLYT), marcador selecionado (módulo RMMKRSCH) e informações do subsistema ELEC.

- RMMKRSCH: Procura no GSD o marcador mais próximo da aeronave e retorna suas informações (tipo do marcador, identificação, posição, potência etc). A principal entrada deste módulo é o valor inteiro da posição da aeronave, calculado pelo módulo RMREPOS.

- RMREPOS: Este módulo processa as requisições de reposicionamento da aeronave, calculando as posições relativas às estações próximas. Recebe como entrada comandos provenientes do terminal do instrutor. Suas saídas são os valores utilizados por outros módulos deste subsistema, ajustados para a nova posição.

- RMRINST: Gera os valores para controle dos instrumentos de radio navegação (HSI, RMI, CDI, Glide, Markers, DME etc). As entradas são os resultados dos módulos RMADF, RMVHFNAV, RMDME e RMMKRRCV.

- RMSECTOR: Desempenha diversas tarefas relacionadas ao gerenciamento de setores de navegação. As principais funções são: Monitoramento da posição da aeronave para detecção de mudança de setor; requisita ao GSD por novos setores quando necessário; monitora a posição quando uma nova estação é selecionada e verifica qual setor ela pertence; inicializa novos setores; e processa o número da estação a partir da identificação de 4 dígitos. Quando necessário, este módulo solicita ao RMMKRSCH e RMCLOST recalculem as estações próximas à aeronave.

- RMSTFAIL: Gerencia as falhas, automáticas ou requisitadas pelo instrutor, nas estações sintonizadas.

- RMTERMAG: Computa os valores de altura do terreno e variação magnética, em relação à estação sintonizada ou as mais próximas. O primeiro valor pode ser calculado através do perfil de terreno durante a aproximação final (obtido pelo GSD) ou através da interpolação da altura das estações sintonizadas e próximas. Estes valores são utilizados pela grande maioria dos módulos deste e de outros subsistemas.

- RMTUNING: Procura e extrai do GSD as informações das estações sintonizadas (VOR, ADF, ILS, DME etc) para serem utilizada por outros módulos. As freqüências selecionadas são fornecidas pelo componente RMFREQS. 
- RMVHFNAV: Simula a operação do receptor VOR (VHF Omnidirectional Range) e ILS (Instrument Landing System) e calcula os valores necessários para acionamento do CDI (Course Deviation Indicator), RMI (Radio Magnetic Indicator), HSI (Horizontal Situation Indicator) e GI (Glideslope Indicator). Recebe como entrada a posição da aeronave (subsistema FLYT), dados da estação selecionada (RMTUNING) e informações do sistema elétrico.

- INITRAID: Este módulo é executado apenas na inicialização do simulador. Sua função é definir constantes e inicializar variáveis deste subsistema.

\section{A.3 Sistema de Controle de Voo Automático (AFCS)}

O AFCS (Automatic Flight Control System), conhecido também como piloto automático, é um sistema que auxilia ou automatiza o voo.

Nas aeronaves atuais, este equipamento faz o controle total do voo. O piloto apenas entra com algumas informações, como altitude, velocidade, proa ou rota etc, e o AFCS atua em todos os controles de voo. Porém, nesta versão do Bell Jet Ranger, o sistema pode apenas fazer pequenas correções visando manter altitude e proa, sendo que qualquer manobra com a aeronave deve ser realizada manualmente pelo piloto.

Nas aeronaves reais, este sistema é composto por um ou mais microcontroladores e programas avançados de controle que recebem a leitura de diversos instrumentos (como altímetro, HSI, GPS etc) e geram sinais elétricos para acionamento de atuadores ligados aos controles de voo (cíclico, coletivo e pedais nos helicópteros, ou leme, airelons e profundores em aviões).

O propósito deste subsistema é simular o piloto automático do Bell Jet Ranger III. O AFCS é composto pelas seguintes rotinas:

- QMADC: Este módulo simula o computador de dados aéreos (ADC - Air Data Computer), ligado ao sistema pitot-static do Bell Jet Ranger. O ADC mede as pressões diferenciais e estáticas e calcula a diferença entre a altitude atual e a programada (para o modo ALT HOLD), e envia para os outros módulos do AFCS. As informações de pressões são fornecidas pelo módulo AMINST1 do subsistema FLYT. 
- QMLOGIC: Simula toda a lógica de chaves e relês de todas as funções do piloto automático (Force trim, manter altitude, manter proa, estabilizador). As entradas são os botões de acionamento do AFCS no cockpit, posições do controle de cíclico e os ângulos de pitch e roll (subsistema FLYT). As saídas são as luzes indicativas no painel e sinalizadores (flags) para outros módulos.

- QMPACLAW: Realiza o controle do ângulo de Pitch da aeronave. Utilizam os sinalizadores do QMLOGIC (quais funcionalidades do AFCS estão ativas, desarme automático, controle do piloto pelo force trim etc), informações do ADC (QMADC) e dados provenientes do subsistema FLYT (ângulo Pitch e sua taxa de variação). O resultado é o posicionamento do atuador do eixo de Pitch no cíclico.

- QMRACLAW: Análogo ao QMPACLAW, este módulo faz o controle do ângulo de Roll da aeronave. São considerados os modos ativos do AFCS, controles de force trim (provenientes do QMLOGIC), ângulos de Roll e Yaw e as respectivas taxas de variações (subsistema FLYT) e a proa (subsistema RAID), para o caso do modo manter proa. A saída é a posição do atuador do eixo de Roll do cíclico.

- QMAPLINK: Este módulo estabelece uma relação entre o AFCS e o modelo aerodinâmico da aeronave. Através das posições dos atuadores de Pitch (QMPACLAW) e Roll (QMRACLAW) é calculada a contribuição nos ângulos das pás do rotor principal.

\section{A.4 Subsistema Combustível (FUEL)}

Este componente simula o sistema de combustível da aeronave. Controla o reabastecimento, calcula a pressão e a quantidade do combustível, determina a disponibilidade para os motores, e controla os indicadores e alarmes associados. Utiliza entradas dos seguintes subsistemas:

- FLYT: informação de pressão estática;

- ENGS: fluxo de combustível devido à operação da turbina;

- ELEC: estado dos barramentos elétricos

- cockpit: Disjuntores e chaves das bombas e válvulas de combustível.

O subsistema FUEL é composto por apenas uma rotina. 


\section{A.5 Subsistema Motores (ENGS)}

Este subsistema simula a operação das turbinas do Bell Jet Ranger III. Utilizando a posição do acelerador e os comandos de partida e associados, calcula as temperaturas, torques e rotações, enviando para os indicadores no cockpit e para outros subsistemas. A maioria dos parâmetros é calculada através de curvas de comportamento da turbina.

A simulação é dividida entre as seguintes rotinas:

- EM04ENG1: Esta rotina implementa as funções matemáticas para os principais parâmetros da turbina. As principais entradas são a rotação do primeiro estágio (N1) normalizada (proveniente de EM04ENG2), fluxo de combustível (proveniente de EM04ENG3) e comandos de ignição (proveniente do cockpit). Os resultados são os valores normalizados de diversos parâmetros, como aceleração do fluxo de combustível, torque de saída, torque de resistência entre outros.

- EM04ENG2: Calcula a velocidade de rotação da turbina, o torque de saída, integração com o segundo estágio (N2), efeitos do sistema de degelo (anti-ice), temperaturas dos gases expelidos, engate com o rotor e simulação da ignição. Recebe entradas do subsistema FLYT (pressão estática, temperatura e velocidade do rotor), do subsistema FUEL (disponibilidade de combustível), do cockpit (comandos de ignição e degelo). Também utiliza os valores normalizados calculados pelo módulo EM04ENG1, como o torque de ignição, fluxo de ar, fluxo de combustível entre outros. As saídas são enviadas para os mostradores no cockpit, para o subsistema FLYT (torque de saída) e para os outros módulos.

- EM04ENG3: Simula o consumo de combustível e o sistema de governor (controle automático da velocidade de rotação da turbina). As entradas provenientes do cockpit são principalmente a posição do acelerador e os comandos do governor. Utiliza também a rotação N1 (proveniente de EM04ENG2) e os parâmetros calculados EM04ENG1. A principal saída desta rotina é o fluxo de combustível normalizado.

- EM04OIL: Esta rotina simula o controle do sistema de lubrificação do motor e transmissão. Utiliza entradas do subsistema FLYT (Rotação do rotor principal e temperatura ambiente) e das rotinas EM04ENG1 e EM04ENG1 (torques, rotação N1 e N2). As pressões e temperaturas calculadas são en- 
viadas aos indicadores no cockpit, e os sinalizadores de temperatura elevada e baixa pressão, para o subsistema ELEC (para acionamento dos alarmes).

\section{A.6 Subsistema Elétrico (ELEC)}

Este subsistema simula o sistema elétrico da aeronave. Nesta simulação são computadas a carga consumida por outros sistemas da aeronave, a tensão de saída dos geradores e a carga da bateria (que pode descarregar ou recarregar).

As entradas provenientes do cockpit são os disjuntores e chaves relacionados ao sistema (bateria, gerador principal, gerador reserva, aviônicos entre outros). Através de equações booleanas, são estabelecidos os estados dos barramentos elétricos do helicóptero (barramento essencial, não essencial, aviônicos e 26VAC).

Utilizando as informações de rotação da turbina (subsistema ENGS) e rotor de cauda (subsistema FLYT), são calculadas as tensões fornecidas pelos geradores. É simulado também o processo de descarga ou recarga da bateria.

As saídas para cockpit são, principalmente as luzes de emergência e avisos, e indicadores de carga. Já as saídas para os demais subsistemas incluem sinalizadores que indicam se um determinado barramento está energizado ou não.

\section{A.7 Subsistema Hidráulico (HYDS)}

O sistema hidráulico controla a carga nos controles primários (cíclico e coletivo) do helicóptero, tornando-os mais suaves ou rígidos. Esta simulação é auxiliada por embreagens de fricção que permitem, através de sinais elétricos, aumentar ou diminuir a carga nos controles.

Este bloco utiliza as entradas do cockpit (acionamento das bombas hidráulicas e ajustes de fricção do cíclico e coletivo) para simular o funcionamento do sistema hidráulico da aeronave. As saídas são enviadas para os atuadores dos controles.

\section{A.8 Subsistema Som (SOND)}

Utilizando informações dos subsistemas FLYT (velocidade dos rotores, impacto de pouso e velocidade da aeronave) e ENGS (velocidades da turbina), este módulo simula os sons de um helicóptero durante o voo e envia os resultado para os circuitos de síntese sonora. 
Os principais efeitos produzidos são:

- sons da turbina;

- lâminas e caixa de engrenagem dos rotores;

- efeitos aerodinâmicos (vento, velocidade etc);

- impacto do pouso;

- ignição. 


\section{Apêndice B - Implementação do estudo de caso}

Listagem B.1: Rede de fluxo de dados principal (arquivo main.cpp

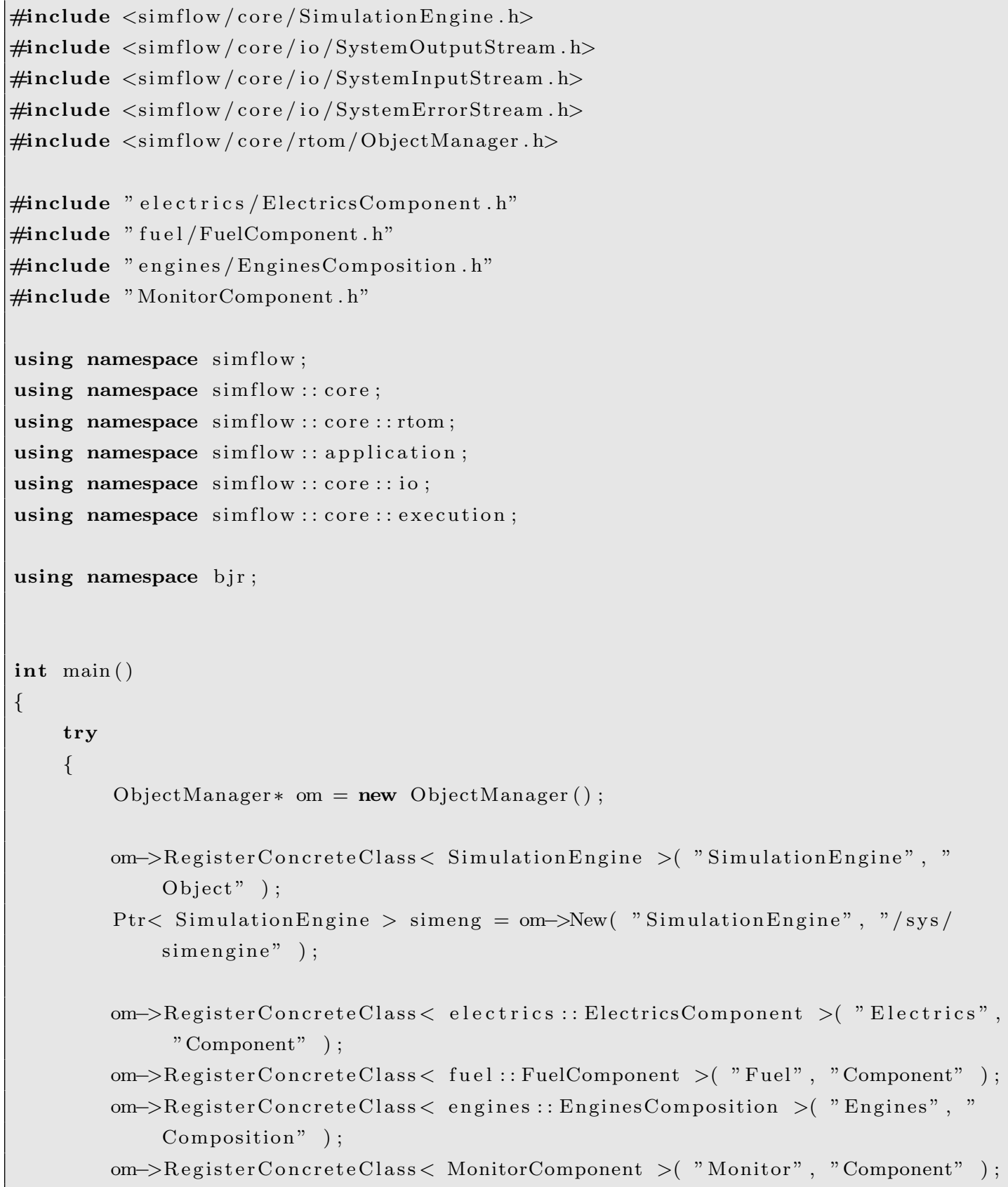




\begin{tabular}{|c|c|}
\hline 37 & $\begin{array}{l}\operatorname{Ptr}<\text { electrics : ElectricsComponent }>\text { electrics }=\text { om }->\text { New }(\text { Electrics", " } \\
\text { /simulation/electrics" ); }\end{array}$ \\
\hline 38 & $\operatorname{Ptr}<$ fuel : FuelComponent $>$ fuel $=$ om $\rightarrow$ New ( "Fuel", " / simulation/fuel" $)$ \\
\hline 39 & $\begin{array}{l}\text { Ptr }<\text { engines : EnginesComposition }>\text { engines }=\text { om- }>\text { New ( "Engines", " / } \\
\quad \text { simulation/engines" ); }\end{array}$ \\
\hline 40 & $\begin{array}{l}\operatorname{Ptr}<\text { MonitorComponent }>\text { monitor }=\text { om }->\text { New }(\text { "Monitor", "/simulation } / \\
\quad \text { monitor" ) ; }\end{array}$ \\
\hline 11 & \\
\hline 42 & //Internal connections \\
\hline 43 & //Electrics input connections \\
\hline 44 & simeng->Connect( engines, "LEXENOUT", electrics, "LEXENOUT" ); \\
\hline 45 & simeng $\rightarrow$ Connect( engines, "LEXOILHT", electrics , "LEXOILHT" ); \\
\hline 46 & simeng->Connect( engines, "LEXOILLO", electrics , "LEXOILLO" ); \\
\hline 47 & simeng $\rightarrow$ Connect ( engines, "LEXSTART", electrics, "LEXSTART" ); \\
\hline 48 & simeng->Connect( engines, "REXN1PC", electrics, "REXN1PC" ); \\
\hline 49 & simeng $\rightarrow$ Connect ( fuel, "LKXAFPMP", electrics , "LKXAFPMP" ); \\
\hline 50 & simeng->Connect ( fuel, "LKXFDPMP", electrics , "LKXFDPMP" ); \\
\hline 51 & \\
\hline 52 & //Fuel input connections \\
\hline 53 & simeng->Connect ( electrics, "LBXDCESB", fuel, "LBXDCESB" ); \\
\hline 54 & simeng $\rightarrow$ Connect ( electrics , "LBXDCNEB", fuel, "LBXDCNEB" ); \\
\hline 55 & simeng->Connect( engines, "REXFLFLO", fuel, "REXFLFLO" ); \\
\hline 56 & \\
\hline 57 & //Engines input connections \\
\hline 58 & simeng $\rightarrow$ Connect ( electrics, "LBXDCESB", engines, "LBXDCESB" ); \\
\hline 59 & simeng->Connect( fuel, "LKXFLAVL", engines, "LKXFLAVL" ); \\
\hline 60 & \\
\hline 61 & //External Connections (Monitor) \\
\hline 62 & $/ /$ Electrics \\
\hline 63 & //Inputs \\
\hline 64 & simeng $\rightarrow$ Connect ( monitor, "LAXLOROT", electrics , "LAXLOROT" ); \\
\hline 65 & simeng $\rightarrow$ Connect ( monitor, "LBMACINV", electrics, "LBMACINV" ); \\
\hline 66 & simeng $\rightarrow$ Connect ( monitor, "LBMBATHT", electrics , "LBMBATHT" ); \\
\hline 67 & simeng $\rightarrow$ Connect ( monitor, "LBMBTAN", electrics , "LBMBTAN" ); \\
\hline 68 & simeng $\rightarrow$ Connect ( monitor, "LBMGENF", electrics , "LBMGENF" ); \\
\hline 69 & simeng->Connect( monitor, "LBMPITHF", electrics, "LBMPITHF"); \\
\hline 70 & simeng->Connect( monitor, "LBMSALTF", electrics, "LBMSALTF") ; \\
\hline 71 & simeng->Connect( monitor, "LBWL00", electrics, "LBWL00"); \\
\hline 72 & simeng $\rightarrow$ Connect ( monitor, "LBWL01", electrics, "LBWL01" ); \\
\hline 73 & simeng $\rightarrow$ Connect ( monitor, "LBWL02", electrics, "LBWL02") ; \\
\hline 74 & simeng->Connect( monitor, "LBWL03", electrics , "LBWL03" ); \\
\hline 75 & simeng $\rightarrow$ Connect ( monitor, "LBWL04", electrics, "LBWL04" ); \\
\hline 76 & simeng $\rightarrow$ Connect ( monitor, "LBWL06", electrics, "LBWL06") ; \\
\hline 77 & simeng $\rightarrow$ Connect ( monitor, "LBWL07", electrics, "LBWL07") ; \\
\hline 78 & simeng $\rightarrow$ Connect ( monitor, "LBWL08", electrics , "LBWL08"); \\
\hline 79 & simeng $\rightarrow$ Connect ( monitor, "LBWL09", electrics, "LBWL09"); \\
\hline 80 & simeng $\rightarrow$ Connect ( monitor, "LBWL10", electrics, "LBWL10"); \\
\hline 81 & simeng $\rightarrow$ Connect ( monitor, "LBWL11", electrics, "LBWL11"); \\
\hline 82 & simeng $\rightarrow$ Connect ( monitor, "LBWL12", electrics , "LBWL12") ; \\
\hline 83 & simeng $\rightarrow$ Connect ( monitor, "LBWL30", electrics , "LBWL30"); \\
\hline 84 & simeng $\rightarrow$ Connect ( monitor, "LC0011", electrics, "LC0011"); \\
\hline 85 & simeng $\rightarrow$ Connect ( monitor, "LC0020", electrics , "LC0020"); \\
\hline 86 & simeng $\rightarrow$ Connect ( monitor, "LC0023", electrics, "LC0023") ; \\
\hline 87 & simeng $\rightarrow$ Connect ( monitor, "LC0024", electrics, "LC0024") ; \\
\hline 88 & simeng $\rightarrow$ Connect ( monitor, "LC0025", electrics , "LC0025") ; \\
\hline 89 & simeng $\rightarrow$ Connect ( monitor, "LC0026", electrics , "LC0026") ; \\
\hline 90 & simeng->Connect ( monitor, "LC0029", electrics, "LC0029" ); \\
\hline
\end{tabular}




\begin{tabular}{|c|c|c|c|}
\hline 91 & simeng $\rightarrow$ Connect ( & monitor, & "LC0032", electrics , "LC0032" ); \\
\hline 92 & simeng $\rightarrow$ Connect ( & monitor, & "LC0036", electrics, "LC0036" ); \\
\hline 93 & simeng $\rightarrow$ Connect ( & monitor, & "LC0037", electrics, "LC0037" ); \\
\hline 94 & simeng $\rightarrow$ Connect ( & monitor, ' & "LC0039", electrics , "LC0039" ); \\
\hline 95 & simeng $\rightarrow$ Connect ( & monitor, ' & "LC0054", electrics, "LC0054" ); \\
\hline 96 & simeng $\rightarrow$ Connect ( & monitor, & "LC0059", electrics, "LC0059" ); \\
\hline 97 & simeng $\rightarrow$ Connect ( & monitor, , & "LC0060", electrics, "LC0060" ); \\
\hline 98 & simeng $\rightarrow$ Connect ( & monitor, ' & "LC0061", electrics , "LC0061" ); \\
\hline 99 & simeng $\rightarrow$ Connect ( & monitor, & "LC0062", electrics, "LC0062" ); \\
\hline & simeng $\rightarrow$ Connect ( & monitor, ' & "LC1036", electrics , "LC1036" ); \\
\hline & simeng $\rightarrow$ Connect ( & monitor, ' & "LC1037", electrics , "LC1037" ); \\
\hline & simeng $\rightarrow$ Connect ( & monitor & "LC1041", electrics, "LC1041" ); \\
\hline & simeng $\rightarrow$ Connect ( & monitor, ' & "LEMENCHP", electrics , "LEMENCHP" ); \\
\hline & simeng $\rightarrow$ Connect ( & monitor, ' & "LIXGDPWR", electrics , "LXXGDPWR" ); \\
\hline & simeng $\rightarrow$ Connect ( & monitor, & "LKMAFFB", electrics , "LKMAFFB" ); \\
\hline & simeng $\rightarrow$ Connect ( & monitor, ' & "LQWL00", electrics , "LQWL00" ); \\
\hline & simeng $\rightarrow$ Connect ( & monitor, ' & "LQWL01", electrics , "LQWL01" ); \\
\hline & simeng $\rightarrow$ Connect ( & monitor, & "LRWL12", electrics , "LRWL12" ); \\
\hline & simeng $\rightarrow$ Connect ( & monitor, & "LRWL15", electrics , "LRWL15" ); \\
\hline & simeng $\rightarrow$ Connect ( & monitor, ' & "LRWLB6", electrics , "LRWLB6" ); \\
\hline & simeng $\rightarrow$ Connect ( & monitor, ' & "LRWLB7", electrics , "LRWLB7" ); \\
\hline & simeng $\rightarrow$ Connect ( & monitor, & "LRWLB8", electrics , "LRWLB8" ); \\
\hline & simeng $\rightarrow$ Connect ( & monitor, ' & "LRWLC0", electrics , "LRWLC0" ); \\
\hline & simeng $\rightarrow$ Connect ( & monitor, ' & "LRWLC1", electrics , "LRWLC1" ); \\
\hline & simeng $\rightarrow$ Connect ( & monitor, & "RAXOMGRR", e lectrics , "RAXOMGRR" ); \\
\hline & \multicolumn{3}{|l|}{ //Outputs } \\
\hline & simeng $\rightarrow$ Connect ( & electrics & , "LBUL00", monitor , "LBUL00" ); \\
\hline & simeng $\rightarrow$ Connect ( & electrics & , "LBUL01", monitor , "LBUL01" ); \\
\hline & simeng $\rightarrow$ Connect ( & electrics & , "LBUL02", monitor , "LBUL02" ); \\
\hline & simeng $\rightarrow$ Connect ( & electrics & , "LBUL03", monitor , "LBUL03" ); \\
\hline & simeng $\rightarrow$ Connect ( & electrics & , "LBUL04", monitor , "LBUL04" ); \\
\hline & simeng $\rightarrow$ Connect ( & electrics & , "LBUL05", monitor , "LBUL05" ); \\
\hline & simeng $\rightarrow$ Connect ( & electrics & , "LBUL14", monitor , "LBUL14" ); \\
\hline & simeng $\rightarrow$ Connect ( & electrics & , "LBUL15", monitor , "LBUL15" ); \\
\hline & simeng $\rightarrow$ Connect ( & electrics & , "LBUL16", monitor , "LBUL16" ); \\
\hline & simeng $\rightarrow$ Connect ( & electrics & , "LBUL17", monitor , "LBUL17" ); \\
\hline & simeng $\rightarrow$ Connect ( & electrics & , "LKUL00", monitor , "LKUL00" ); \\
\hline & simeng $\rightarrow$ Connect ( & electrics & , "LKUL01", monitor , "LKUL01" ); \\
\hline & simeng $\rightarrow$ Connect ( & electrics & , "RBDO00", monitor , "RBDO00" ); \\
\hline & simeng $\rightarrow$ Connect ( & electrics & , "RKDO02", monitor , "RKDO02" ); \\
\hline & simeng $\rightarrow$ Connect ( & electrics & , "LEUL00", monitor , "LEUL00" ); \\
\hline & simeng $\rightarrow$ Connect ( & electrics & , "LEUL01", monitor , "LEUL01" ); \\
\hline & simeng $\rightarrow$ Connect ( & electrics & , "LEUL02", monitor , "LEUL02" ); \\
\hline & simeng $\rightarrow$ Connect ( & electrics & , "LEUL03", monitor , "LEUL03" ); \\
\hline & simeng $\rightarrow$ Connect ( & electrics & , "LEUL04", monitor , "LEUL04" ); \\
\hline & simeng $\rightarrow$ Connect ( & electrics & , "LEUL05", monitor , "LEUL05" ); \\
\hline & simeng $\rightarrow$ Connect ( & electrics & , "LEUL06", monitor , "LEUL06" ); \\
\hline & simeng $\rightarrow$ Connect ( & electrics & , "LBX26VAC", monitor , "LBX26VAC" ) ; \\
\hline & simeng $\rightarrow$ Connect ( & electrics & , "LBXAVESB" , monitor , "LBXAVESB" ) ; \\
\hline & simeng $\rightarrow$ Connect ( & electrics & , "LBXAVNEB", monitor , "LBXAVNEB" ); \\
\hline & simeng $\rightarrow$ Connect ( & electrics & , "LBXDCESB", monitor , "LBXDCESB" ); \\
\hline & simeng $\rightarrow$ Connect ( & electrics & , "LBXDCNEB" , monitor , "LBXDCNEB" ) ; \\
\hline & simeng $\rightarrow$ Connect ( & electrics & , "LBXPTAV", monitor , "LBXPTAV" ); \\
\hline & simeng $\rightarrow$ Connect ( & electrics & , "RBLBATCH", monitor, "RBLBATCH" ); \\
\hline & //Fuel & & \\
\hline
\end{tabular}




\begin{tabular}{|c|c|}
\hline 148 & //Input \\
\hline 149 & simeng $\rightarrow$ Connect ( monitor, "RAXPSTAT", fuel, "RAXPSTAT" ); \\
\hline 150 & simeng $\rightarrow$ Connect ( monitor, "LIXFFREZ", fuel, "LIXFFREZ" ); \\
\hline 151 & simeng $\rightarrow$ Connect ( monitor, "RIXDFQTY", fuel, "RIXDFQTY" ); \\
\hline 152 & simeng $\rightarrow$ Connect ( monitor, "RIKRST", fuel , "RIKRST" ); \\
\hline 153 & simeng $\rightarrow$ Connect ( monitor, "LC0046", fuel, "LC0046" ); \\
\hline 154 & simeng->Connect ( monitor, "LC0047", fuel, "LC0047" ); \\
\hline 155 & simeng $\rightarrow$ Connect ( monitor, "LC0045", fuel, "LC0045" ); \\
\hline 156 & simeng $\rightarrow$ Connect ( monitor, "LC0044", fuel, "LC0044") ; \\
\hline 157 & simeng ->Connect ( monitor, "LKWL00", fuel, "LKWL00" ) ; \\
\hline 158 & simeng $\rightarrow$ Connect ( monitor, "LKMFPMPF", fuel, "LKMFPMPF" ); \\
\hline 159 & simeng $\rightarrow$ Connect ( monitor, "LKMAPMPF", fuel , "LKMAPMPF" ) ; \\
\hline 160 & simeng $\rightarrow$ Connect ( monitor, "LKMLEAK", fuel, "LKMLEAK" ); \\
\hline 161 & simeng $\rightarrow$ Connect ( monitor, "LKMVLVF", fuel, "LKMVLVF" ) ; \\
\hline 162 & \\
\hline 163 & //Output \\
\hline 164 & simeng $\rightarrow$ Connect ( fuel, "LKXAFPMP", monitor, "LKXAFPMP" ); \\
\hline 165 & simeng $\rightarrow$ Connect ( fuel, "LKXFDPMP", monitor, "LKXFDPMP" ); \\
\hline 166 & simeng $\rightarrow$ Connect ( fuel, "LKXFLVLV", monitor, "LKXFLVLV" ) ; \\
\hline 167 & simeng $\rightarrow$ Connect ( fuel, "RKXFLQTY", monitor, "RKXFLQTY" ) ; \\
\hline 168 & simeng $\rightarrow$ Connect ( fuel, "LKXFLAVL", monitor, "LKXFLAVL" ); \\
\hline 169 & simeng $\rightarrow$ Connect ( fuel, "RKDO00", monitor, "RKDO00" ); \\
\hline 170 & simeng->Connect ( fuel, "RKDO01", monitor, "RKDO01" ); \\
\hline 171 & \\
\hline 172 & //Engines \\
\hline 173 & //Input \\
\hline 174 & simeng $\rightarrow$ Connect ( monitor, "LAMLROTR", engines, "LAMLROTR" ); \\
\hline 175 & simeng $\rightarrow$ Connect ( monitor, "LAXONGND", engines, "LAXONGND" ); \\
\hline 176 & simeng $\rightarrow$ Connect ( monitor, "LC0025", engines, "LC0025" ); \\
\hline 177 & simeng $\rightarrow$ Connect ( monitor, "LC0031", engines, "LC0031" ); \\
\hline 178 & simeng $\rightarrow$ Connect ( monitor, "LC0043", engines, "LC0043") ; \\
\hline 179 & simeng $\rightarrow$ Connect ( monitor, "LC0048", engines, "LC0048" ); \\
\hline 180 & simeng $\rightarrow$ Connect ( monitor, "LC0049", engines, "LC0049" ); \\
\hline 181 & simeng $\rightarrow$ Connect ( monitor, "LC0050", engines, "LC0050") ; \\
\hline 182 & simeng->Connect( monitor, "LC0053", engines, "LC0053" ); \\
\hline 183 & simeng $\rightarrow$ Connect ( monitor, "LEMCMPST", engines, "LEMCMPST" ); \\
\hline 184 & simeng $\rightarrow$ Connect ( monitor, "LEMENGF", engines, "LEMENGF" ); \\
\hline 185 & simeng $\rightarrow$ Connect ( monitor, "LEMEOPI", engines, "LEMEOPI" ); \\
\hline 186 & simeng $\rightarrow$ Connect ( monitor, "LEMEOTI", engines, "LEMEOTI" ); \\
\hline 187 & simeng $\rightarrow$ Connect ( monitor, "LEMGOVOS", engines, "LEMGOVOS" ); \\
\hline 188 & simeng->Connect ( monitor, "LEMGOVUS", engines, "LEMGOVUS" ); \\
\hline 189 & simeng $\rightarrow$ Connect ( monitor, "LEMHOILT", engines, "LEMHOILT" ); \\
\hline 190 & simeng $\rightarrow$ Connect ( monitor, "LEMHOTST", engines, "LEMHOTST" ); \\
\hline 191 & simeng->Connect ( monitor, "LEMHTOT", engines, "LEMHTOT" ); \\
\hline 192 & simeng $\rightarrow$ Connect ( monitor, "LEMHTROT", engines, "LEMHTROT" ); \\
\hline 193 & simeng $\rightarrow$ Connect ( monitor, "LEMLOILP", engines, "LEMLOILP" ); \\
\hline 194 & simeng $\rightarrow$ Connect ( monitor, "LEMLTROP", engines, "LEMLTROP" ); \\
\hline 195 & simeng $\rightarrow$ Connect ( monitor, "LEMSTRTF", engines, "LEMSTRTF" ); \\
\hline 196 & simeng->Connect ( monitor, "LEMTN2I", engines, "LEMTN2I" ); \\
\hline 197 & simeng $\rightarrow$ Connect ( monitor, "LEMTORQ", engines, "LEMTORQ" ); \\
\hline 198 & simeng $\rightarrow$ Connect ( monitor, "LEMTOTI", engines, "LEMTOTI" ); \\
\hline 199 & simeng $\rightarrow$ Connect ( monitor, "LEMXOPI", engines, "LEMXOPI" ); \\
\hline 200 & simeng $\rightarrow$ Connect ( monitor, "LEMXOTI", engines, "LEMXOTI" ); \\
\hline 201 & simeng $\rightarrow$ Connect ( monitor, "LEWL00", engines, "LEWL00" ); \\
\hline 202 & simeng $\rightarrow$ Connect ( monitor, "LEWL01", engines, "LEWL01" ); \\
\hline 203 & simeng $\rightarrow$ Connect ( monitor, "LEWL02", engines, "LEWL02" ); \\
\hline 204 & simeng->Connect( monitor, "LEWL03", engines, "LEWL03" ); \\
\hline
\end{tabular}




\begin{tabular}{|c|c|}
\hline 205 & simeng $\rightarrow$ Connect ( monitor, "LIXTOTRE", engines, "LIXTOTRE" ); \\
\hline 206 & simeng ->Connect ( monitor, "LKMCTRLF", engines, "LKMCTRLF" ); \\
\hline 207 & simeng $\rightarrow$ Connect ( monitor, "LKMENGPF", engines, "LKMENGPF" ); \\
\hline 208 & simeng $\rightarrow$ Connect ( monitor, "LWWL00", engines, "LWWL00" ); \\
\hline 209 & simeng $\rightarrow$ Connect ( monitor, "RAXA", engines, "RAXA" ); \\
\hline 210 & simeng $\rightarrow$ Connect ( monitor, "RAXAST", engines, "RAXAST" ); \\
\hline 211 & simeng $\rightarrow$ Connect ( monitor, "RAXOMRPM", engines, "RAXOMRPM" ); \\
\hline 212 & simeng $\rightarrow$ Connect ( monitor, "RAXP", engines, "RAXP" ); \\
\hline 213 & simeng $\rightarrow$ Connect ( monitor, "RAXPS", engines, "RAXPS" ); \\
\hline 214 & simeng $\rightarrow$ Connect ( monitor, "RAXPSTAT", engines, "RAXPSTAT" ); \\
\hline 215 & simeng $\rightarrow$ Connect ( monitor, "REAO00", engines, "REAO00" ); \\
\hline 216 & \\
\hline 217 & //Output \\
\hline 218 & simeng->Connect( engines, "LEUR00", monitor, "LEUR00" ); \\
\hline 219 & simeng ->Connect ( engines, "LEXCLTCH", monitor, "LEXCLTCH" ); \\
\hline 220 & simeng $\rightarrow$ Connect ( engines, "LEXENOUT", monitor, "LEXENOUT" ); \\
\hline 221 & simeng $\rightarrow$ Connect ( engines, "LEXGOVDN", monitor, "LEXGOVDN" ); \\
\hline 222 & simeng $\rightarrow$ Connect ( engines, "LEXGOVUP", monitor, "LEXGOVUP" ); \\
\hline 223 & simeng $\rightarrow$ Connect ( engines, "LEXLIT", monitor, "LEXLIT" ); \\
\hline 224 & simeng $\rightarrow$ Connect ( engines, "LEXOILHT", monitor, "LEXOILHT" ); \\
\hline 225 & simeng ->Connect ( engines, "LEXOILLO", monitor, "LEXOILLO" ); \\
\hline 226 & simeng->Connect ( engines, "LEXSTART", monitor, "LEXSTART" ); \\
\hline 227 & simeng $\rightarrow$ Connect ( engines, "LWUL02", monitor, "LWUL02" ); \\
\hline 228 & simeng $\rightarrow$ Connect ( engines, "REDO00", monitor, "REDO00" ); \\
\hline 229 & simeng $\rightarrow$ Connect ( engines, "REDO01", monitor, "REDO01" ); \\
\hline 230 & simeng $\rightarrow$ Connect ( engines, "REDO02", monitor, "REDO02" ); \\
\hline 231 & simeng $\rightarrow$ Connect ( engines, "REDO04", monitor, "REDO04" ); \\
\hline 232 & simeng $\rightarrow$ Connect ( engines, "REDO05", monitor, "REDO05" ); \\
\hline 233 & simeng $\rightarrow$ Connect ( engines, "REDO06", monitor, "REDO06"); \\
\hline 234 & simeng $\rightarrow$ Connect ( engines, "REDO07", monitor, "REDO07" ); \\
\hline 235 & simeng $\rightarrow$ Connect ( engines, "REDO08", monitor, "REDO08" ); \\
\hline 236 & simeng $\rightarrow$ Connect ( engines, "REXFLFLO", monitor, "REXFLFLO" ); \\
\hline 237 & simeng $\rightarrow$ Connect ( engines, "REXN1PC", monitor, "REXN1PC" ); \\
\hline 238 & simeng $\rightarrow$ Connect ( engines, "REXN2PC", monitor, "REXN2PC" ); \\
\hline 239 & simeng $\rightarrow$ Connect ( engines, "REXOPTQ", monitor, "REXOPTQ" ); \\
\hline 240 & simeng $\rightarrow$ Connect ( engines, "REYSTTQ", monitor, "REYSTTQ" ); \\
\hline 241 & simeng $\rightarrow$ Connect ( engines, "REYNRETQ", monitor, "REYNRETQ" ); \\
\hline 242 & simeng $\rightarrow$ Connect ( engines, "RELTOTOP", monitor, "RELTOTOP" ); \\
\hline 243 & \\
\hline 244 & \\
\hline 245 & \\
\hline 246 & $\operatorname{Ptr}<$ ExecutionGroup $>$ eg0 = simeng $\rightarrow$ NewExecutionGroup ( "group0" ) \\
\hline 247 & $\operatorname{Ptr}<$ ExecutionGroup $>$ eg1 = simeng $\rightarrow$ NewExecutionGroup ( "group1" ) \\
\hline 248 & $\operatorname{Ptr}<$ ExecutionGroup $>$ eg $2=$ simeng $\rightarrow$ NewExecutionGroup ( "group2" ) \\
\hline 249 & $\operatorname{Ptr}<$ ExecutionGroup $>$ eg $3=$ simeng $\rightarrow$ NewExecutionGroup ( "group3" ) ; \\
\hline 250 & $\operatorname{Ptr}<$ ExecutionGroup $>$ eg $4=$ simeng $\rightarrow$ NewExecutionGroup ( "group4" ) \\
\hline 251 & \\
\hline 252 & eg0 $\rightarrow$ AddSimulationElement ( engines ); \\
\hline 253 & eg1 $\rightarrow$ AddSimulationElement ( fuel ) ; \\
\hline 254 & eg1->AddSimulationElement( electrics ) ; \\
\hline 255 & eg2->AddSimulationElement ( om->Find ( "/simulation/engines/EM04ENG1" ) ); \\
\hline 256 & eg3->AddSimulationElement ( om->Find( "/simulation/engines/BM04ENG3" ) ) ; \\
\hline 257 & \\
\hline 258 & eg4->AddSimulationElement ( monitor ) ; \\
\hline 259 & \\
\hline 260 & //Set the base frequency to $30 \mathrm{~Hz}$ \\
\hline 261 & simeng $\rightarrow$ SetBaseFrequency $(30)$ \\
\hline
\end{tabular}




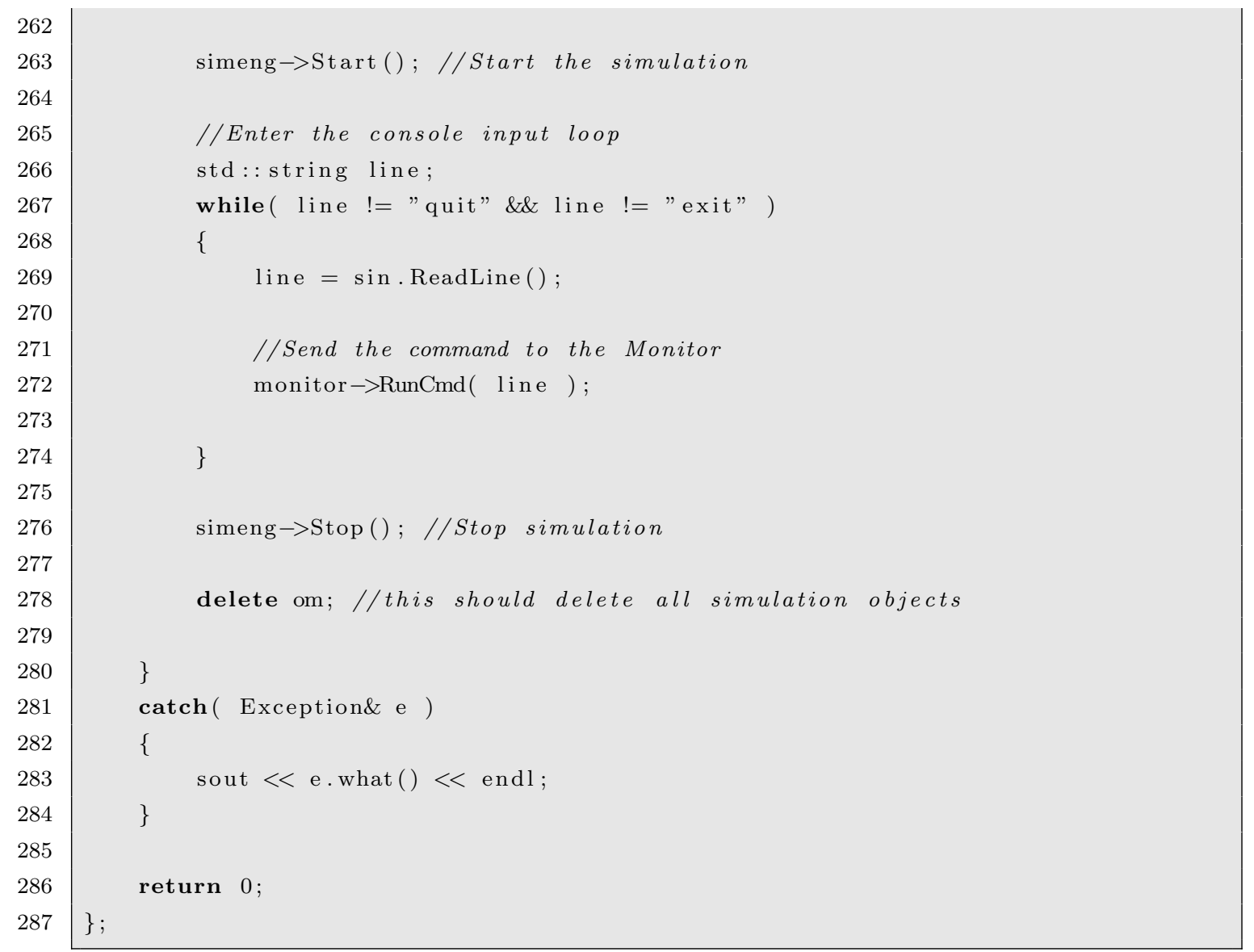

Listagem B.2: Rede de fluxo de dados do subsistema de motores (ENGS)

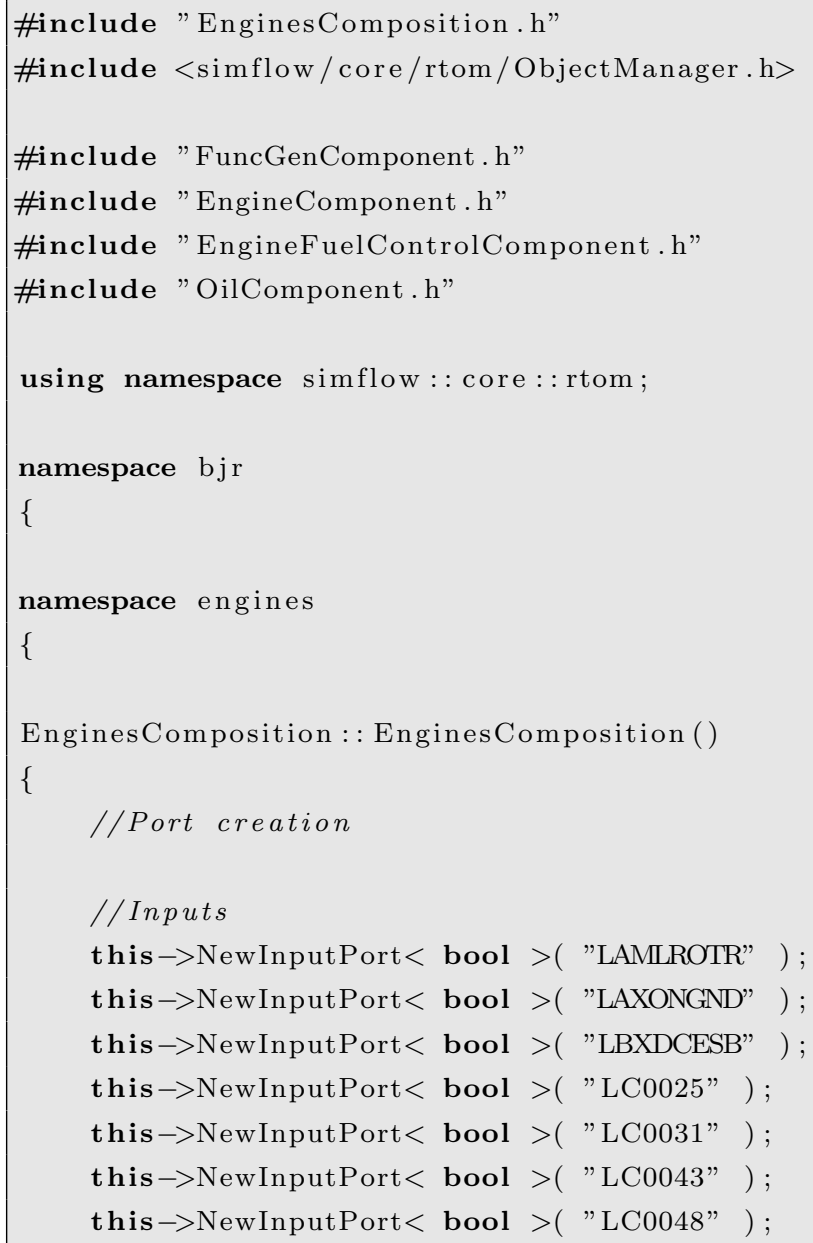




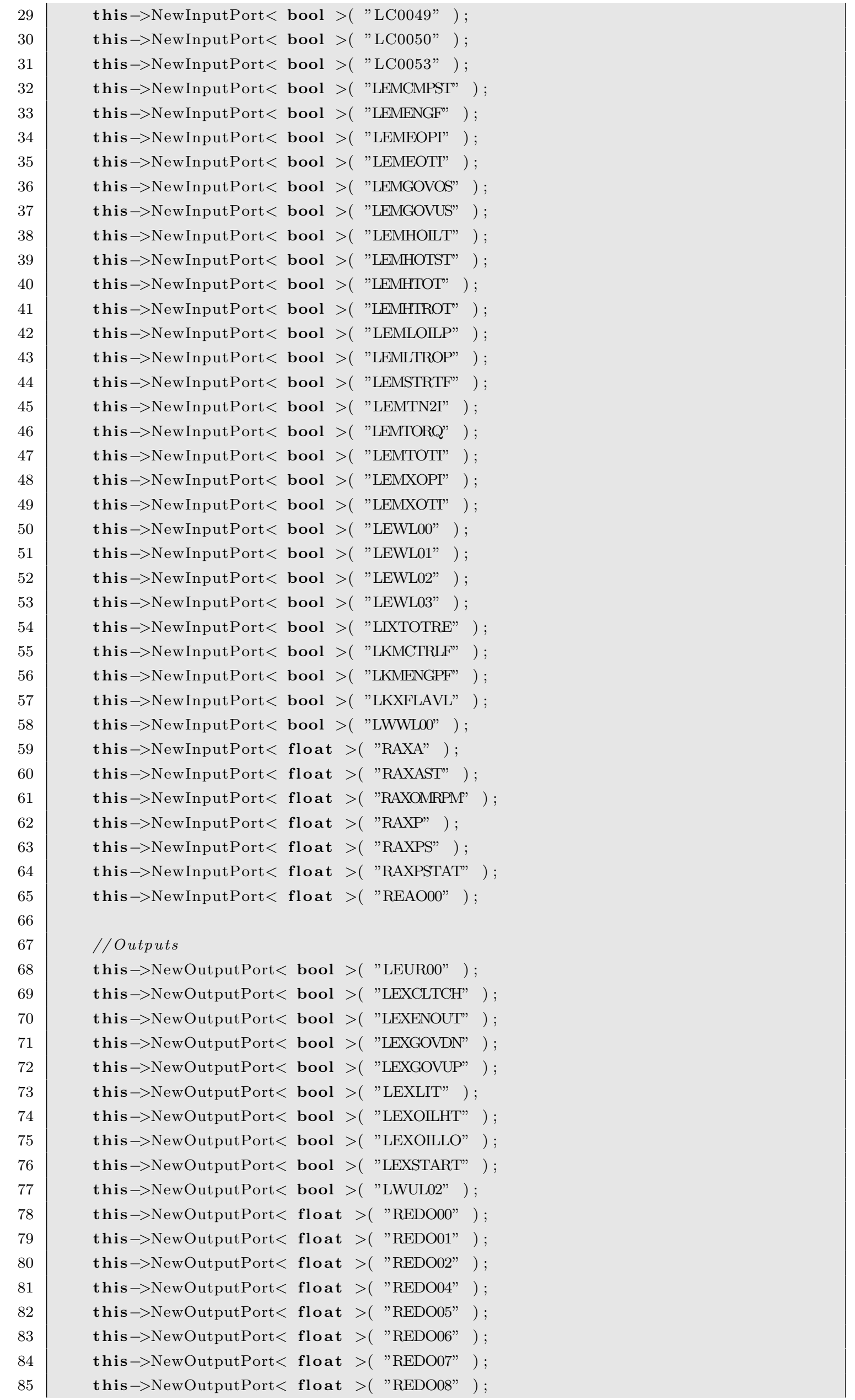




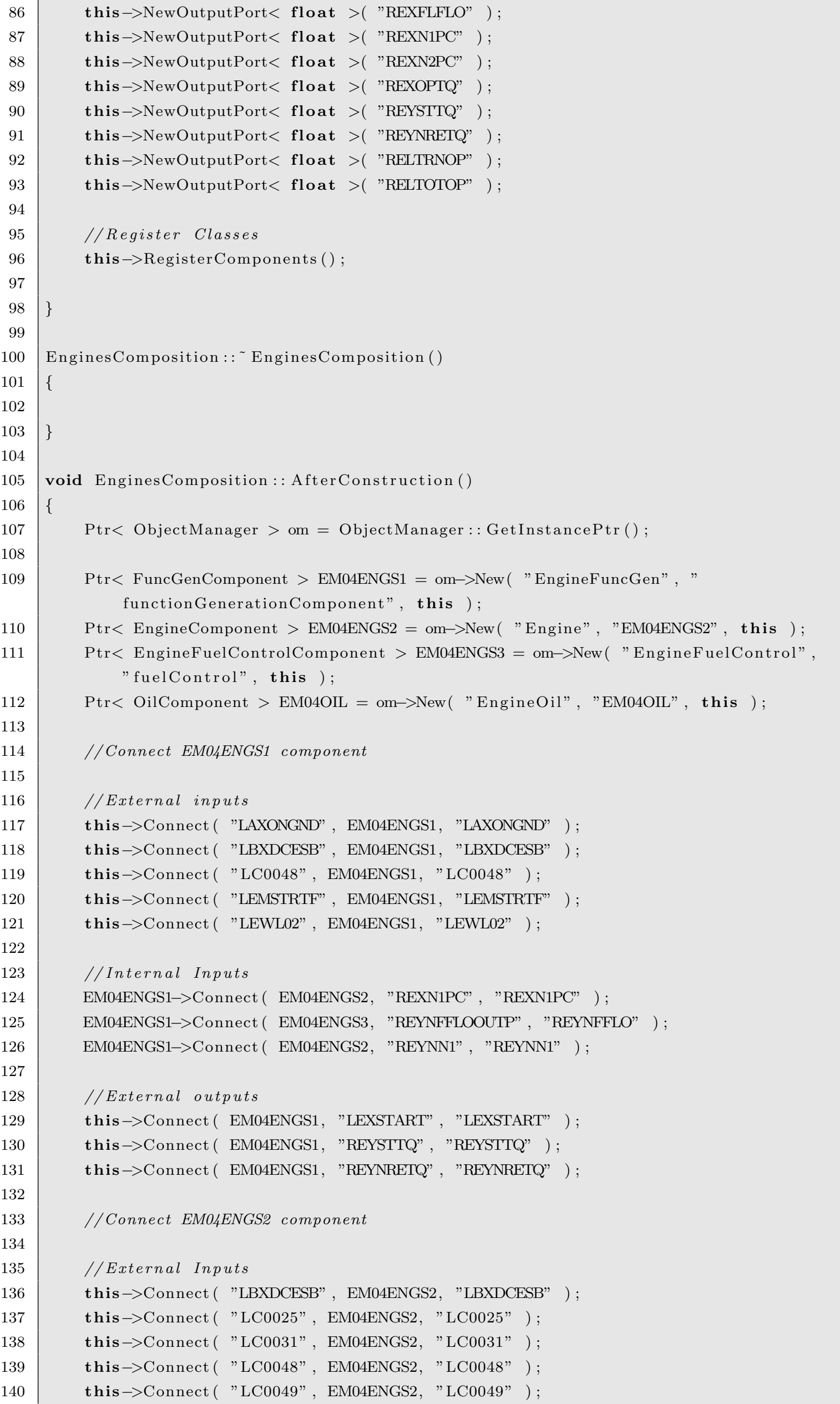




\begin{tabular}{|c|c|}
\hline 141 & this $\rightarrow$ Connect ( "LC0053", EM04ENGS2, "LC0053" ); \\
\hline 142 & this $\rightarrow$ Connect ( "LEMCMPST", EM04ENGS2, "LEMCMPST" ) ; \\
\hline 143 & this $\rightarrow$ Connect ( "LEMENGF", EM04ENGS2, "LEMENGF" ) ; \\
\hline 144 & this $\rightarrow$ Connect ( "LEMHOTST", EM04ENGS2, "LEMHOTST" ) ; \\
\hline 145 & this $\rightarrow$ Connect ( "LEMHTOT", EM04ENGS2, "LEMHTOT" ) ; \\
\hline 146 & this $\rightarrow$ Connect ( "LEMTN2I", EM04ENGS2, "LEMTN2I" ); \\
\hline 147 & this $\rightarrow$ Connect ( "LEMTORQ", EM04ENGS2, "LEMTORQ" ) ; \\
\hline 148 & this $\rightarrow$ Connect ( "LEMTOTI", EM04ENGS2, "LEMTOTI" ) ; \\
\hline 149 & this $\rightarrow$ Connect ( "LEWL02", EM04ENGS2, "LEWL02" ) ; \\
\hline 150 & this $\rightarrow$ Connect ( "LEWL03", EM04ENGS2, "LEWL03" ) ; \\
\hline 151 & this $\rightarrow$ Connect ( "LIXTOTRE", EM04ENGS2, "LIXTOTRE" ) ; \\
\hline 152 & this $\rightarrow$ Connect ( "LKXFLAVL", EM04ENGS2, "LKXFLAVL" ) ; \\
\hline 153 & this $\rightarrow$ Connect ( "LWWL00", EM04ENGS2, "LWWL00" ) ; \\
\hline 154 & this $\rightarrow$ Connect ( "RAXA", EM04ENGS2, "RAXA" ) ; \\
\hline 155 & this->Connect ( "RAXAST", EM04ENGS2, "RAXAST" ); \\
\hline 156 & this $\rightarrow$ Connect ( "RAXOMRPM", EM04ENGS2, "RAXOMRPM" ) ; \\
\hline 157 & this $\rightarrow$ Connect ( "RAXP" , EM04ENGS2, "RAXP" ) ; \\
\hline 158 & this $\rightarrow$ Connect ( "RAXPS", EM04ENGS2, "RAXPS" ); \\
\hline 159 & this $\rightarrow$ Connect ( "RAXPSTAT", EM04ENGS2, "RAXPSTAT" ); \\
\hline 160 & \\
\hline 161 & \\
\hline 162 & //Intenal Inputs \\
\hline 163 & EM04ENGS2->Connect ( EM04ENGS1, "REYNACTQ", "REYNACTQ" ) ; \\
\hline 164 & EM04ENGS2->Connect ( EM04ENGS1, "REYNASTQ", "REYNASTQ" ) ; \\
\hline 165 & EM04ENGS2->Connect ( EM04ENGS1, "REYNRETQ", "REYNRETQ" ) ; \\
\hline 166 & EM04ENGS2->Connect ( EM04ENGS1, "REYSTTQ" , "REYSTTQ" ); \\
\hline 167 & EM04ENGS2->Connect ( EM04ENGS1, "REYNAIRF" , "REYNAIRFINP" ) ; \\
\hline 168 & EM04ENGS2->Connect ( EM04ENGS3, "REYNFFLOOUTP", "REYNFFLOINP" ) ; \\
\hline 169 & \\
\hline 170 & //External Outputs \\
\hline 171 & this $\rightarrow$ Connect ( EM04ENGS2, "LEUR00", "LEUR00" ) ; \\
\hline 172 & this $\rightarrow$ Connect ( EM04ENGS2, "LEXCLTCH", "LEXCLTCH" ); \\
\hline 173 & this $\rightarrow$ Connect ( EM04ENGS2, "LEXENOUT", "LEXENOUT" ) ; \\
\hline 174 & this $\rightarrow$ Connect ( EM04ENGS2, "LEXLIT" , "LEXLIT" ); \\
\hline 175 & this $\rightarrow$ Connect ( EM04ENGS2, "LWUL02", "LWUL02" ); \\
\hline 176 & this $\rightarrow$ Connect ( EM04ENGS2, "REDO00" , "REDO00" ); \\
\hline 177 & this $->$ Connect ( EM04ENGS2, "REDO01", "REDO01" ); \\
\hline 178 & this $\rightarrow$ Connect ( EM04ENGS2, "REDO02" , "REDO02" ) ; \\
\hline 179 & this->Connect ( EM04ENGS2, "REDO04", "REDO04" ); \\
\hline 180 & this $\rightarrow$ Connect ( EM04ENGS2, "REXFLFLO", "REXFLFLO" ); \\
\hline 181 & this $\rightarrow$ Connect ( EM04ENGS2, "REXN1PC", "REXN1PC" ); \\
\hline 182 & this $\rightarrow$ Connect ( EM04ENGS2, "REXN2PC", "REXN2PC" ); \\
\hline 183 & this->Connect ( EM04ENGS2, "REXOPTQ", "REXOPTQ" ); \\
\hline 184 & this $\rightarrow$ Connect ( EM04ENGS2, "RELTOTOP", "RELTOTOP" ) ; \\
\hline 185 & \\
\hline 186 & \\
\hline 187 & //Connect EM04ENGS3 component \\
\hline 188 & \\
\hline 189 & //External inputs \\
\hline 190 & th is $\rightarrow$ Connect ( "LAMLROTR", EM04ENGS3, "LAMLROTR" ) ; \\
\hline 191 & this $\rightarrow$ Connect ( "LBXDCESB", EM04ENGS3, "LBXDCESB" ) ; \\
\hline 192 & this $\rightarrow$ Connect ( "LC0050", EM04ENGS3, "LC0050" ); \\
\hline 193 & this $\rightarrow$ Connect ( "LEMGOVOS", EM04ENGS3, "LEMGOVOS" ); \\
\hline 194 & this $\rightarrow$ Connect ( "LEMGOVUS", EM04ENGS3, "LEMGOVUS" ); \\
\hline 195 & this ->Connect ( "LEWL00", EM04ENGS3, "LEWL00" ); \\
\hline 196 & this $\rightarrow$ Connect ( "LEWL01", EM04ENGS3, "LEWL01" ) ; \\
\hline 197 & this $\rightarrow$ Connect ( "LKMCTRLF", EM04ENGS3, "LKMCTRLF" ) ; \\
\hline
\end{tabular}




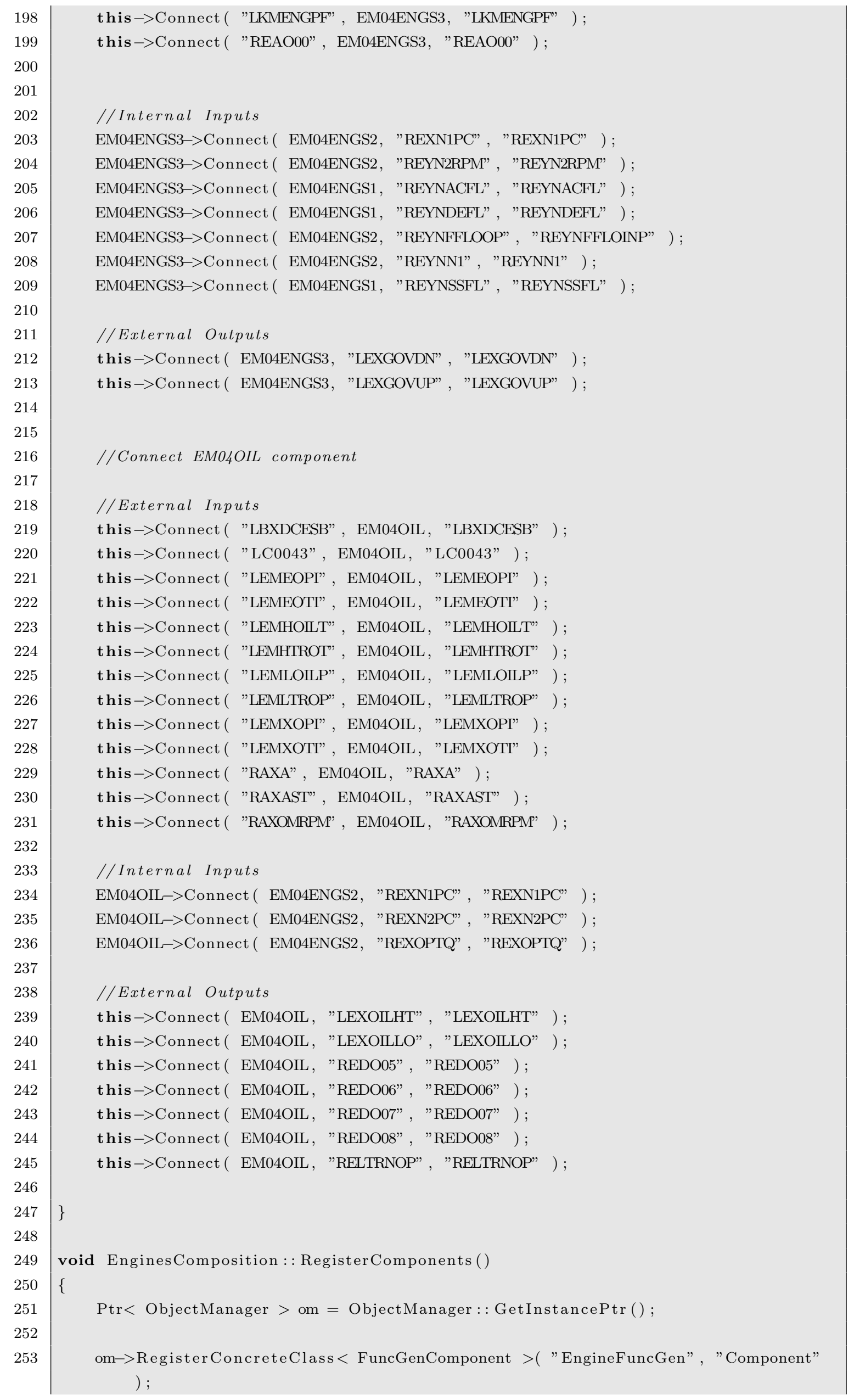




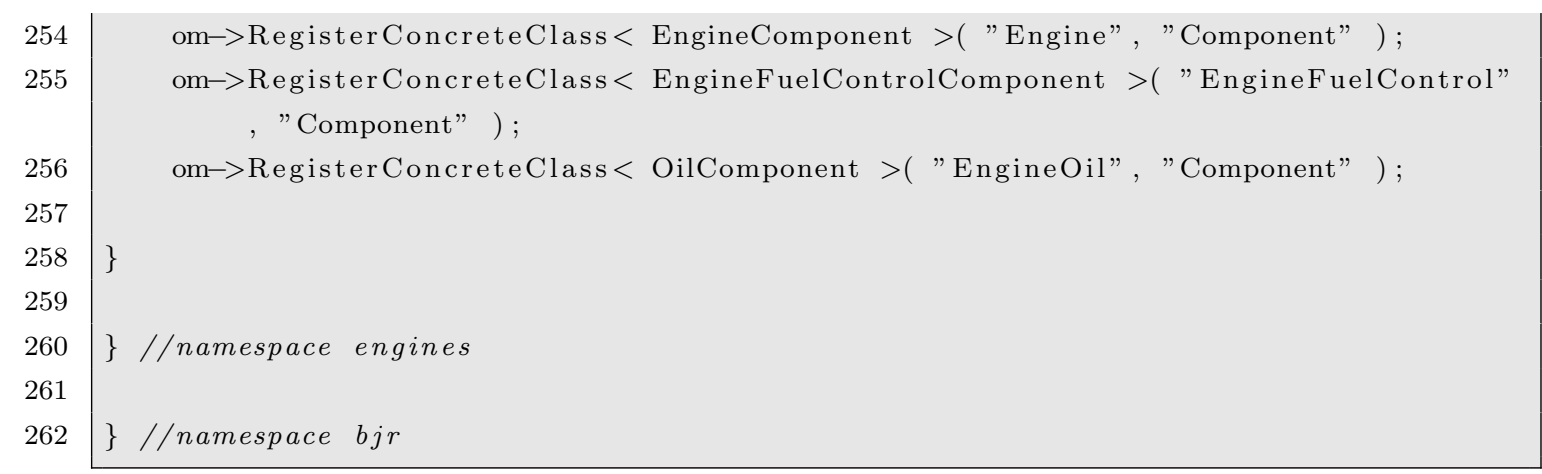




\section{Anexo A - Procedimentos normais de operação da aeronave Bell Jet Ranger III}

Tabela A.1: ENGINE PRE-START CHECK

\begin{tabular}{ll}
\hline FLIGHT CONTROLS & Check freedom, Position for start \\
THROTTLE & Full open, flight idle, closed \\
LANDING LIGHT & off \\
NIGHT SCANNER LIGH & stow \\
ENGINE ANTI-ICE & off \\
HYDRAULIC SYSTEM (Control boost) & off \\
MASTER AVIONICS & off \\
ALTIMETER & Set to field elevation \\
INSTRUMENTS & static Zero \\
OVERHEAD SWITCHES & off (except anti-collision light on) \\
FUEL BOOST SWITCHES & on \\
CIRCUIT BREAKERS & in \\
FUEL VALVE & on \\
ROTOR BRAKE & off \\
CABIN HEATER & off \\
BATTERY SWITCH & on \\
CAUTION SWITCH & on test warning light, low rotor horn \\
CAUTION SWITCH & off \\
\hline
\end{tabular}

Tabela A.2: ENGINE STARTING

\begin{tabular}{ll}
\hline MAIN ROTOR & clear \\
THROTTLE & Full open , flight idle, closed \\
STARTER & Engage check for engine oil pressure at $10 \% \mathrm{~N} 1$ \\
THROTTLE & open to flight idle at $15 \%$ N1 with TOT at or below $150^{\circ} \mathrm{C}$ \\
MAIN ROTOR & turning by $25 \%$ of N1 \\
STARTER & Release at $58 \% \mathrm{~N} 1$ \\
CHECK ENGINE AND TRANSMISSION OIL PRESSURE \\
STABILIZE at flight idle ( $60 \% 62 \% \mathrm{~N} 1$ ) for one minute \\
THROTTLE & open to $70 \% \mathrm{~N} 1$ \\
GENERATOR & on \\
MASTER AVIONICS & on (Headsets on) \\
\hline
\end{tabular}


Tabela A.3: ENGINE RUN-UP CHECK

\begin{tabular}{ll}
\hline CAUTION SWITCH & on \\
CAGE GYRO AND GYRO SWITCH & on \\
POSITION LIGHTS & As required \\
FUEL BOOST PUMPS & Check individually \\
HYDRAULIC CONTROL SWITCH & off, check operation of flight controls \\
HYDRAULIC CONTROL SWITCH & on \\
THROTTLE & Full open ( torque below 40\% ) \\
GOVERNOR & set to 100\% N2 \\
ENGINE ANTI-ICE & on, check TOT rise Switch off \\
INSTRUMENTS & Check proper readings (3-6-8-10) \\
\hline
\end{tabular}

Tabela A.4: ENGINE SHUTDOWN

\begin{tabular}{ll}
\hline THROTTLE & $\begin{array}{l}\text { Flight idle, check full RPM } \\
\text { to } 65 \% \text { N1 should take } 3 \text { to } 5 \\
\text { seconds }\end{array}$ \\
hydraulic switch off \\
off \\
BOOST PUMPS SWITCHES & stabilize for 2 minutes \\
TOT & off \\
CAUTION SWITCH & close \\
THROTTLE & decreasing \\
TOT and N1 & off \\
FUEL VALVE & off \\
POSITION LIGHT & off \\
ATTITUDE INDICATOR \& GYRO SWITCH & off \\
GENERATOR & below $38 \%$ NR \\
APPLY ROTOR BRAKE & off \\
MASTER AVIONICS & Zero, then Battery off \\
N1 &
\end{tabular}

